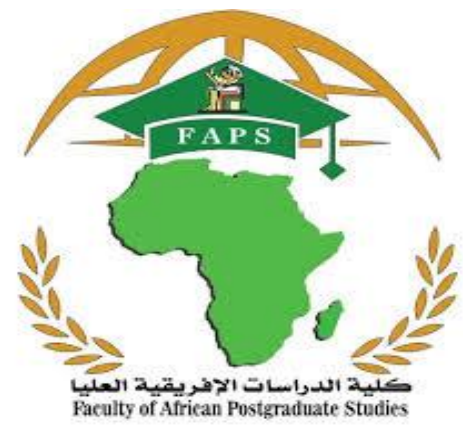

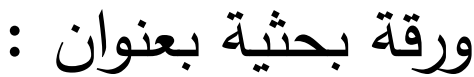

أثر وباء كورونا على أداء الاقتصاد المصرى ( التداعيات وسياسات المواجهة )

مقدمة للمشاركة فى المؤتمر العلمى الخامس لكلية التجارة بعنوان :

( أثر أزمة كورونا على الاقتصاد القومى - المقترحات والحلول )

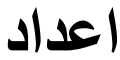

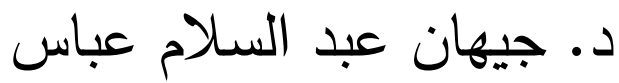 \\ مدرس الاقتصاد- كلية الدراسات الافريقية العليا - جامعة القاهرة.
}




\section{أثر وباء كورونا على أداء الاقتصاد المصرى ( التذاعيات وسياسات المواجهة )}

الملخص :-

في ضوء المتغيرات التي مر بها العالم، منذ ظهور فيروس كورونا "كوفيد 19" وانتشاره بين جميع

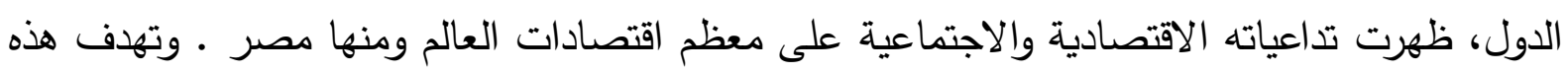

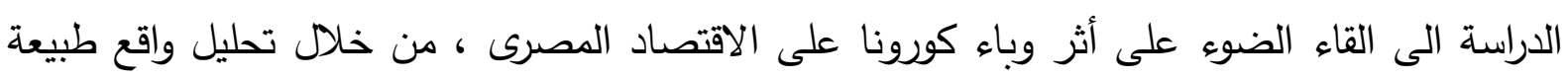

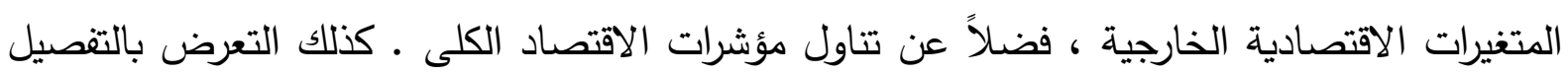

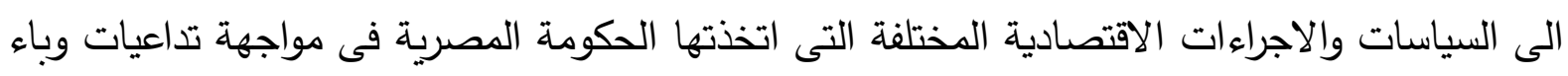
كورونا .

وتستخدم الدراسة منهجية محددة تعتمد على التحليل الوصفى والاستقرائى لمؤشرات ميزان المدفوعات

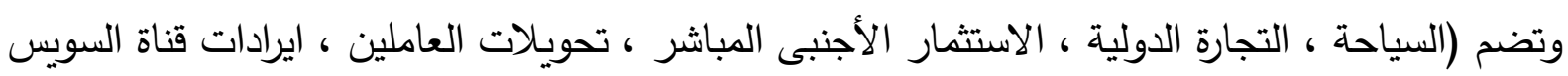

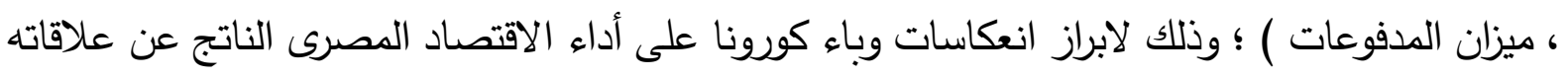

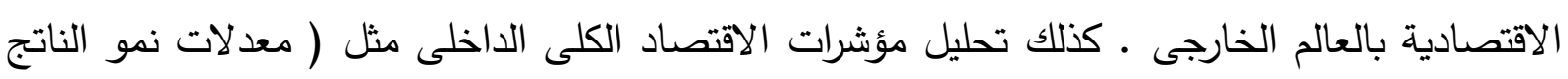

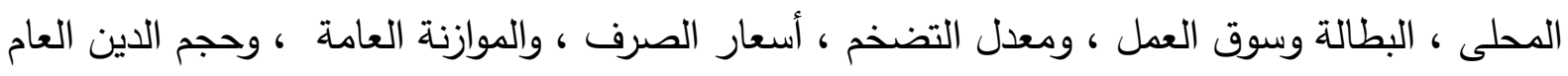

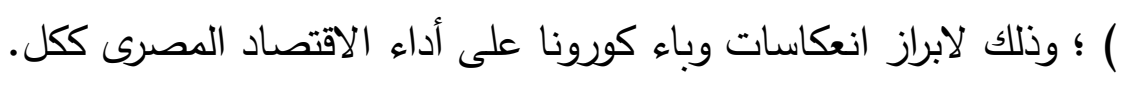

\section{وقد توصلت الدراسة الى عدد من النتائج أهمها مايلى :}

- ان المتغيرات الاقتصادية الخارجية الناجمة من علاقات مصر بدول العالم الخارجى ، كانت هى الأكثر تأثرا بوباء كورونا وخاصة السياحة والتجارة الدولية .

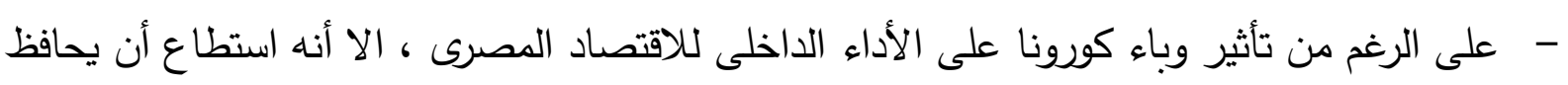

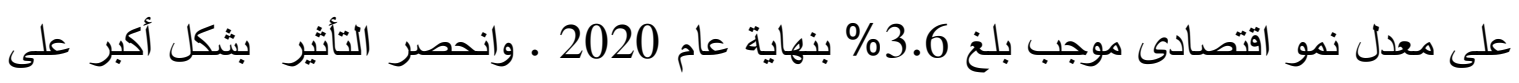

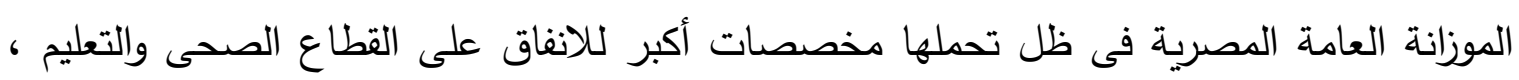
واجراءات الحماية الاجتماعية .

- تتوع هيكل الاقتصاد المصري ساهم بشكل كبير فى مواجهة الأزمة، كذلك نتائج برنامج الإصلاح الاقتصادي الذى بدأته الحكومة المصرية في 2016 قبل أزمة فيروس كورونا. يضاف الافئ الى ذلى ذلك طبيعة

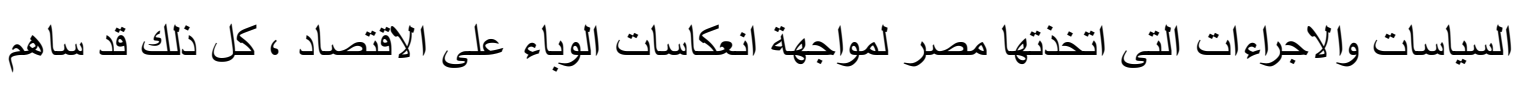

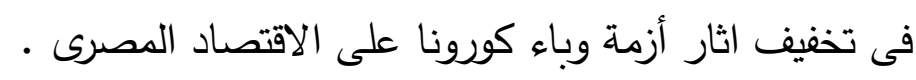
- الكلمات المفتاحية : وباء كورونا ، الاقتصاد المصرى ، مؤشرات الاقتصاد الكلى ل 


\section{Abstract:}

In light of the changes that the world has gone through, since the emergence of the Coronavirus and its spread among all countries, its economic and social repercussions have appeared on most of the world's economies, including Egypt. This study aims to shed light on the impact of the Corona epidemic on the Egyptian economy, by analyzing the reality of the nature of external economic variables, as well as dealing with macroeconomic indicators. As well as exposure in detail to the various economic policies and measures taken by the Egyptian government in the face of the repercussions of the Corona epidemic.

The study uses a specific methodology based on descriptive and inductive analysis of the balance of payments indicators and includes (tourism, international trade, foreign direct investment, workers remittances, Suez Canal revenues, the balance of payments). This is to highlight the repercussions of the Corona epidemic on the performance of the Egyptian economy resulting from its economic relations with the outside world. As well as analyzing internal macroeconomic indicators such as (GDP growth rates, unemployment and the labor market, inflation rate, exchange rates, the general budget, and the size of public debt); This is to highlight the repercussions of the Corona epidemic on the performance of the Egyptian economy as a whole.

\section{The study reached a number of results, the most important of which are:}

- The external economic changes resulting from Egypt's relations with the countries of the outside world, were the most affected by the Corona epidemic, especially tourism and international trade.

- Despite the impact of the Corona epidemic on the internal performance of the Egyptian economy, it managed to maintain a positive economic growth rate of $3.6 \%$ by the end of 2020. The impact was limited to the Egyptian public budget, in light of its higher allocations for spending on the health sector, education, and social protection measures.

- The diversification of the structure of the Egyptian economy contributed greatly to facing the crisis, as well as the results of the economic reform program that the Egyptian government started in 2016 before the Coronavirus crisis. In addition to this, the nature of the policies and measures taken by Egypt to confront the repercussions of the epidemic on the economy, all of this has contributed to mitigating the effects of the Corona epidemic crisis on the Egyptian economy.

Key words: Corona epidemic, Egyptian economy, macroeconomic indicators. 
تسببت أزمة وباء كورونا في إحداث تراجع كبير لمعظم اقتصادات العالم ومنها مصر ، حيث تسبب

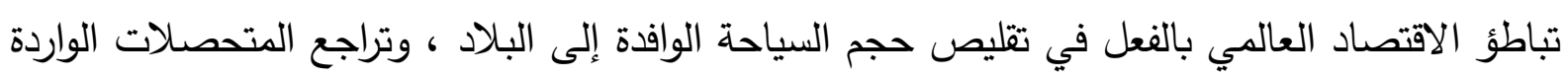

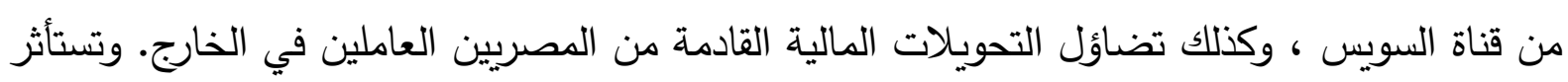

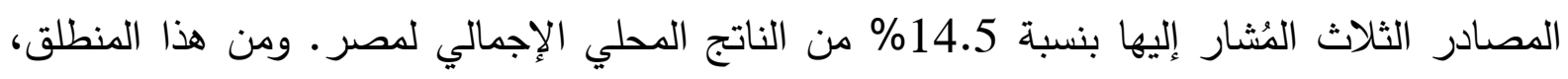

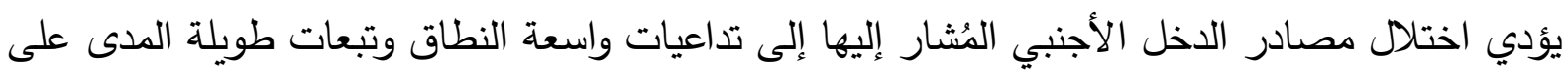

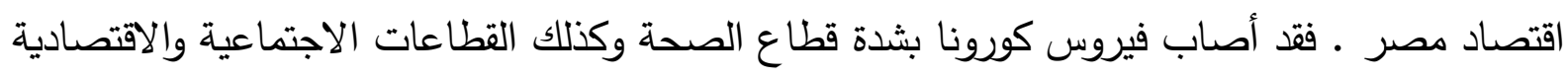

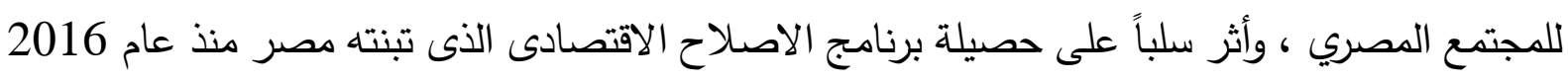

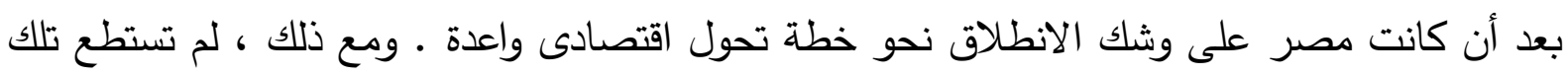

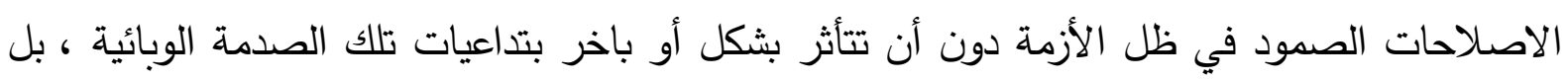

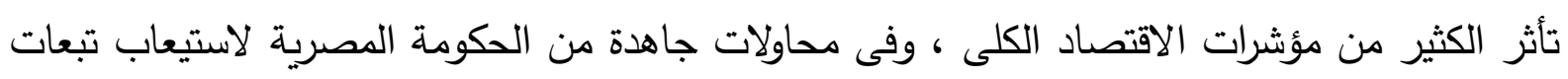

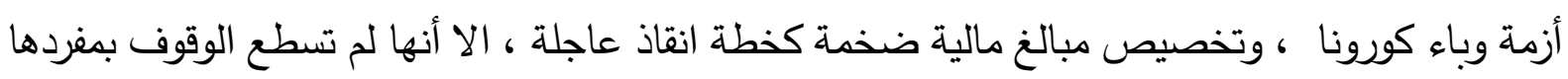

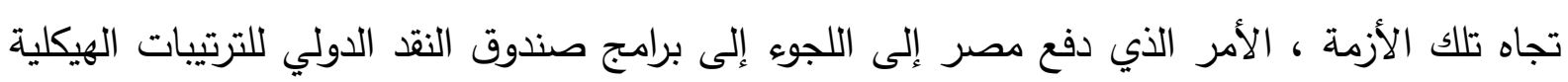

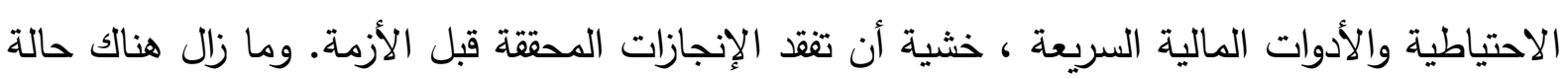

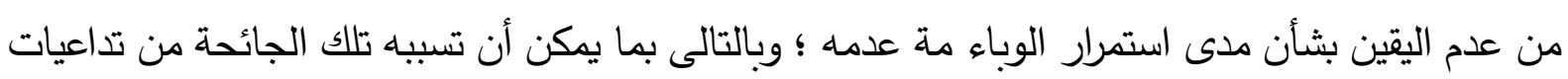
اقتصادية .

: (2\1)

- دراسات باللغة العربية : - 20 -

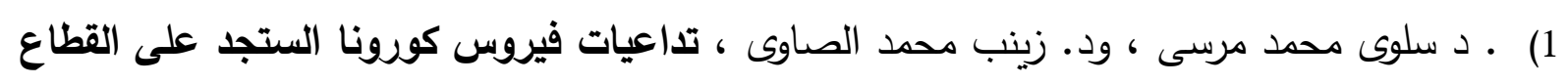

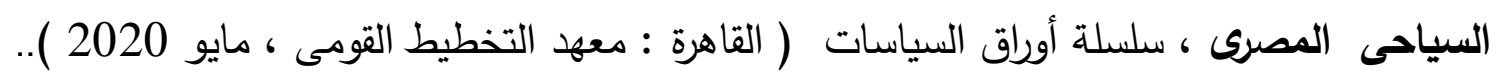

تتناول هذه الدراسة انعكاسات وباء كورونا على القطاع السياحى فى مصر ، وتعرضت الى تطور

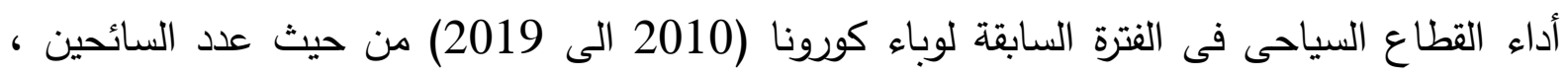

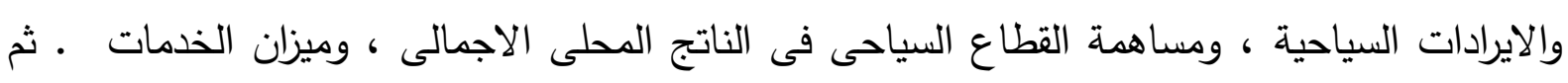

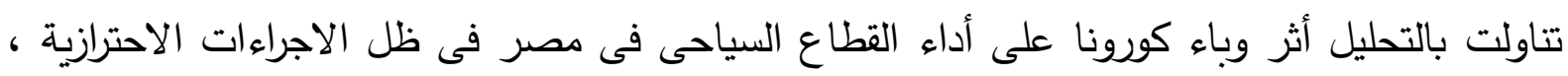

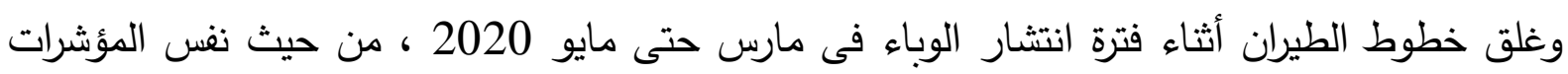

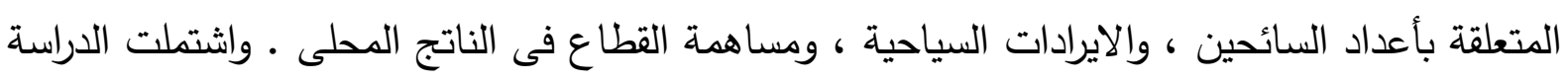

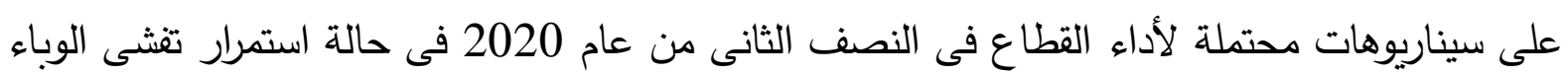


من عدمه ـ كما تعرضت الدراسة بالتضصيل الى الجهود التى قامت بها مصر لمواجهة تداعيات الوباء على

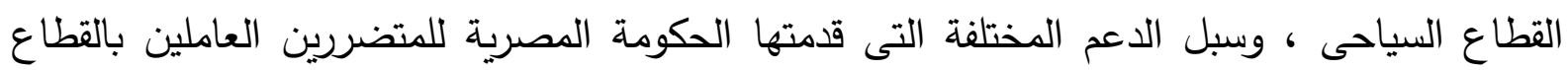
السياحى • واختتمت الدراسة ببعض المقترحات للتخفيف من اثار الأزمة على القطاع السياحى.

2) د. سالى محمد فريد ، تداعيات كورونا على العوائد المصرية بالنقد الأجنبى ، سلسلة أوراق السياسات

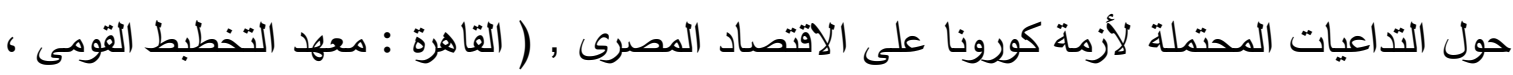

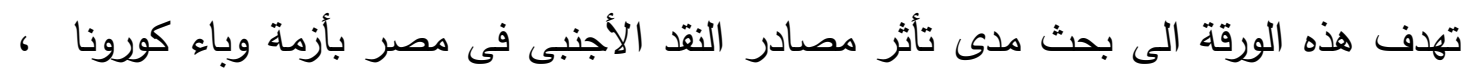

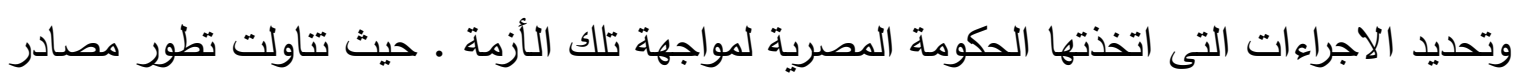
النقد الأجنبى قبل وبعد وباء كورونا من حيث ( عوائد قطاع السياحة ، وعوائد الصادرات ، والاستثمار

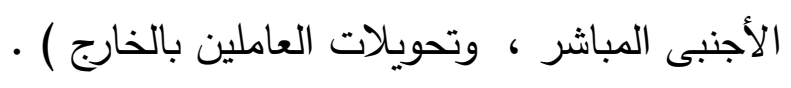

وتوصلت الدراسة الى عدة نتائج أهمها وجود تأثير سلبى على مصادر النقد الأجنبى فى مصر

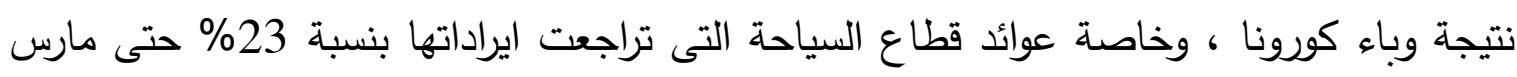

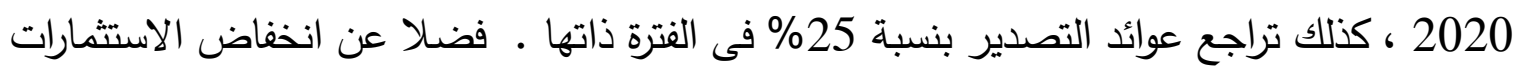

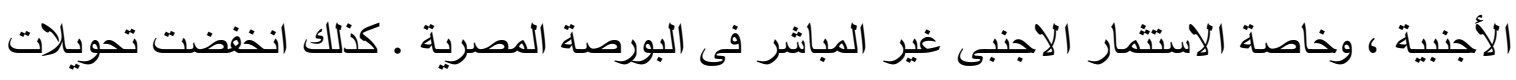

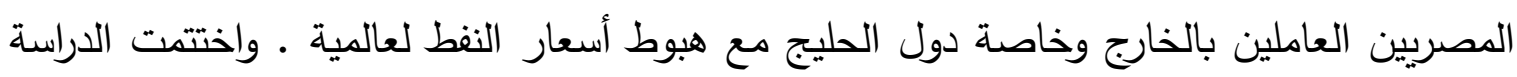

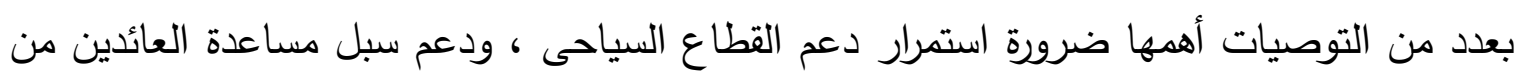

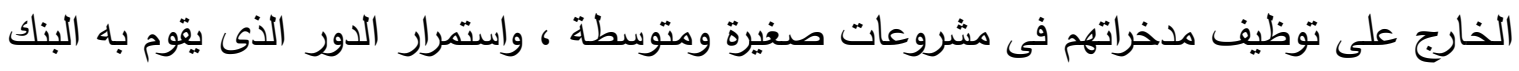

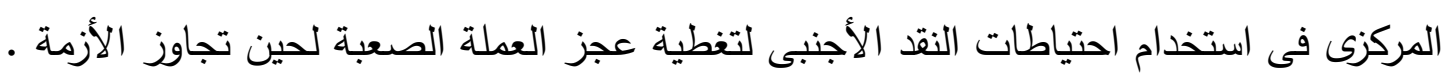

3) سارة ناصح ، مؤشرات مختلطة : كيف اثر وباء كورونا على التجارة الخارجية المصرية ، المركز

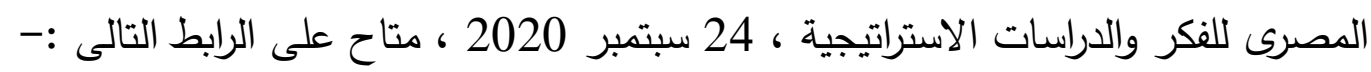
https://www.ecsstudies.com/11060 ركزت هذه الدراسة على أثر وباء كورونا على التجارة الخارجية المصرية ، حيث تناولت فى البداية التأثير على جانب الصادرات المصرية التى سجلت انخفاض في مارس دولار أمريكي بنسبة انخفاض قدرها 16.92 \% عن الثهر السابق للانتشار وهو فبراير من العام ذاته ،

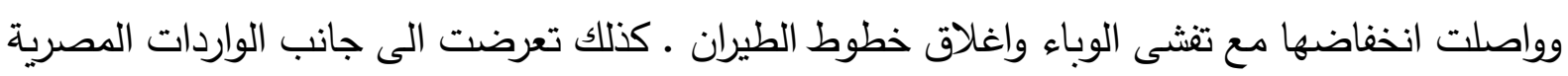
التى بلغت 5316 مليون دولار أمريكي في يناير 2020 مقارنة بنحو 6517 مليون دولار أمريكي في الثياء

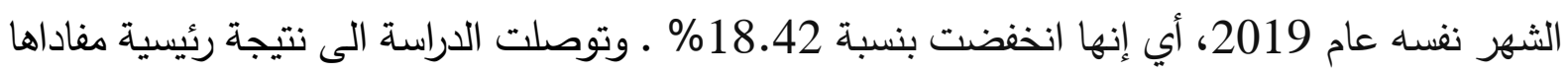
أن هناك عامل ايجابى فى هذا الانخفاض وهو مزيد من الاعتماد على المنتج المحلى المصرى ، وانخفاض 
عجز الميزان التجاري وهو ما يعد مؤشرًا إيجابيًا يؤكد قدرة الاقتصاد الدصري على تحويل المحنة إلى منحة

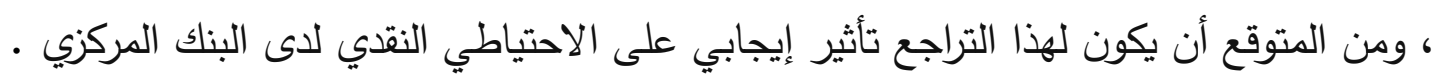

- دراسات باللغة الانجليزية :

1)Ministry of Planning and Economic Development , REGIONAL PROGRAM POLICY NOTE 06 , Impact of COVID-19 on the Egyptian economy: Economic sectors, jobs, and households ( Cairo : Ministry of Planning and Economic Development, June 2020).

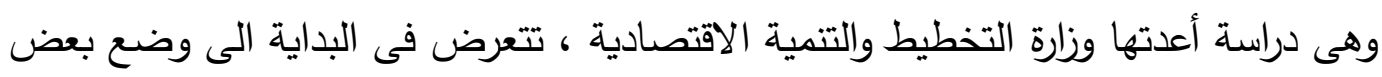

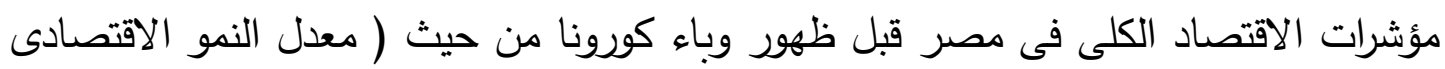

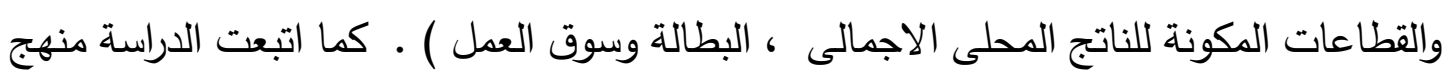
التحليل الفعلى لتلك المؤشرات بالاضافة الى التوقع بما ستكون عليه فى نهاية عام ظهور وباء التهاء

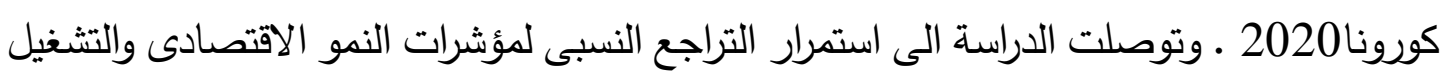

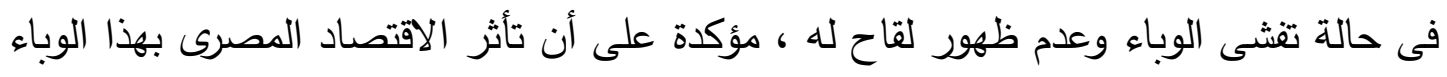

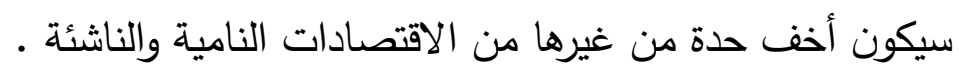

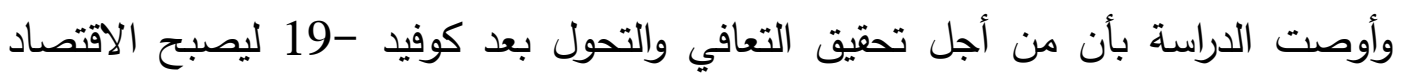

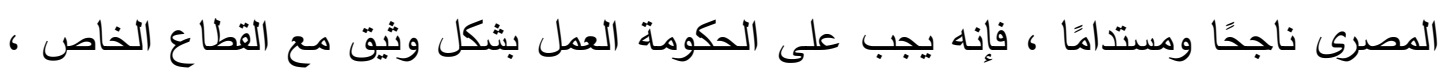

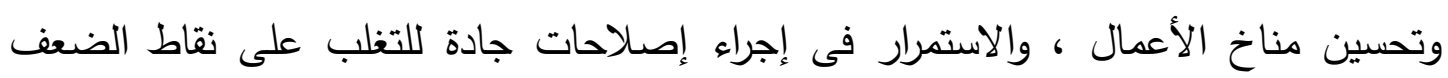
المؤسسية.

2) Ministry of Planning and Economic Development, Monthly Economic Review, Issue.3, (Cairo : Ministry of Planning and Economic Development, November. 2020).

وهو التقرير الثهرى الذى تصدره وزارة التخطيط والتتمية الاقتصادية ، والذى تم تخصيصه لتوضيح انعكاسات وباء كورونا على بعض القطاعات الاقتصادية فى مصر منها القطاع الحقيقى ويشمل (ايرادات

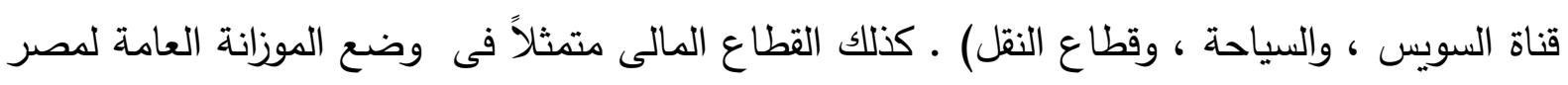

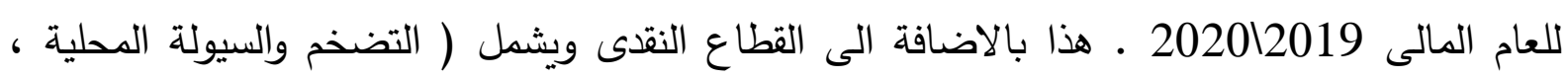

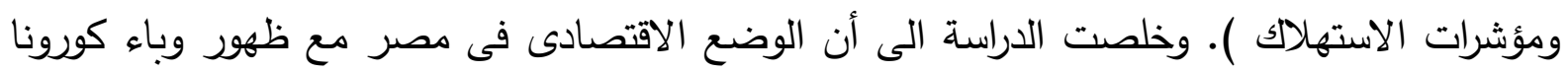

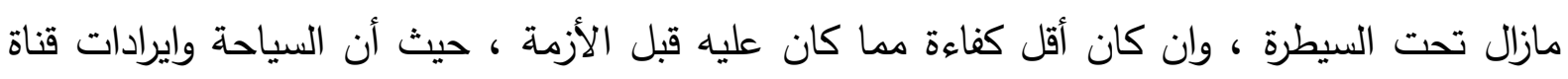

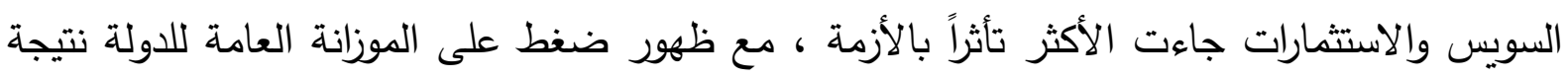


ارتفاع المصروفات المخصصة لقطاع الصحة والاجراءات التحفيزية للاقتصاد ، وتراجع الكثير من الايرادات

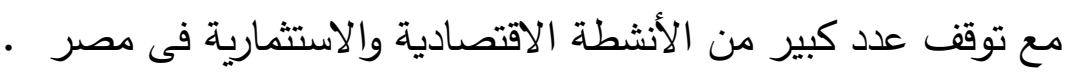

، من خلال التعرض الى الدراسات السابقة التى تناولت أثر وباء كورونا على أداء الاقتصاد المصرى

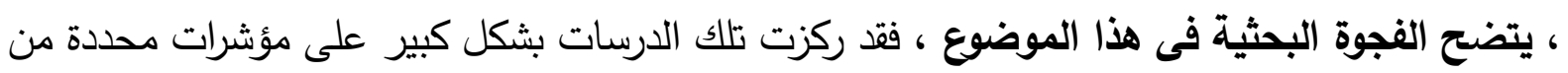

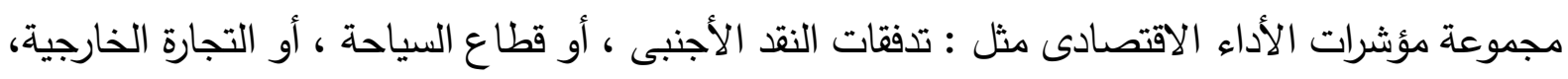

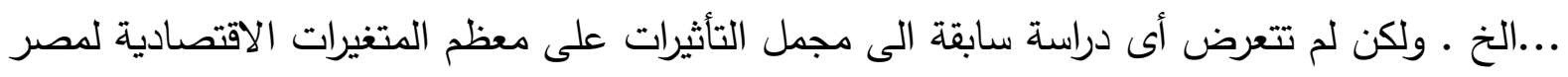

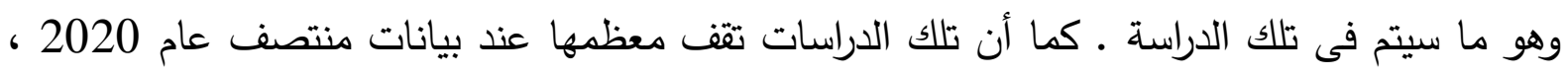
واتبعت اسلوب التوقع لما ستكون عليه تلك المؤشرات بنهاية عام 2020 فى وسط حالة من عدم اليقين بشأن استمرار الوباء من عدمه ـ أما هذه الدراسة فسوف عتيه لتاول بشكل أشمل لمعظم تلك المتغيرات الخارجية

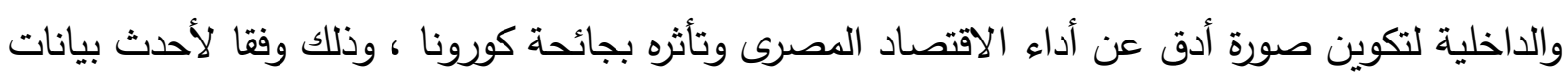
صادرة عن نهاية عام 2020 من المؤسسات والوزارات المعنية فى مصر كذلك المؤسيسات الدولية. (311) - مشكلة الدراسة : على الرغم من المراحل الاصلاحية التى مر بها الاقتصاد المصرى منذ عام

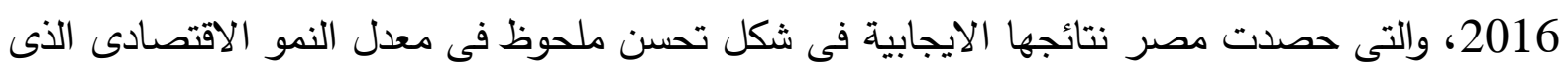

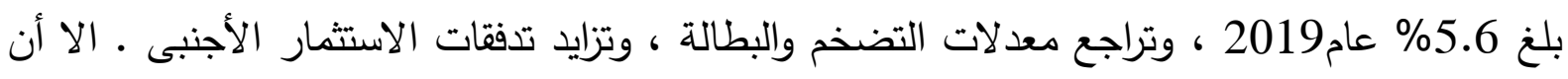

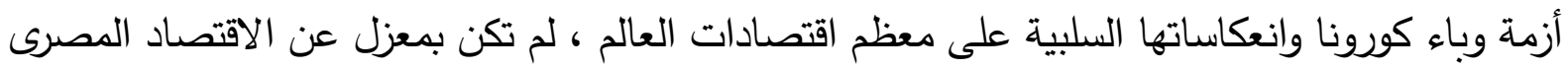

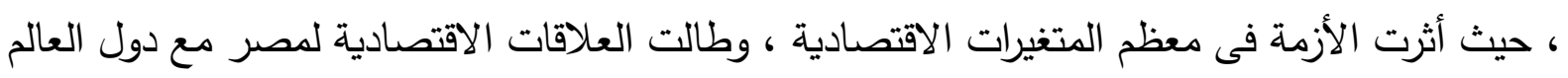

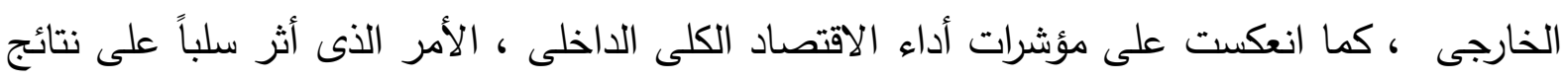

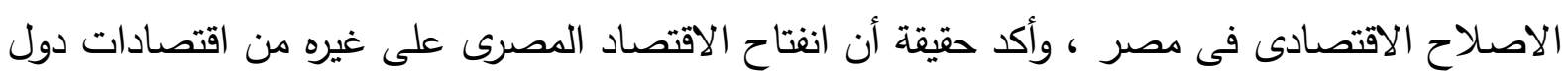

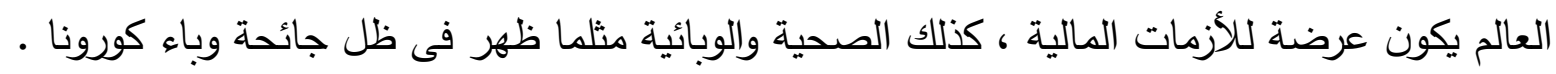
(4l1)- - هدف الدراسة : تهدف الدراسة الى القاء الضوء على أثر وباء كورونا على الاقتصاد المصرى

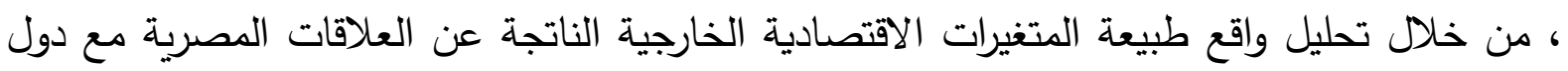

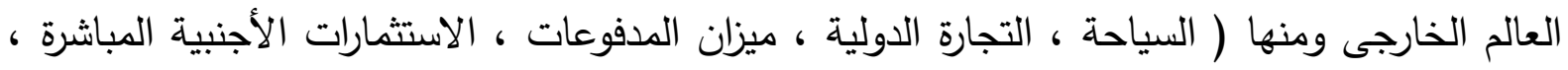

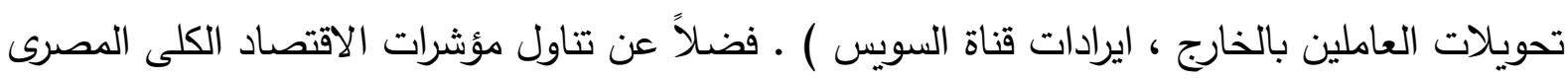

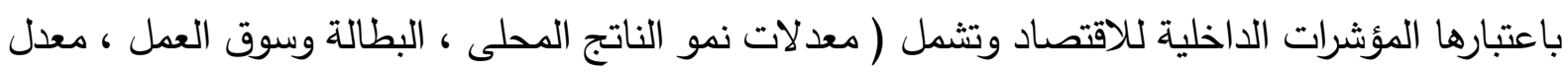

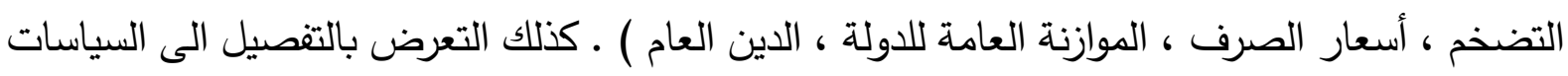

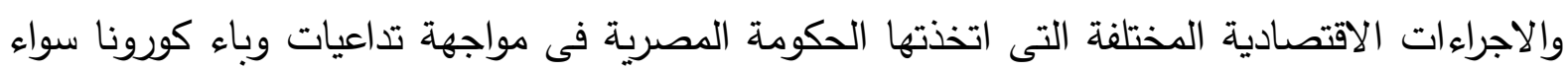
على جانب السياسة المالية أو النقدية ، كذلك الاجتماعية . 
(5l1)- أهمية الدارسة : تسببت جائحة وباء كورونا فى العديد من التداعيات السلبية التى طالت معظم

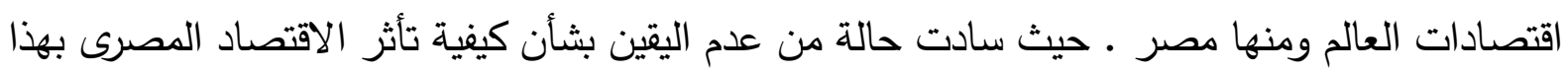

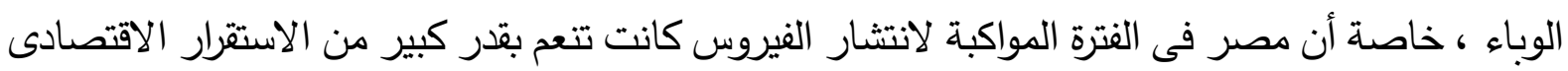

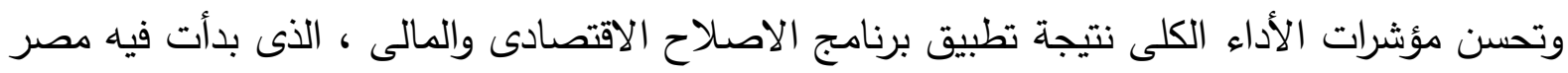

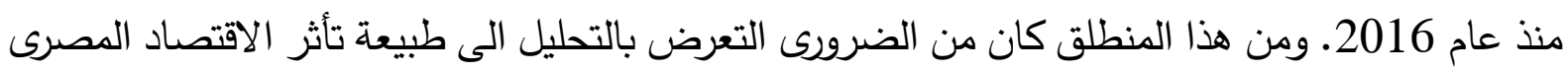

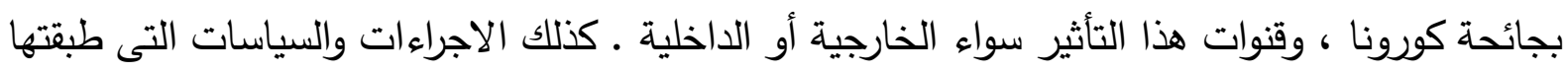

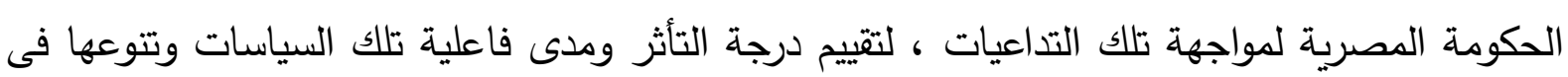

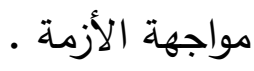

(611)- فروض الدراسة : تتطلق الدراسة من فرضية رئيسية تسعى الى اختبار مدى صحتها من عدمها

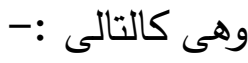

- أثرت أزمة وباء كورونا بشكل واضح على العلاقات الاقتصادية بين مصر ودول العالم الخارجى ، كذلك على مؤشرات الاقتصاد الكلي المصري .

(711)- منهجية الدراسة : تستخدم الدراسة منهجية محددة تعتمد على التحليل الوصفى والاستقرائى

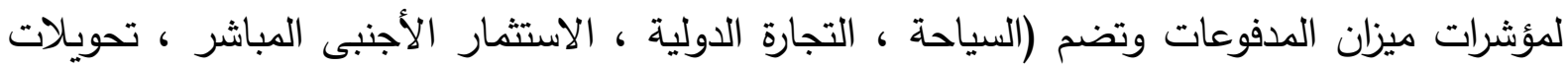

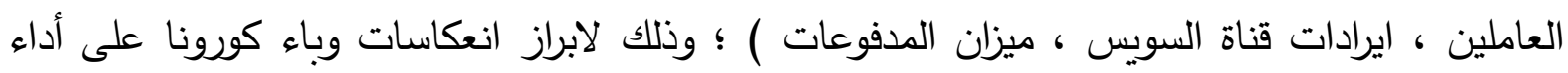

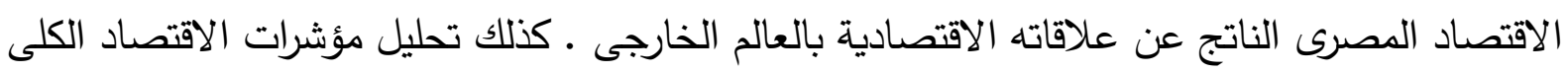

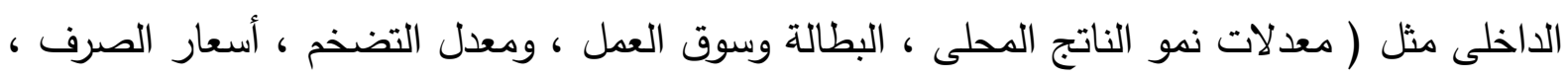

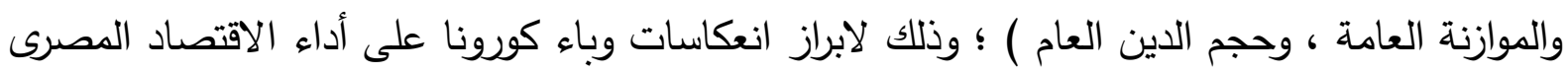
ككل .

(811) - مصادر البيانات : اعتمدت الدراسة على عرض وتحليل البيانات الواردة من تقارير المؤسسات

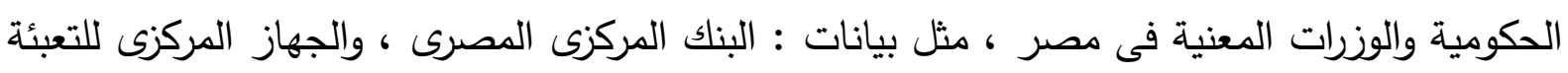
العامة والاحصاء ، ووزارة المالية ، ووزارة التخطيط والتتمية الاقتصادية ـ كذلك قواعد البيانات الدولية المنشورة بموقع البنك الدولى ، ومنظمة السياحة العالمية .

(911) - خطة الدراسة : تتناول الدراسة خمس نقاط رئيسية تتمثل فيما يلى :-

1) قنوات التأثير الخارجية على الاقتصاد المصرى

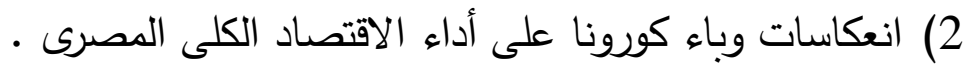

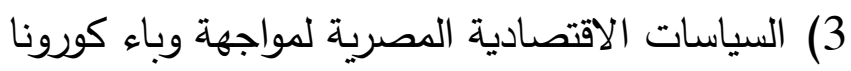


4) الاشادات الدولية بصمود الاقتصاد الدصرى أمام جائحة كورونا

5) نتائج الدراسة

6 ) توصيات الدراسة

أولاً - قنوات التأثير الخارجية على الاقتصاد المصرى :

1

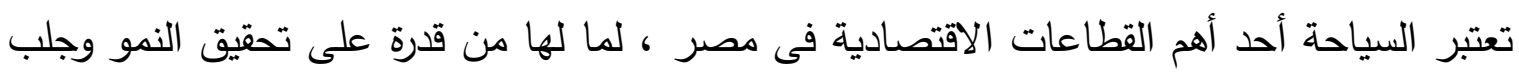

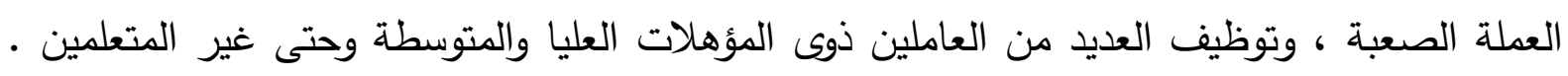

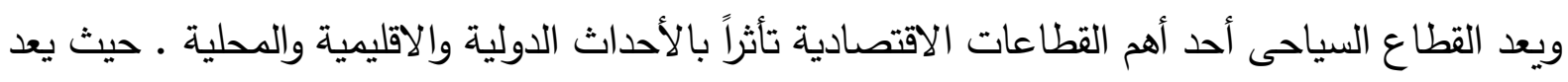
قطاع السياحة والسفر أحد أهم القطاعات المتضررة بفعل تفشى وباء كورونا ، مع توقف حركة السياحة والطيران بشكل كامل منذ فبراير 2020. وقد حقق قطاع السياحة المصرى قبل أزمة وباء كورونا نمواً

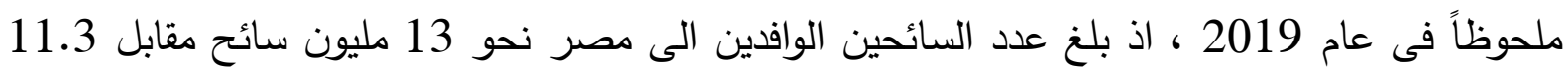

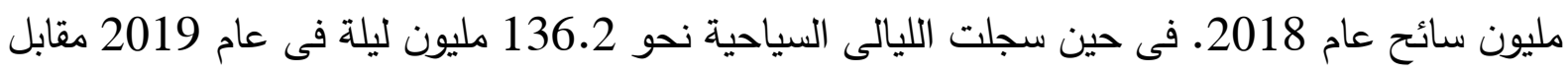

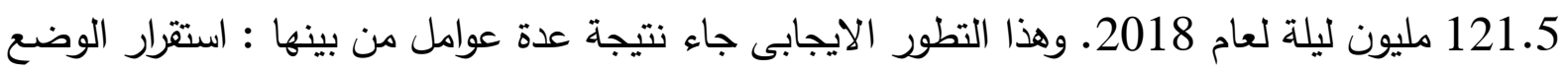

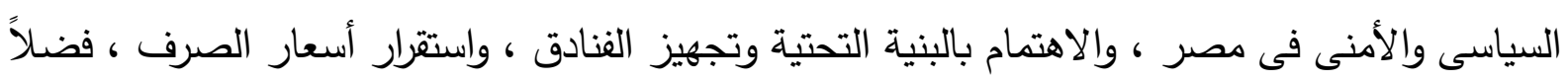

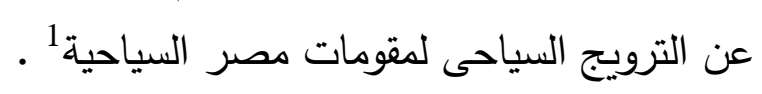

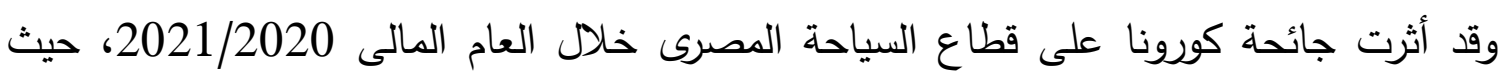
انخفض عدد السائحين إلى 2.2 مليون سائح يمثلون 19\% من عن السياحة المعتادة مقارنة بعام 2018؛

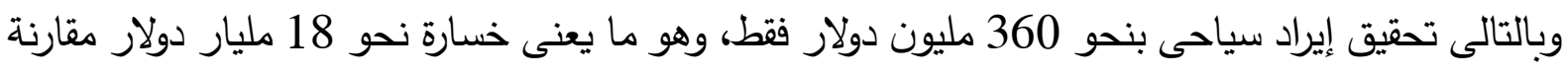

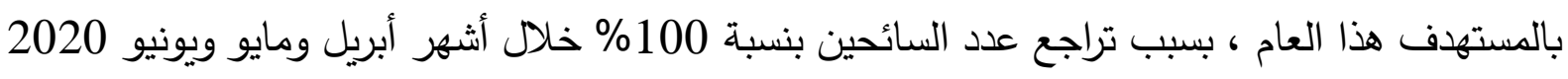
والتى تمثل ذروة الأزمة، حيث شهد شهر أبريل 2020 أقل عدد سياحة وافدة بنحو 1000 سائح فقط بائط

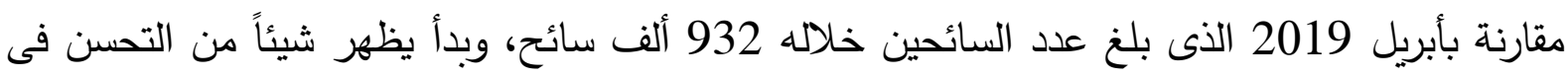
يوليو وأغسطس 2020 بوفود 89 ألفا و223 ألف سائح على التوالى، لتنخفض نسبة نرائ تراجع الحركة السياحية إلى 82\% فى أغسطس 2020. ويلى ولاحظ من الجدول رقم (1) تحقق معدل تغير موجب فى أعداد

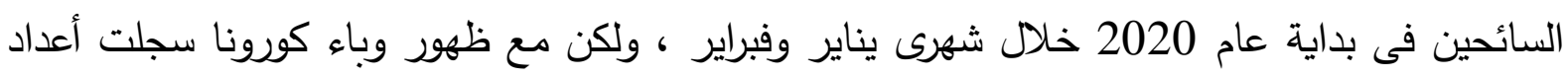

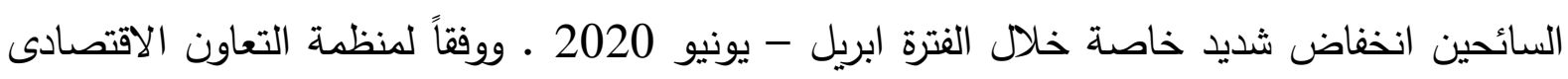

1 1 أ ـ ـ سلوى محمد مرسى ، ود. زينب محمد الصاوى ، تداعيات فيروس كورونا الستجد على القطاع السياحى المصرى

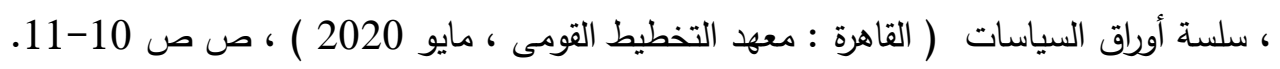


والتتمية ، يعد قياس الاثار الحالية والمستقبلية للأزمة على قطاع السياحة أمراً صعباً ، حيث كثفت الأزمة

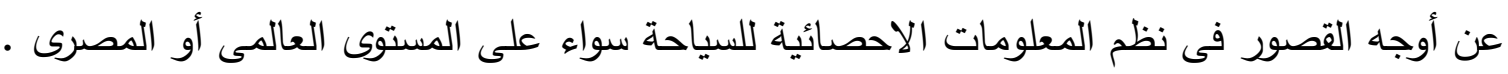
جدول رقم (1) تطور أعداد السياح الوافدين الى مصر عامى 2019 و 2020

ألف سائح

\begin{tabular}{|c|c|c|c|}
\hline معدل التغير\% & أثناء الأزمة 2020 & قبل الأزمة عام 2019 & الشهور \\
\hline 10 & 945 & 861 & يناير \\
\hline 6 & 942 & 885 & فبراير \\
\hline $64-$ & 398 & 1097 & مارس \\
\hline $100^{-}$ & 1 & 1220 & ابريل \\
\hline $100^{-}$ & 2 & 932 & مايو \\
\hline $100^{-}$ & 4 & 1083 & يونيو \\
\hline 93- & 89 & 1225 & يوليو \\
\hline $82-$ & 223 & 1221 & أغسطس \\
\hline
\end{tabular}

المصدر : من اعداد الباحثة استتادا الى قاعدة بيانات منظمة السياحة العالمية لفترة كوفيد 19.

ولقد كان لانخفاض أعداد السياح الوافدين الى مصر أثره السلبى على الايرادات من هذا القطاع ، كأل حيث انخفضت الايرادات السسياحية فى النصف الأول من عام 2020 بنحو 55\% مقارنة بالفترة المناظرة

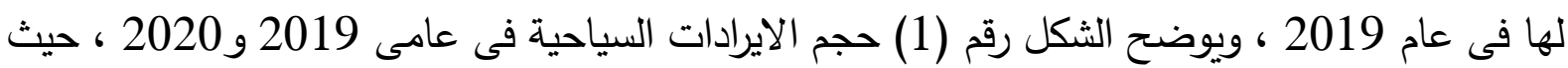

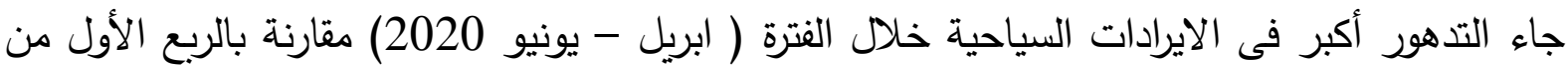

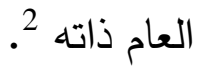

\section{شكل رقم (1) حجم الايرادات السياحية فى مصر خلال عامى 2019 ، و2020}

2 ) المركز المصرى للدراسات الاقتصادية ، متابعة اثار كوفيد على الاقتصاد المصرى قطاع السياحة ، نوفمبر 2020 ،

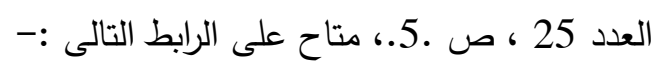

http://www.eces.org.eg/PublicationsDetails?Lang=AR\&C=1\&T=1\&ID=1254\&\%D8\%B1\%D 8\%A3\%D9\%8A-\%D9\%81\%D9\%8A-\%D8\%AE\%D8\%A8\%D8\%B1-

(\%D8\%B1\%D8\%A3\%D9\%8A-\%D9\%81\%D9\%8A-

\%D8\%A3\%D8\%B2\%D9\%85\%D8\%A9)---

\%D8\%A7\%D9\%84\%D8\%B9\%D8\%AF\%D8\%AF-25-

\%D9\%85\%D8\%AA\%D8\%A7\%D8\%A8\%D8\%B9\%D8\%A9-

\%D8\%A2\%D8\%AB\%D8\%A7\%D8\%B1-\%D9\%83\%D9\%88\%D9\%81\%D9\%8A\%D8\%AF-19-\%D8\%B9\%D9\%84\%D9\%89-

\%D8\%A7\%D9\%84\%D8\%A7\%D9\%82\%D8\%AA\%D8\%B5\%D8\%A7\%D8\%AF-

\%D8\%A7\%D9\%84\%D9\%85\%D8\%B5\%D8\%B1\%D9\%8A---

$\% \mathrm{D} 9 \% 82 \% \mathrm{D} 8 \% \mathrm{~B} 7 \% \mathrm{D} 8 \% \mathrm{~A} 7 \% \mathrm{D} 8 \% \mathrm{~B} 9-$

\%D8\%A7\%D9\%84\%D8\%B3\%D9\%8A\%D8\%A7\%D8\%AD\%D8\%A9\&fbclid=IwAR2BTlr w03CTk4HdD1MET_QESL7DILp93ZlpXteX-1gTcajr6wYqH92nE6Y 


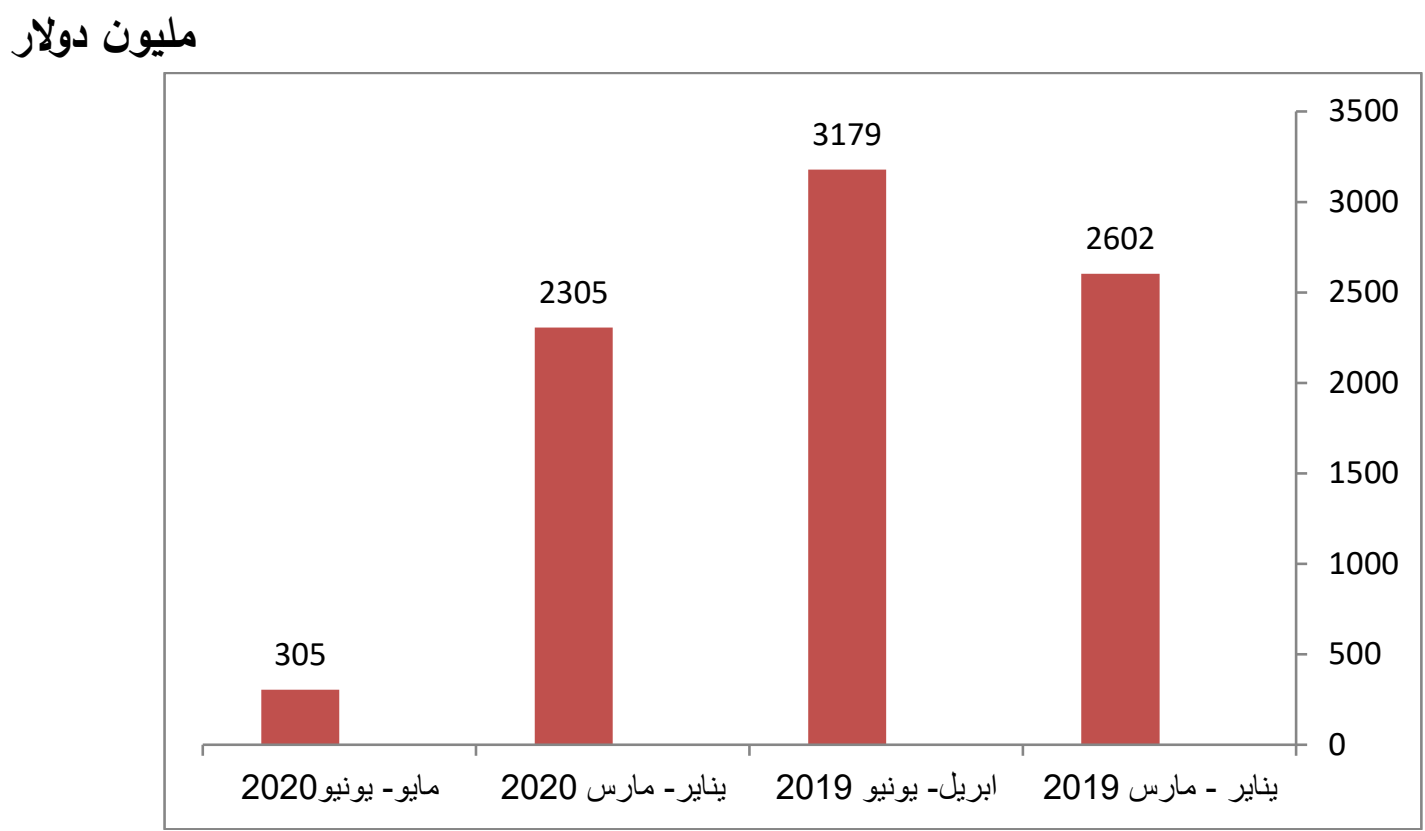

المصدر : من اعداد الباحثة استتادا الى قاعدة بيانات منظمة السياحة العالمية لفترة كوفيد 19.

بلغت القيمة الاجمالية للصادرات المصرية 33. 2 مليار دولار فى سبتمبر 2020 مقابل 2.39 مليار دولار فى سبمتبر 2019. ومن أهم السلع التى ارتفعت قيمة صادراتها كل من : اللدائن بأشكالها الأولية ، والمواد الغذائية ، والسجاد ، والأدوية ، ومستحضرات الصيدلة ، والاثاث ، والسكر • بينما كانت

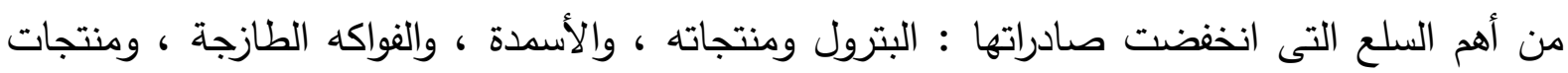

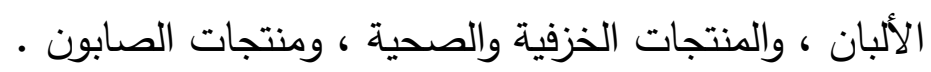

أما بالنسبة للواردات المصرية فقد شهدت القيمة الاجمالية انخفاضا لتصل الى 5.03 مليار دولار فى سبتمبر 2020 مقابل 6.39 مليار دولار فى سبتمبر 2019 ـ ومن أهم السلع التى ارتفعت واراتها :

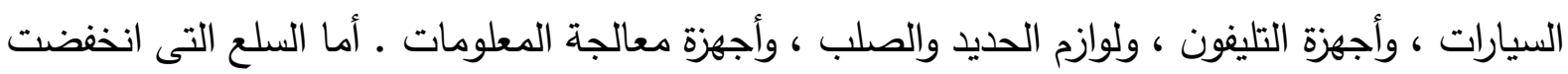

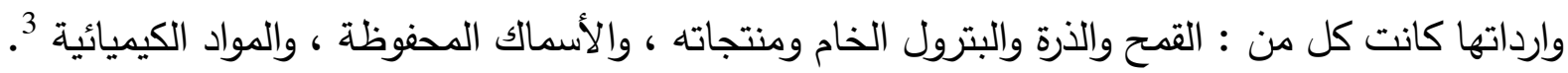
ويوضح الجدول التالى قيمة الصادرات والواردات سواء البترولية أو غير البترولية كما يلى :-

\section{جدول رقم (2) قيمة الصادرات والواردات المصرية خلال الفترة (2019 ، و2020)}

مليون دولار

3 ) الجهاز المركزى للتعبئة العامة والاحصاء ، نشرة التجارة الخارجية ، أكتوبر 2020 ، متاح على الرابط التالى :https://www.capmas.gov.eg/Pages/Publications.aspx?page id=5107\&Yera=23320 


\begin{tabular}{|c|c|c|c|c|}
\hline أغسطس 2019 & سبتمبر 2019 & أغسطس 2020 & سبتمبر 2020 & 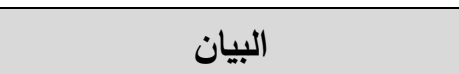 \\
\hline 2027 & 2098 & 1695 & 2008 & الصادرات غير البترولية \\
\hline 367 & 230 & 219 & 203 & صادرات البترول الخام ومنتجاته \\
\hline 2394 & 2328 & 1914 & 2328 & اجمالى الصادرات \\
\hline 5662 & 4547 & 4390 & 4547 & الواردات غير البترولية \\
\hline 732 & 486 & 544 & 486 & الواردات من البترول ومنتجاته \\
\hline 6394 & 5033 & 4934 & 5033 & اجمالى الواردات \\
\hline 8788 & 7361 & 6848 & 7361 & حجم التجارة \\
\hline
\end{tabular}

المصدر : الجهاز المركزى للتعبئة العامة والاحصاء ، نشرة التجارة الخارجية ، اكتوبر 2020 ، متاح على الرابط التالى :https://www.capmas.gov.eg/Pages/Publications.aspx?page_id=5107\&Yera=23320

وإجمالًا أدت جائحة كورونا إلى انخفاض الصادرات بنسبة 4.7\% خلال الربع الأول من 2020 مقارنة بالفترة نفسها من عام 2019 ، بينما عادت الى نفس مستواها الذى كانت عليه فى سبتمبر 2019 لتصل

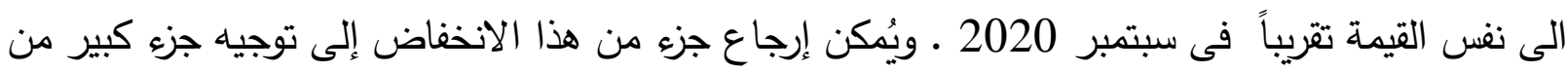

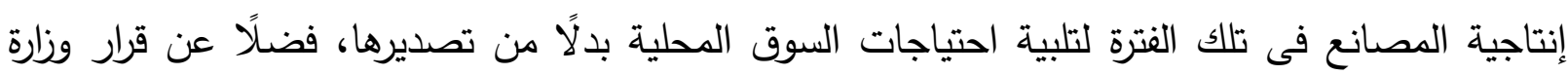

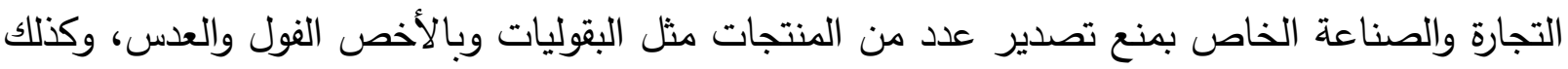

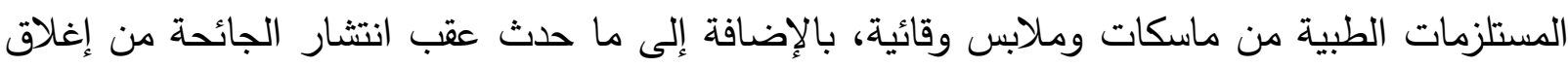

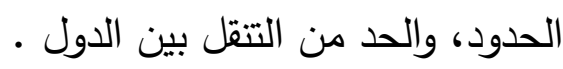

كما أدت أزمة كورونا إلى تراجع عجز الميزان التجاري بصفة عامة منذ بداية عام 2020 حتى الآن

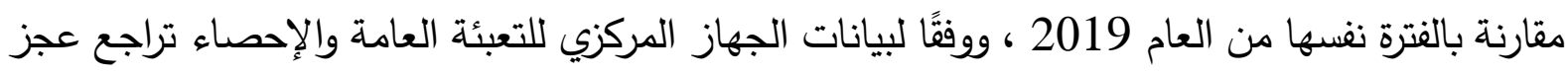

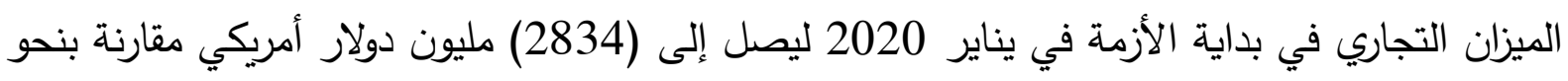

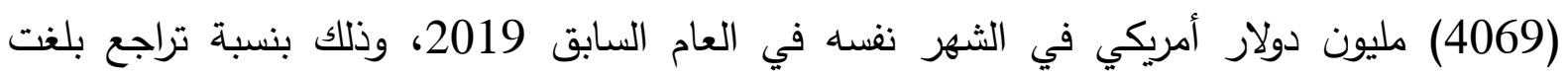

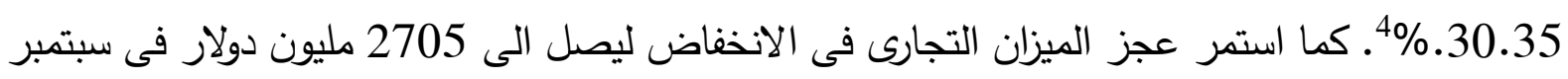
2020 مقارنة بنحو 4000 مليون دولار كعجز للفترة سبتمبر 2019 ؛ ويرجع ذلك اللى انخفاض الئاض الواردات

4 ) سارة ناصح ، مؤشرات مختلة : كيف أثث وباء كورونا على التجارة الخارجية المصرية ، المركز الدصرى للفكر https://www.ecsstudies.com/11060

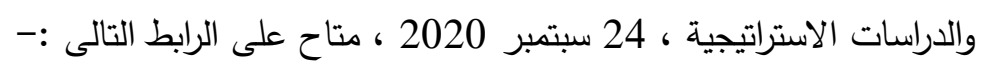

- الجهاز المركزى للتعبئة العامة والاحصاء ، بيانات التجارة الخارجية ، أكتوبر 2020 ، متاح على الرابط التالى :https://www.capmas.gov.eg/Pages/IndicatorsPage.aspx?Ind_id=5736 
والصادرات لعام 2020 نتيجة تفشى وباء مقارنة بالفترة السابقة لهذا الوباء كما هو موضح بالثكل رقم

شكل رقم (2) الميزان التجارى لمصر خلال الفترة ( سبتمبر 2020 ، وسبتمبر 2019)

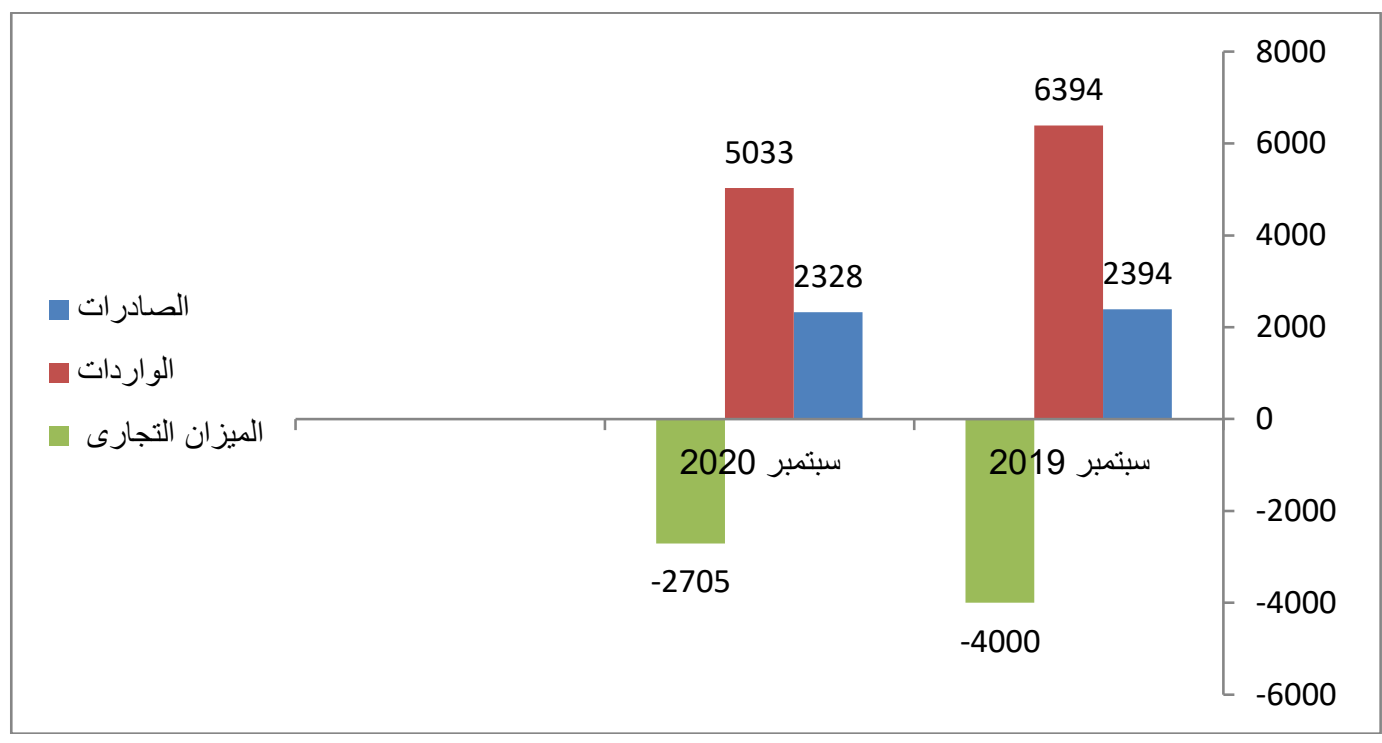

المصدر : : من اعداد الباحثة استتادا الى بيانات :-

- الجهاز المركزى للتعبئة العامة والاحصاء ، نثرة التجارة الخارجية ، اكتوبر 2020 ، متاح على الرابط التالى :https://www.capmas.gov.eg/Pages/Publications.aspx?page_id=5107\&Yera=23320

\section{3) الاستثمارات الأجنبية المباشرة :}

وفقا لبيانات منظمة الأمم المتحدة للتجارة والتتمية ( اونكتاد) ، زاد الاستثمار الاجنبى المباشر فى الآلي

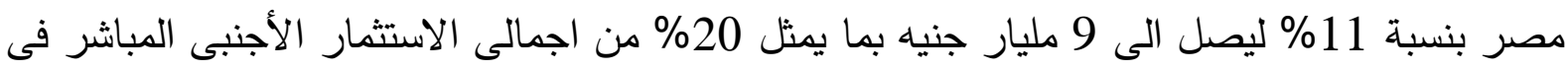

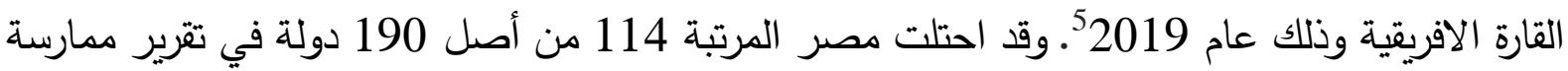
أنشطة الأعمال لعام 2020 الصادر عن البنك الدولي ، متقدمة بذلك 6 مراكز مقارنة بالعام 2018.

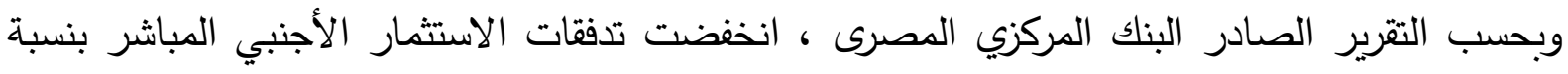

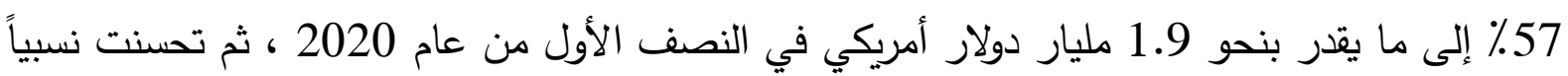

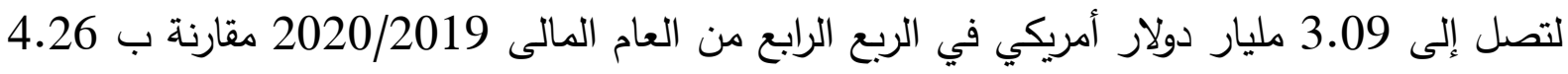

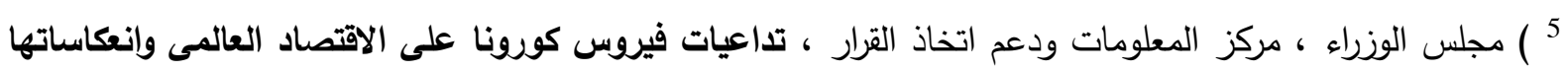

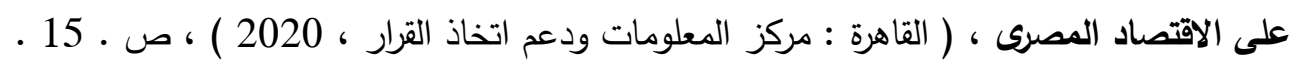


مليار دولار أمريكي في الربع الأول من عام 2020. ويوضح الثكل رقم (3) اجمالى الاستثمار الأجنبى

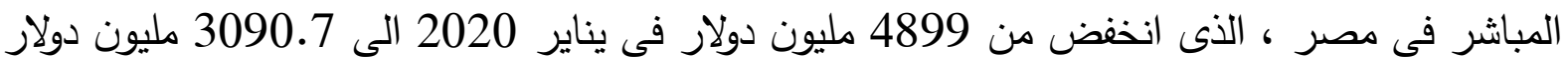
في يوليو 2020 نتيجة تفشى وباء كورونا وتداعياته السلبية على الاقتصاد العالمى والمصرى ، والإغلاق

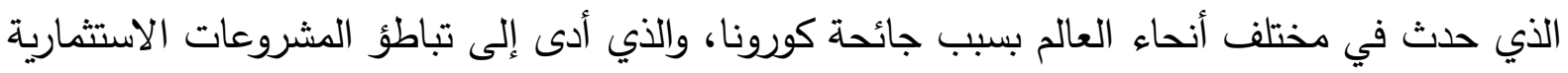

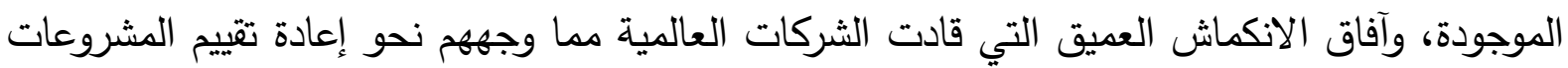

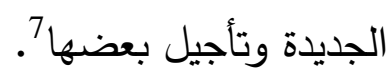

\section{شكل رقم (3) اجمالى رصيد الاستثمار الأجنبى المباشر فى مصر خلال الفترة (يوليو 2017-حتى يوليو 2020)}

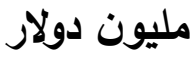

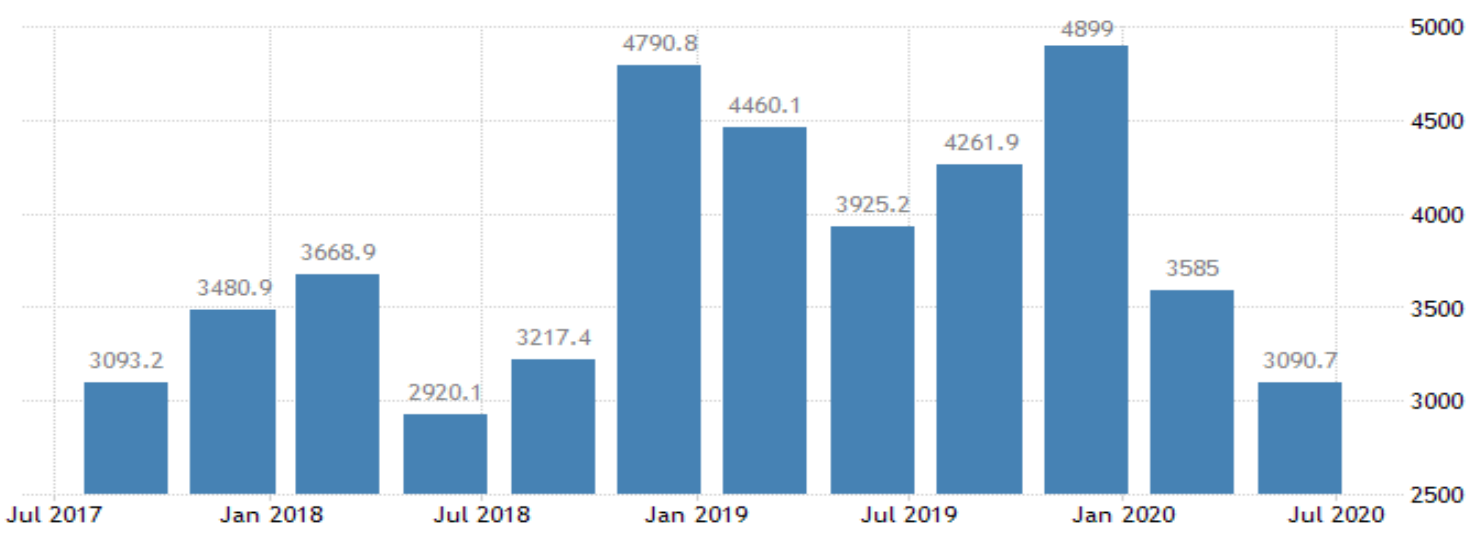

Source : Trading Economics, Egypt Foreign Direct Investment, Available at :https://tradingeconomics.com/egypt/foreign-direct-investment

وتعد المملكة المتحدة أكبر مستثر في مصر ، تليها بلجيكا والولايات المتحدة الأمريكية والإمارات العربية المتحدة. ويتركز الاستثمار الأجنبي المباشر في صناعة النفط والغاز (حوالي ثلاثة أرباع إجمالي

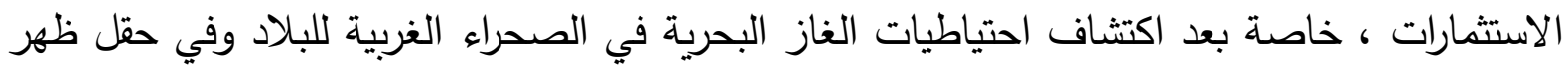

$\left.{ }^{6}\right)$ Nordea , Country profile Egypt , Foreign direct investment (FDI) in Egypt, Available at : https://www.nordeatrade.com/en/explore-new-market/egypt/investment

$\left.{ }^{7}\right)$ Lara Williams , " The state of play: FDI in Egypt " , Invesment Monitor , 28 Aug 2020 Available at :

https://investmentmonitor.ai/middle-east-north-africa/the-state-of-play-fdi-in-egypt 
البحري ، وهو الأكبر في البحر الأبيض المتوسط) ، يليه قطاع العقارات. والتصنيع والخدمات المالية

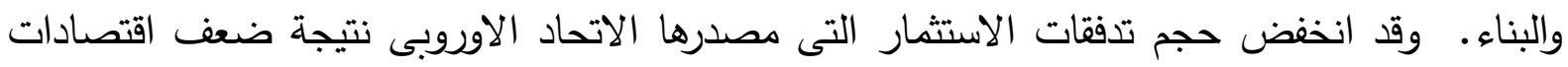

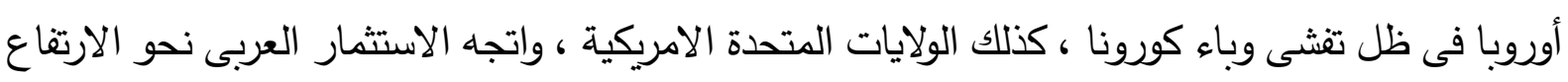

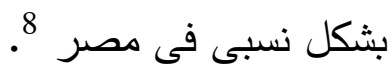

4) تحويلات المصريين العاملين بالخارج :

تطورت تحويلات العاملين في مصر بشكل سريع خلال السنوات القليلة الماضية، حيث باتت مصر تعتمد على تحويلات العاملين بالخارج بنسبة كبيرة، فقد بلغت تحويلات العاملين بالخارج في عام 2018

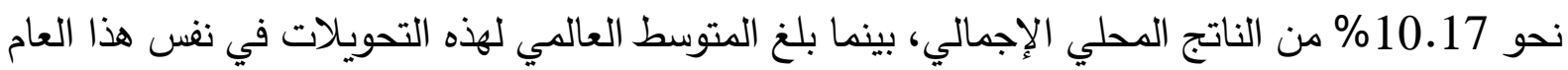

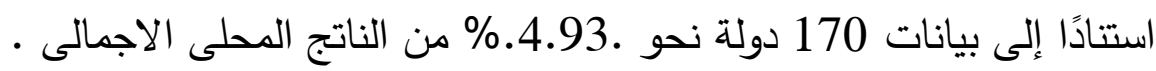

ويتضح من بيانات الثكل رقم (4)، أن تحويلات العاملين بالخارج كانت في تزايد بشكل عام ، خاصة

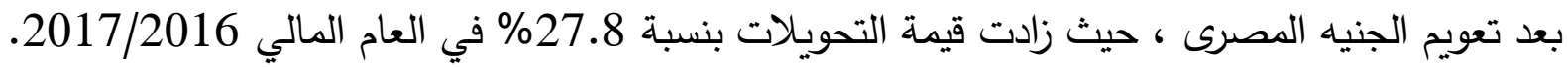
ووفقًا لبيانات ميزان المدفوعات الصادر عن البنك المركزي، بلغ حجم تحويلات العاملين بالخارج 6712.6

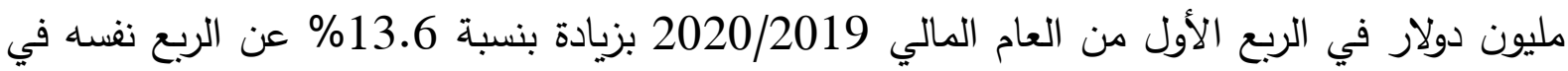
العام السابق الذي بلغ 5908.9 مليون دولار، سجلت تحويلات المصريين العاملين بالخارج ارتفاعاً خلال الفترة مارس الى مايو 2020 بمقدار 1.3 مليار دولار بمعدل زيادة سنوي 19.6\% لتسجل نحو 7.8

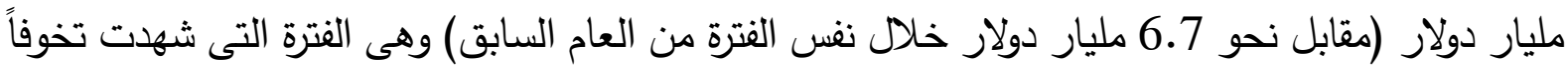

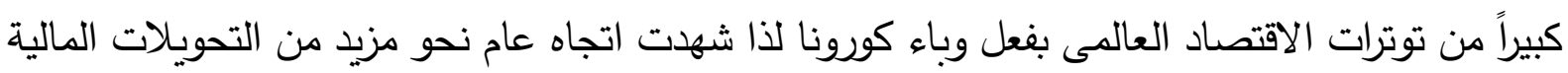

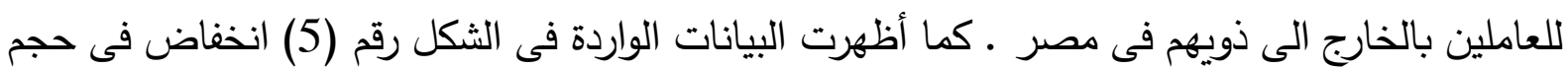

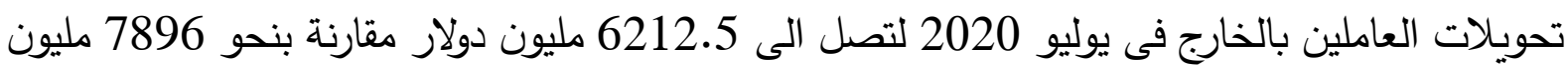
دولار فى يناير 2020

8 8 ) وزارة المالية ، التقرير المالى الثهرى ، ( القاهرة : وزارة المالية ، نوفمبر 2020 )، المجلد 15 ، عدد 13 ، ص .

9) Reuters , Egypt workers' remittances rose to $\$ 8$ billion in the July-September quarter , DECEMBER 7, 2020 , Available at :-

https://www.reuters.com/article/egypt-cenbank-int-idUSKBN28H1PF 


\section{شكل رقم (4) حجم تحويلات العاملين بالخارج خلال الفترة (يوليو 2017-يوليو 2020)}

\section{مليون دولار}

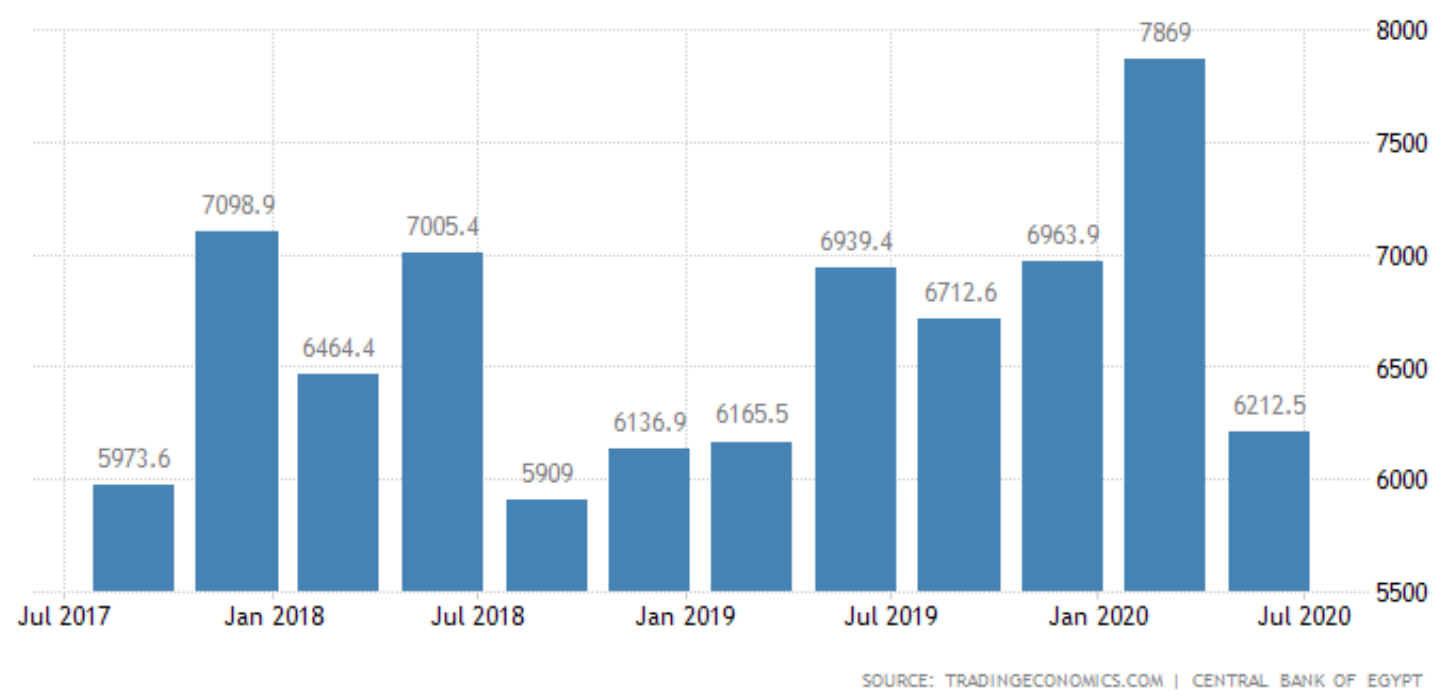

Source : Trading Economics , " Egypt Remittances ", 2020 , Available at :-

https://tradingeconomics.com/egypt/remittances

\section{4) ايرادات قناة السويس :}

أثرت جائحة كورونا على ايرادات قناة السويس ، حيث انخفضت الإيرادات إبتداءً من أبريل بشكل

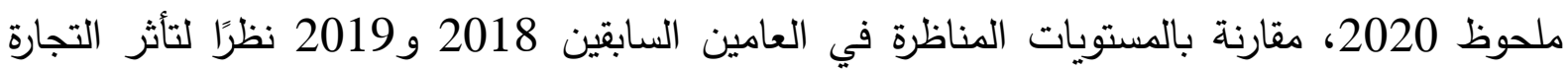
العالمية بشكل عام بالجائحة ، ويتضح من الثكل رقم (5) تراجع ايرادات القناة من

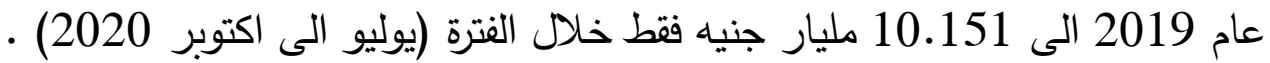




\section{شكل رقم (5) ايرادات قناة السويس خلال الفترة (2014 - 2020)}

\section{مليون جنيه}

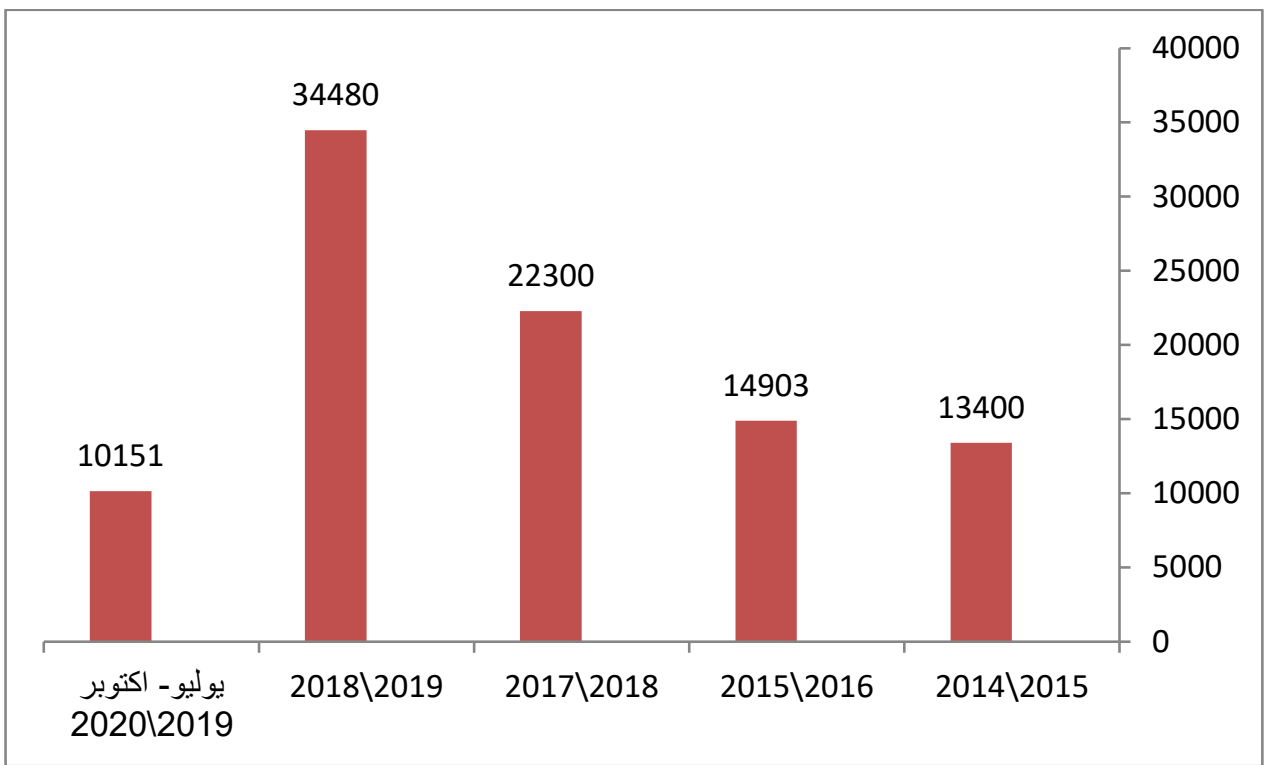

المصدر : من اعداد الباحثة استتادا الى بيانات :-

- - وزارة المالية ، التقرير المالى الثهرى ، ( القاهرة : وزارة المالية ، نوفمبر 2020 )، المجلد 15 ، عدد 13 ، ص28.

كما يرجع الانخفاض فى ايرادات قناة السويس أثناء تفشى أزمة وباء كورونا الى تراجع عدد السفن العابرة بالقناة كذلك حمولتها ، حيث انخفض عدد السفن العابرة فى الربع الاول من عام 2020 الى 4740 ناقلة مقارنة بنحو 4656 فى نهاية الربع الرابع من عام 2019 ، كما استمرت فى الانخفاض لتصل لى 4713 ناقلة فى الربع الأخير من عام 2020 كما هو موضح فى الشكل رقم (6) . 
شكل رقم (6) عدد السفن العابرة بقناة السويس وحمولتها خلال الفترة ( 2018-2020)

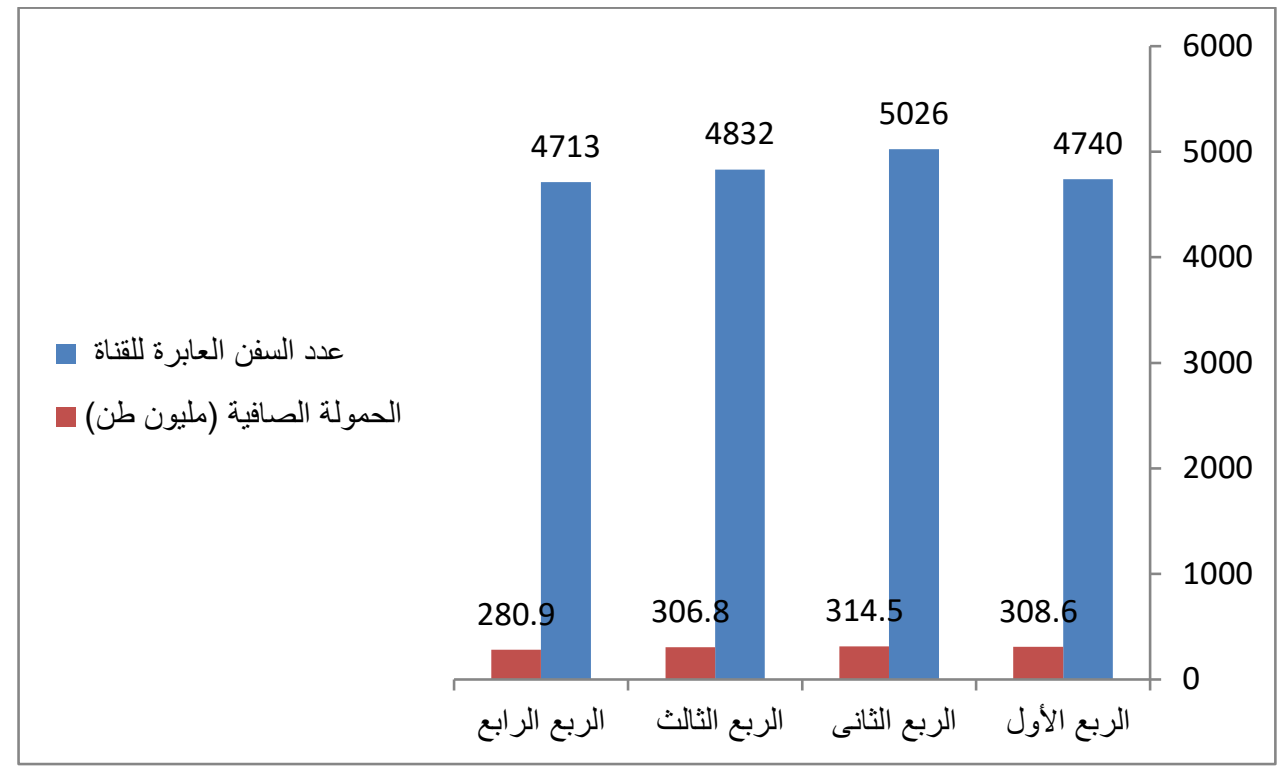

المصدر : من اعداد الباحثة استتادا الى :

- - البنك المركزى المصرى ، النشرة الاحصائية الشهرية ، اكتوبر 2020 ، العدد 283 ، ( القاهرة : البنك المركزى

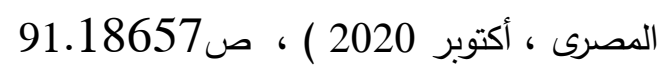

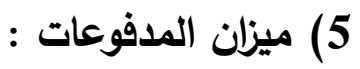

كشف البنك المركزى عن تحقيق ميزان المدفوعات عجزاً كلياً بلغ 8.6 مليار دولار خلال العام المالى 2020/2019،.حيث شهدت المعاملات الجارية للاقتصاد المصرى مع العالم الخارجي استقراراً فى مستوى العجز خلال العام المالى 2020/2019 ( الذى شهد النصف الثانى منه التداعيات السلبية لانتشار جائحة كورونا) ليصل الى نحو 11.2 مليار دولار بارتفاع طفيف عن مستوى العجز المحقق خلال العام المالى 2019/2018 الذى سجل نحو 10.9 مليار دولار ، وجاءت تلك النتيجة على خلاف التوقعات التى أجمعت على حدوث صدمة قوية لحساب المعاملات الجارية فى أغلب دول العالم وليس مصر فقط ، الا ان التحسن المحلوظ فى الميزان التجارى غير البترولى وارتفاع التحويلات الجارية دون مقابل قد ساهم فى تخفيف هذه الصدمة على الاقتصاد المصرى. وعلى الرغم من ذلك ، حافظ الحساب الرأسمالى والمالى لميزان المدفوعات المصرى على تحقيق صافى تدفق للداخل بلغ 5.4 مليار دولار ، الأمر الذى ساعد بجانب بناء احتياطيات قوية من النقد الأجنبى - على التخيف من حدة العجز الكلى بميزان المدفوعات 
ليقتصر على نحو 8.6 مليار دولار مقابل 102.5 مليون دولار في عام 2018-2019. كماهو موضح

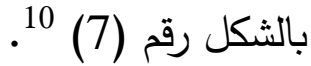

شكل رقم (7) البنود التفصيلية لميزان المدفوعات المصرى خلال الفترة (2015-2020)

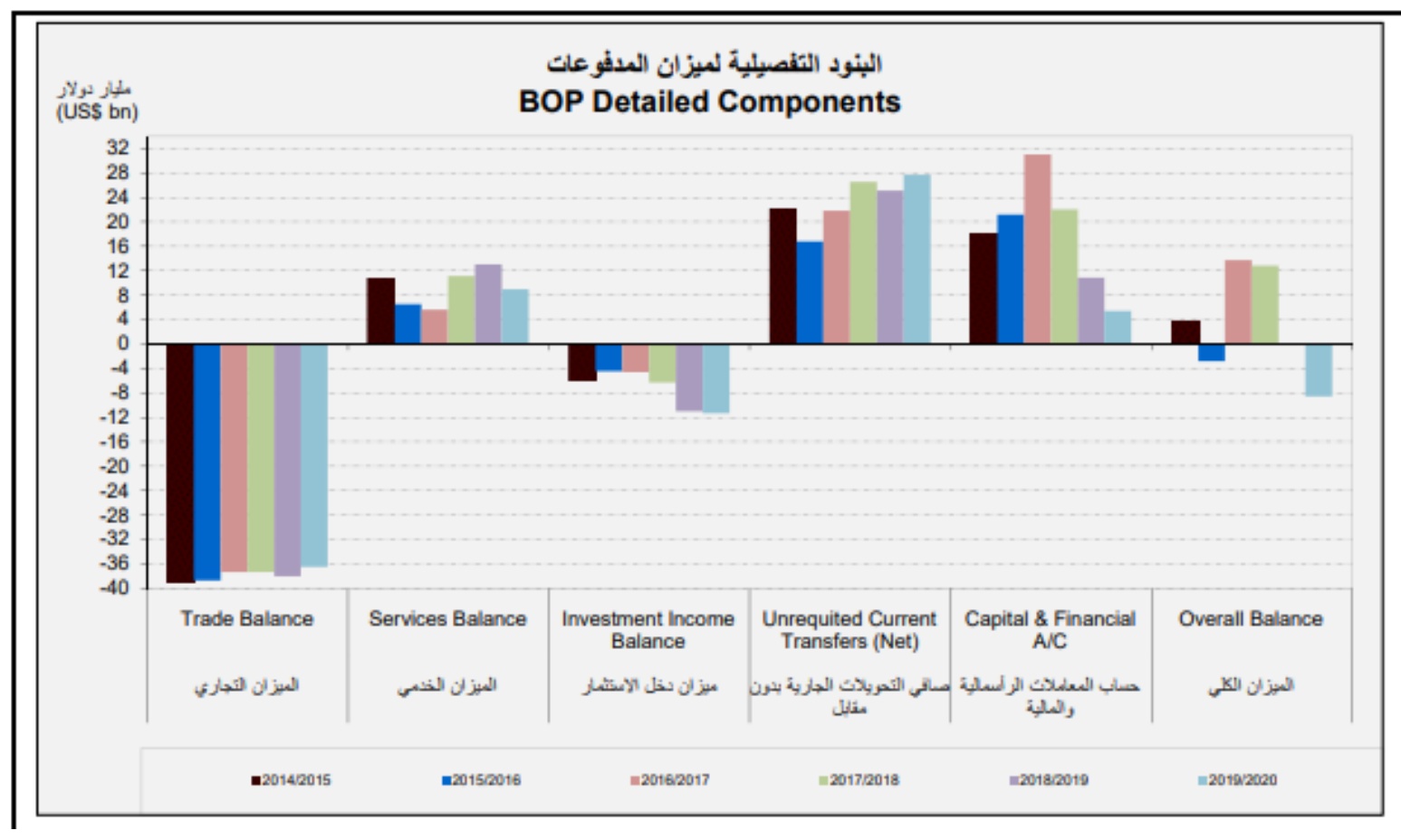

المصدر : البنك المركزى المصرى ، النشرة الاحصائية الثهرية ، اكتوبر 2020 ، العدد 283 ، ( القاهرة : البنك المركزى المصرى ، أكتوبر 2020 ) ، ص .102. ثانياً- انعكاسات وباء كورونا على أداء الاقتصاد الكلى المصرى :

وفى هذا الجزء سيتم التحليل حول تداعيات فيروس كورونا المستجد على الاقتصاد المصري من خلال

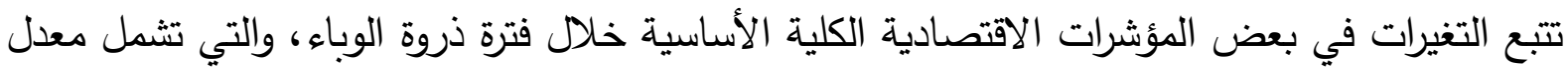

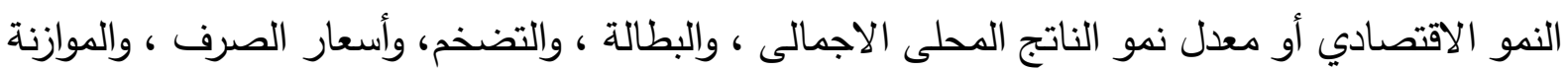

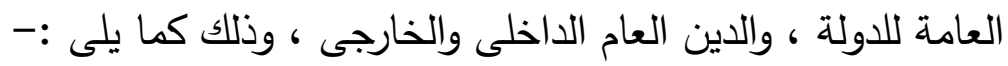

10 ، الحسينى حسن ، " ميزان الددفوعات يسجل عجزا 8.6 مليار دولار خلال العام المالى 202012019 " ، ، جريدة المال

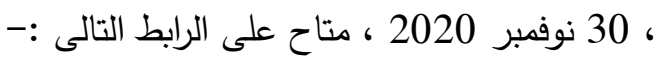
https://almalnews.com/\%D9\%85\%D9\%8A\%D8\%B2\%D8\%A7\%D9\%86\%D8\%A7\%D9\%84\%D9\%85\%D8\%AF\%D9\%81\%D9\%88\%D8\%B9\%D8\%A7\%D8\%AA\%D9\%8A\%D8\%B3\%D8\%AC\%D9\%84-\%D8\%B9\%D8\%AC\%D8\%B2\%D8\%A7\%D9\%8B18-6-\%D9\%85\%D9\%84\%D9\%8A\%D8\%A7\%D8\%B1-\%D8\%AF\%D9\%88\%D9\%84 


\section{1}

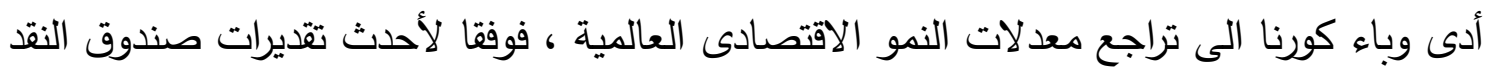

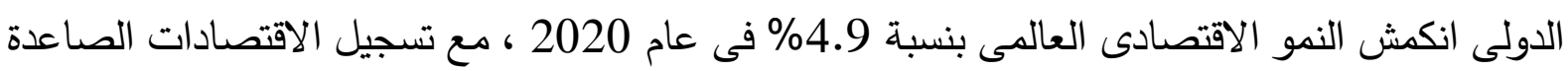
معدلات نمو سلبية تصل الى -3\% . وتعتبر مصر الدولة الوحيدة فى الاقتصادات الناشئة والنامية التى التى

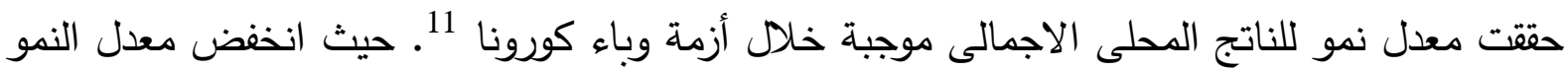

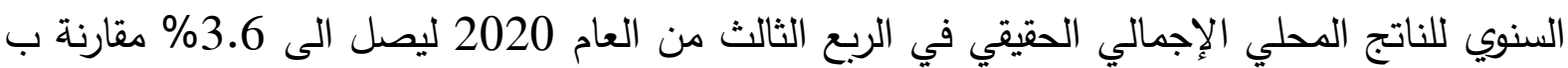
5.6 فى عام 2019 كماهو موضح بالثكل رقم (8) .

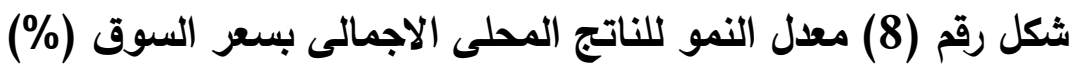

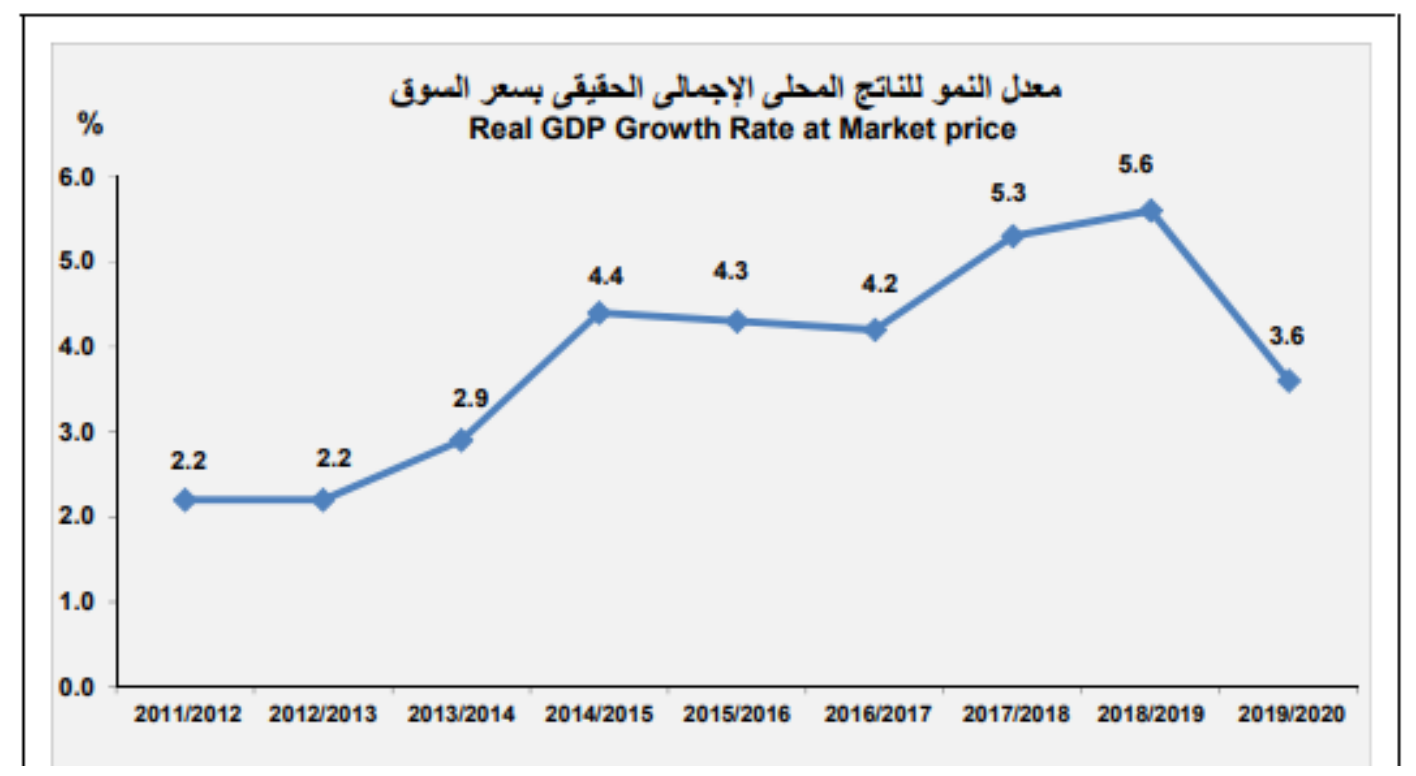

المصدر : البنك المركزى المصرى ، النثرة الاحصائية الثهرية ، العدد 283 ، ( القاهرة : البنك المركزى المصرى :

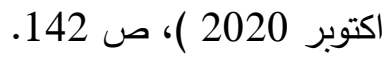

حيث يتكون الناتج المحلى الاجمالى فى عام 2020 من القطاعات التالية :-

6) الزراعة: يلعب الإنتاج الزراعي المحلي دورًا رئيسيًا في تحقيق الأمن الغذائي ، خاصة في أوقات الأل

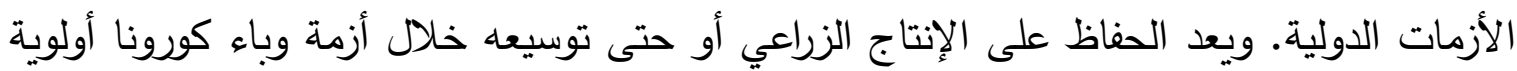

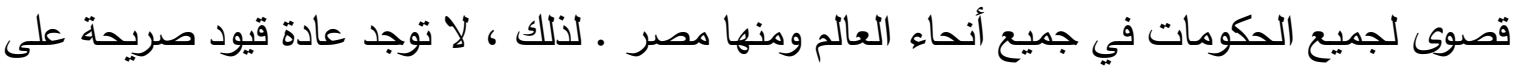

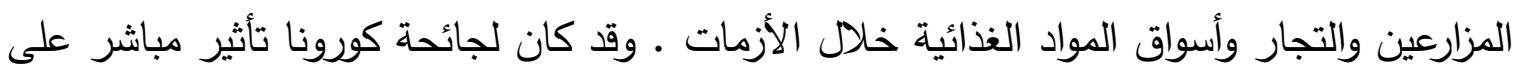

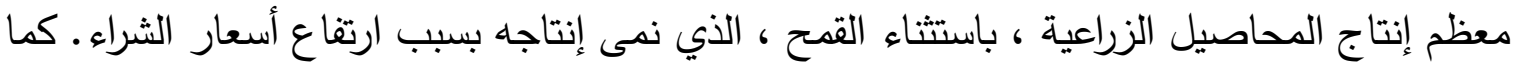

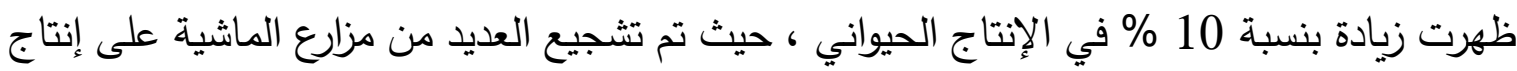
المزيد من اللحوم ومنتجات الألبان لتعويض الانخفاض المحتمل في منتجات الثروة الحيوانية المستوردة.

11 (11) مجلس الوزراء ، مركز المعلومات ودعم واتخاذ القرار ، مرجع سبق ذكره ، ص . 6 . 
7) قطاع الصناعة : وهو قطاع يشمل العديد من الصناعات منها معالجة الأغذية، حيث تعتبر المنتجات

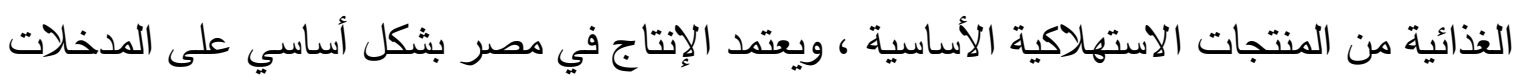

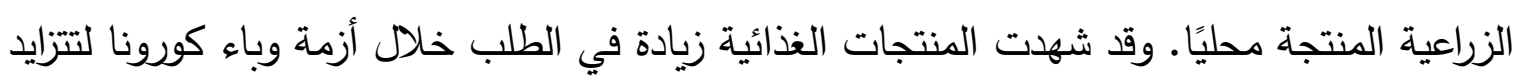

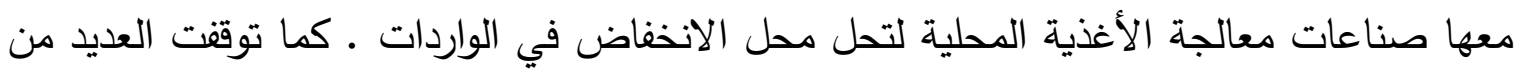

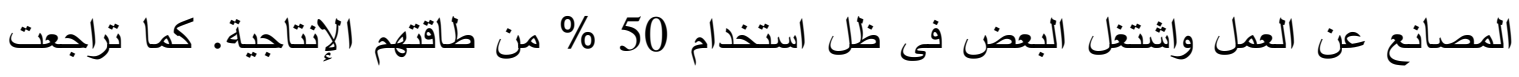

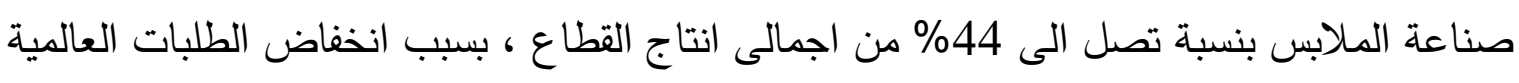

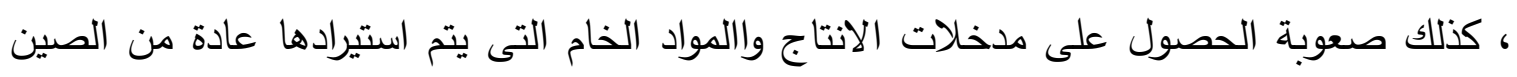

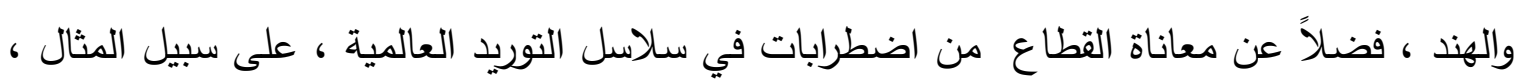
الصين هي مصدر 50 \% من واردات مصر من المنسوجات والغزل مجتمعة .

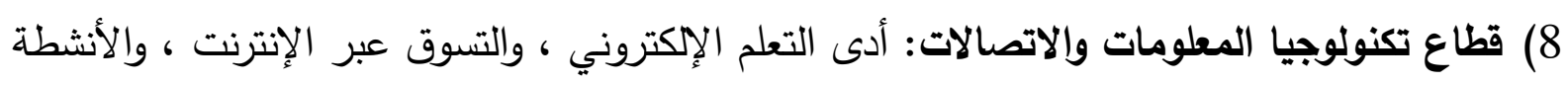

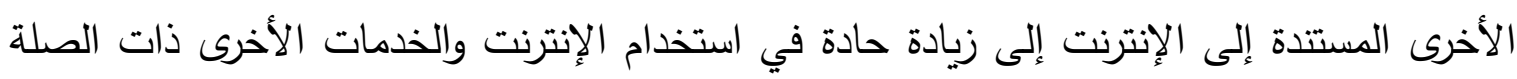

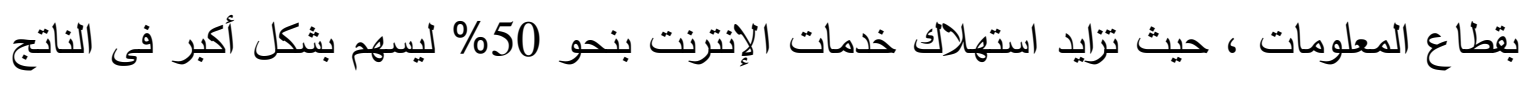

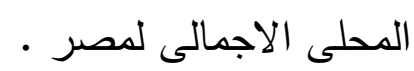

9) قطاع النقل : انخفضت الحركة الجوية بشكل كبير وهي مقتصرة بشكل أساسي على الثحن ونقل

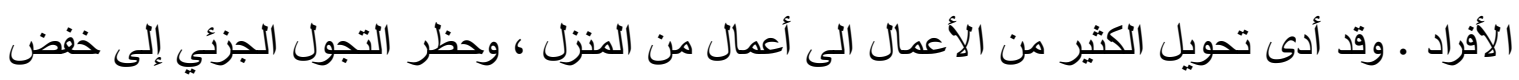

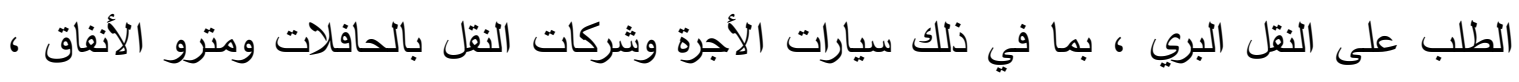

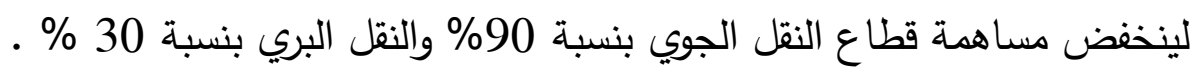

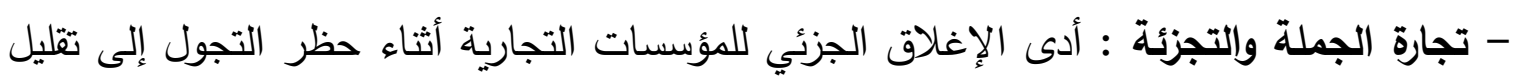

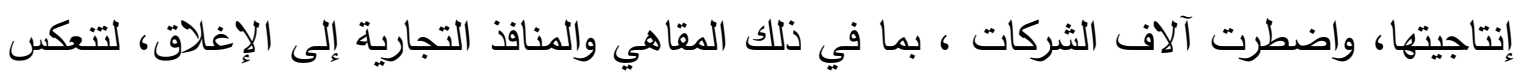

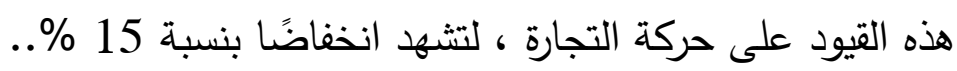

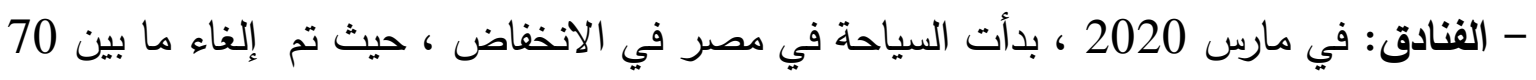

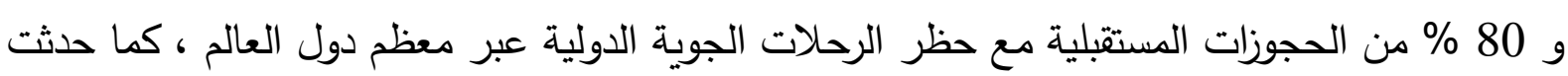

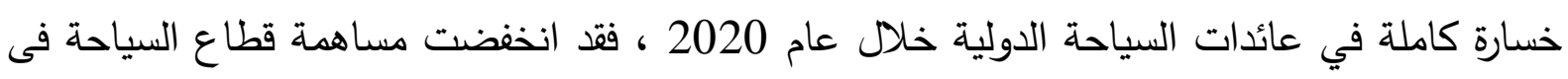

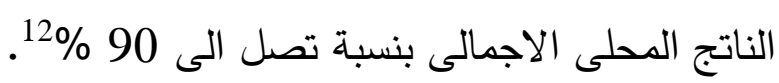
2) البطالة وسوق العمل : أعلن الجهاز المركزى للتعبئة العامة والإحصاء نتائج بحث القئل القوى العاملة للربع

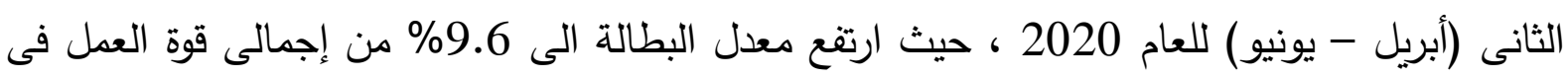

${ }^{12}$ ) Ministry of Planning and Economic Development, Impact of COVID-19 on the Egyptian economy: Economic sectors, jobs, and households, REGIONAL PROGRAM POLICY NOTE 06 , (Cairo : Ministry of Planning and Economic Development, June 2020) , PP.2-5. 
الربع الأول من عام 2020 ، مقابل 8.1\% فى الربع الأول من العام السابق 2019، بتراجع بلغت نسبته

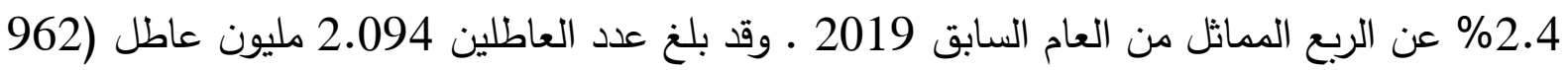

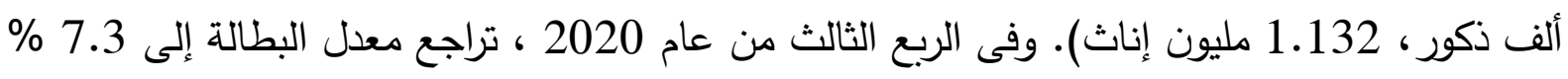

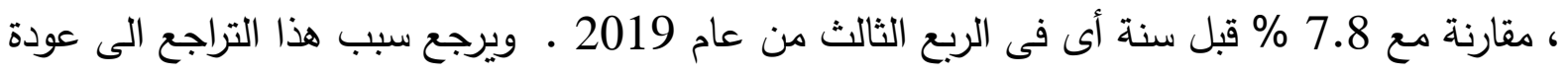
الأنشطة اليومية المعتادة لطبيعتها، وذلك بعد التخفيف التدريجي للقرارات الاحترازية التي اتخذتها الدولة

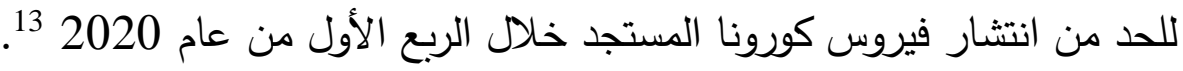

أما فيما يتعلق بالقطاع غير الرسمى ، فقد نحو 1.6 مليون فرد لوظائفهم فى هذا القطاع ، حيث يشكل

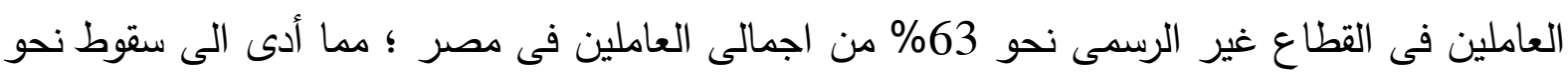

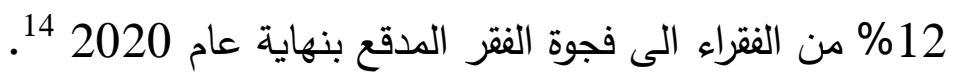

شكل رقم (9) معدل البطالة السنوى فى مصر (\%)

13 ) الجهاز المركزى للتعبئة العامة والاحصاء ، معدل البطالة السنوى ، 2020 ، متاح على الرابط التالى :https://www.capmas.gov.eg/Pages/IndicatorsPage.aspx?Ind_id=1117

- جريدة الثرق الأوسط ، " ارتقاع معدل البطالة بمصرالى 9,6\% فى الربع الثانى من 2020 "، 17 أغسطس 2020 ،

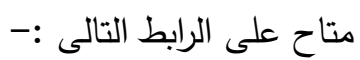
https://aawsat.com/home/article/2453066/\%D8\%A7\%D8\%B1\%D8\%AA\%D9\%81\%D8\%A7 \%D8\%B9-\%D9\%85\%D8\%B9\%D8\%AF\%D9\%84\%D8\%A7\%D9\%84\%D8\%A8\%D8\%B7\%D8\%A7\%D9\%84\%D8\%A9\%D8\%A8\%D9\%85\%D8\%B5\%D8\%B1-\%D8\%A5\%D9\%84\%D9\%89-96\%D9\%81\%D9\%8A-\%D8\%A7\%D9\%84\%D8\%B1\%D8\%A8\%D8\%B9\%D8\%A7\%D9\%84\%D8\%AB\%D8\%A7\%D9\%86\%D9\%8A-\%D9\%85\%D9\%86-2020 - اسماء رفعت ، البطالة وتحسين اوضاع سوق العمل فى مصر ، المركز المصرى للفكر وللدراسات الاستراتيجية ، 17

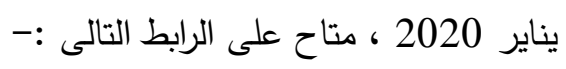
https://www.ecsstudies.com/13168/?fbclid=IwAR2DbGppT-hQQJMDo88b-qUMgKgCBgDrvMw0QKEuRy3SRij02w00O4ccME

14 


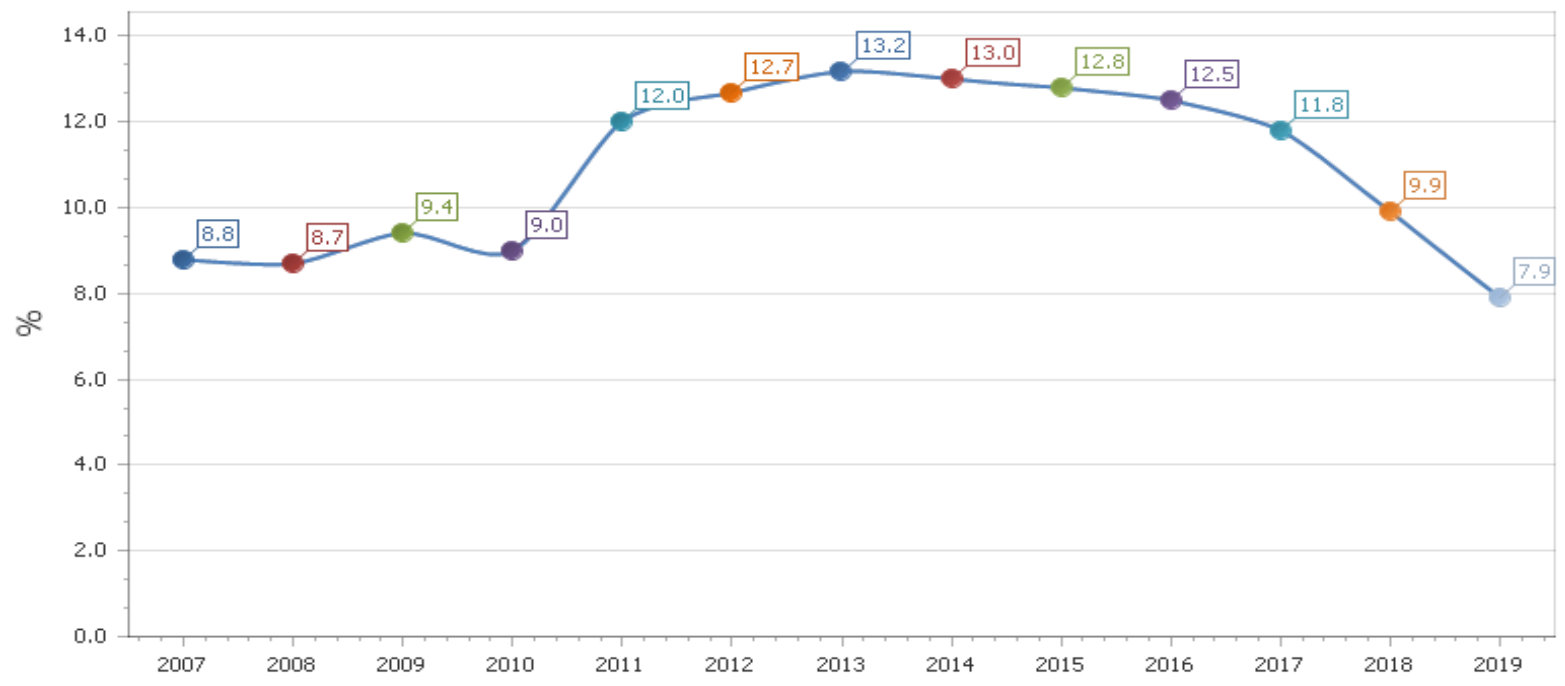

المصدر : الجهاز المركزى للتعبئة العامة والاحصاء ، معدل البطالة السنوى ، متاح على الرابط التالى :-

https://www.capmas.gov.eg/Pages/IndicatorsPage.aspx?Ind_id=1117

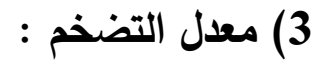

سجل المعدل السنوي للتضخم العام متوسط ربع سنوي بلغ \% معن 3.8 خلال الربع الثالث من عام

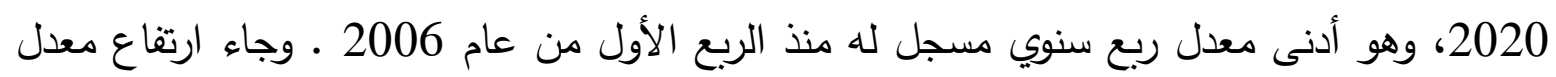

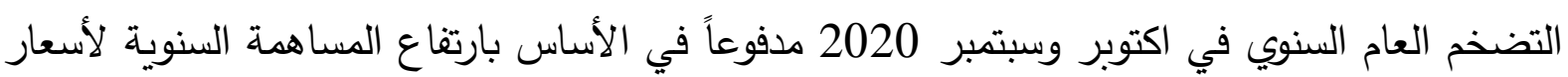

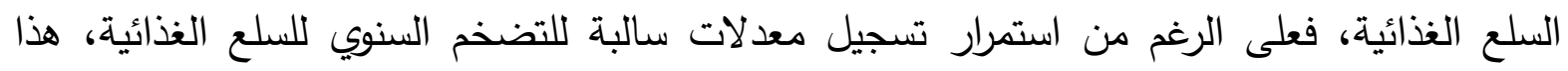

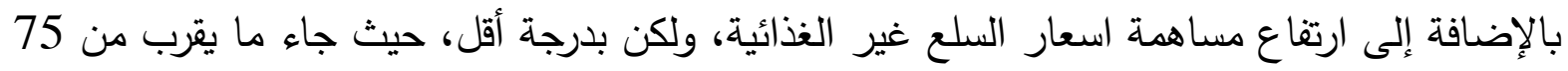

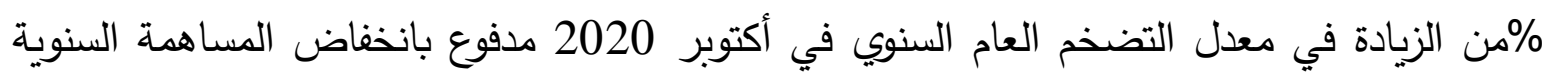

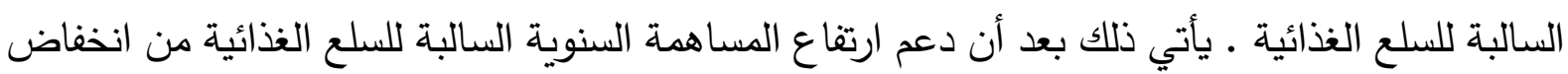
المعدل السنوي للتضخم العام في يوليو وأغسطس. 2020

وعلاوة على ذلك، ارتفع المعدل السنوي للتضخم الأساسي للشهر الثالث على التوالي الى \% 3.9

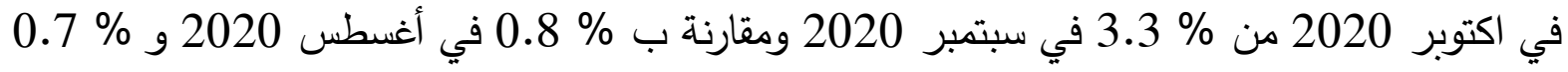
في يوليو 2020 وكما كان متوقعاً، جاء ارتفاع معدل التضخم الأساسي في سبتمبر 2020 نتيجة التأثير السلبي لفترة الأساس، بسبب آلية ربط السلسلة العاشرة للأرقام القياسية لأسعار المستهلكين بالسلسلة

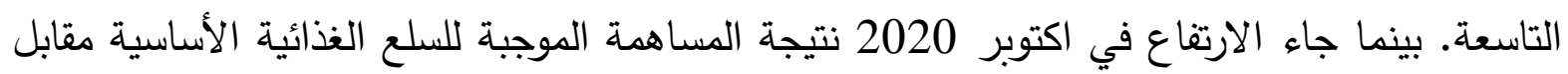

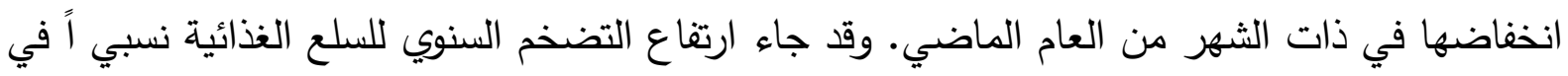

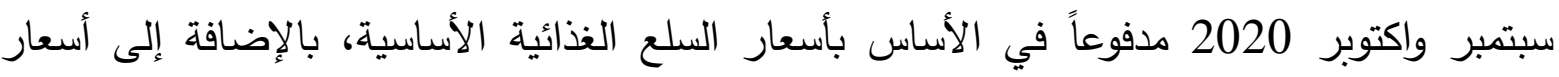


الخضروات والفاكهة الطازجة، ولكن بدرجة اقل .في ذات الوقت، جاء الانخفاض في اسعار السلع الغذائية

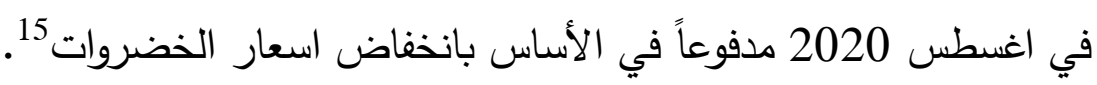

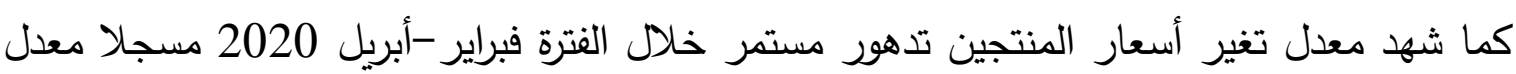
تراجع سنوي بلغ 18.8 \% في نهاية الفترة. ويُعزى هذا التراجع إلى انخفاض أسعار أنثطة الزراعة وصيد الفيد الأسماك والتعدين واستغلال الدحاجر وخدمات الغذاء والإقامة بنسب 4.5 \% 4.5 و و67.7 \% التوالي. ويُلاحظ أن تأثير كوفيد-19 على معدل التضخم السنوي لأسعار المستهلكين محدود إذا ما قورن بأثر الجائحة على معدل التغير السنوي لأسعار المنتجين 16.

شكل رقم (10) معدل التضخم السنوى العام والأساسى (نسب مئوية)

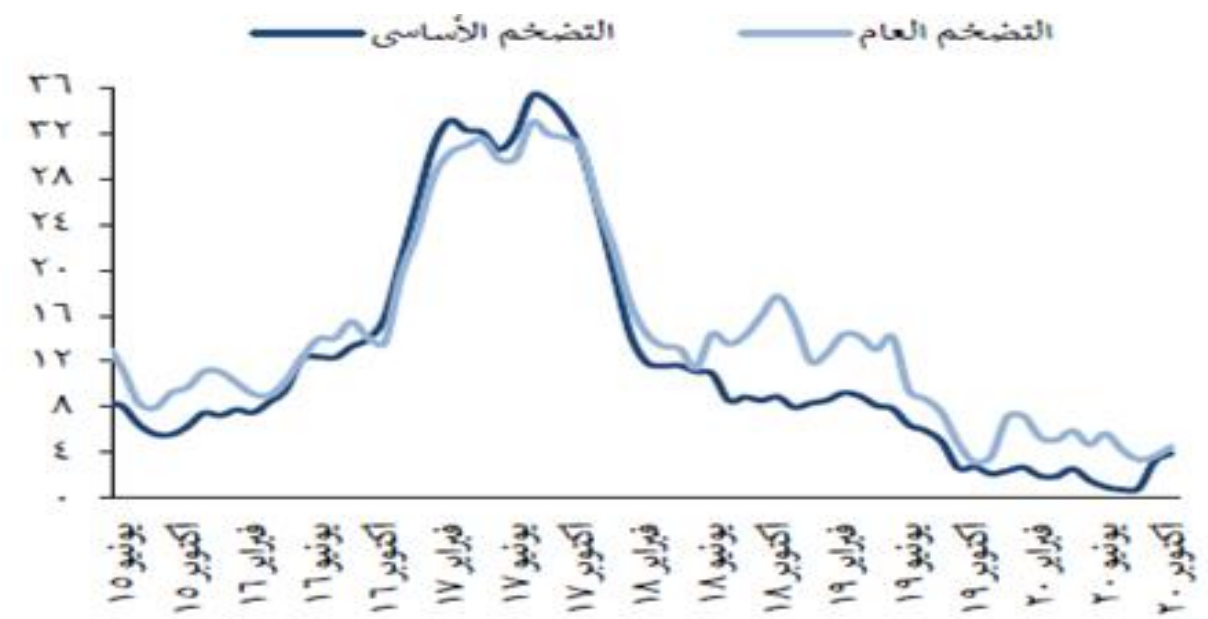

10)المصدر : البنك المركزى المصرى ، تقرير السياسة النقدية 2020 ، ( القاهرة : البنك المركزى المصرى ، 2020)،

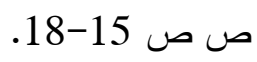

4) - (4 أسعار الصرف:

يقاس أداء العملة من حيث الارتفاعات والانخفاضات مقابل الدولار الأمريكي خلال فترة زمنية محددة

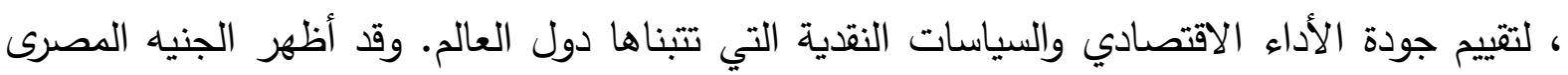

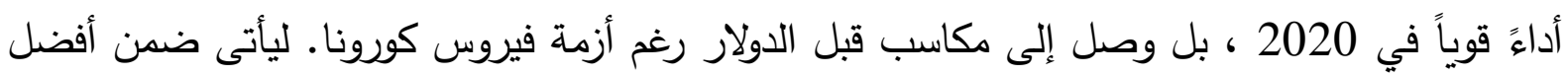
العملات في الأسواق الناشئة خلال عام 2020، حيث ودل التست حركة الجنيه المصري أمام الدولار الأمريكي

15 15 البنك المركزى المصرى ، تقرير السياسة النقدية 2020 ، (القاهرة : البنك المركزى المصرى ، 2020)، ص ص . $18-15$

16 16 الجهاز المركزى للتعبئة العامة والاحصاء ، معدل التضخم ، 2020 ، متاح على الرابط التالى :https://www.capmas.gov.eg/Pages/IndicatorsPage.aspx?page_id=6130\&ind_id=2542 
بحالة من الاستقرار النسبي وسط اتجاه عرضي ما بين الارتفاع والانخفاض، على الرغم من تأثر مصادر

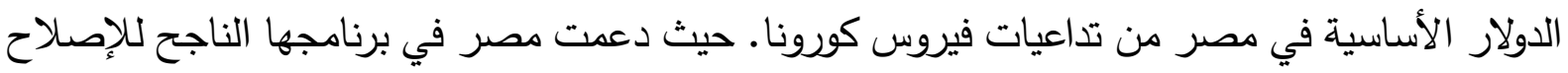

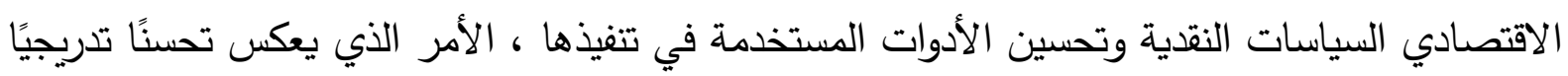

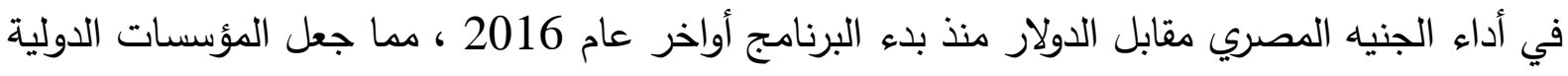

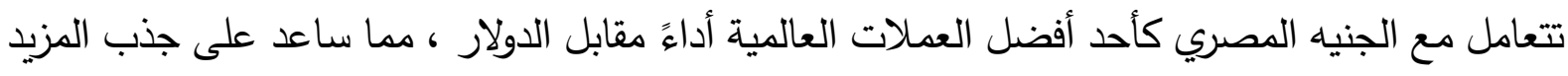

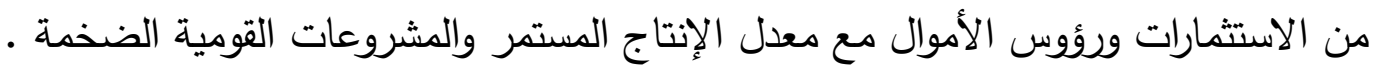
وقد سجل سعر صرف الدولار الأمريكي أمام الجنيه المصري منذ أواخر يناير 2020 حتى نهاية الأنية

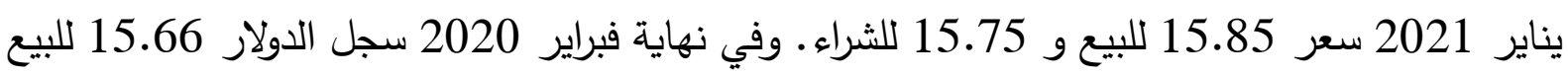

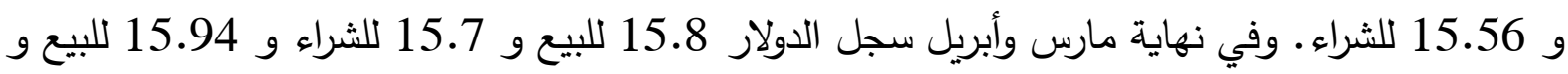

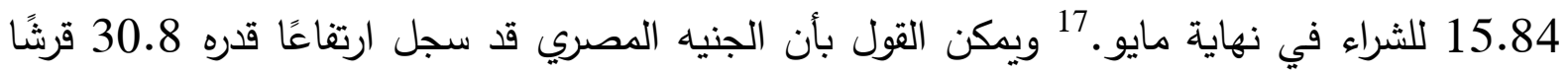

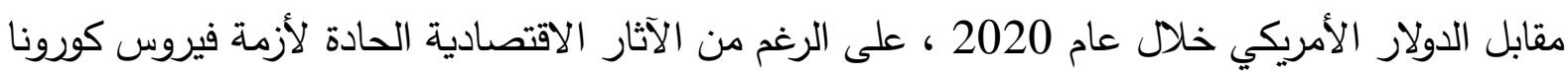

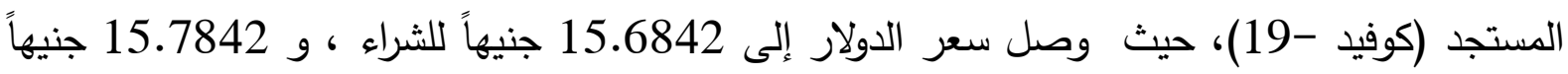
للبيع بنهاية العام الماضي 2020 ـ مقارنة بـ 15.9931 جنيهاً للشراء و 16.0931 جنيهاً للبيع بنهاية .${ }^{18} 2019$

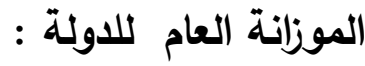

تحملت الموزانة المالية لعام 2019-2020 تخصيص 100 مليار جنيه لمواجهة انعكاسات وباء كورونا على الاقتصاد المصرى ، والتى تم تخصيصها لتغطية بعض الالتزامات العاجلة منها : حوافز

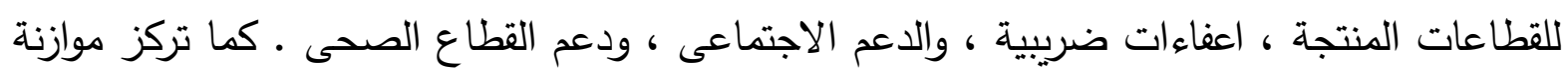

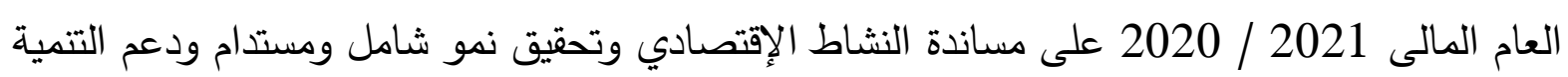

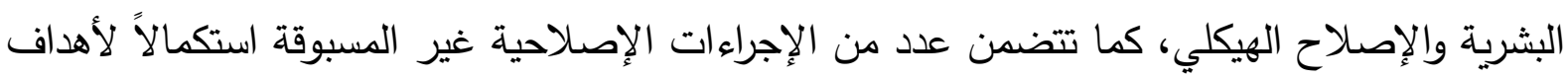

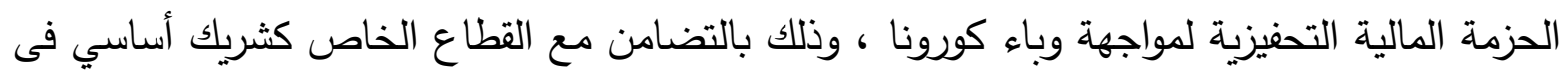
التصدي للأزمة والحفاظ على حياة المواطنين.

17) State Information Service, " EGP among best world currencies against dollars in 4 years" , 15 February 2021, Available at :-

https://www.sis.gov.eg/Story/154246?lang=en-GB

${ }^{18}$ ) Daily News , " Egyptian pound appreciates 30 piasters against US dollar in 2020

despite COVID-19" , January 2.2020, Available at :-

https://dailynewsegypt.com/2021/01/02/egyptian-pound-appreciates-30-piasters-against-usdollar-in-2020-despite-covid-19/ 
وتستهدف الحكومة بمشروع موازنة العام المالي 2020-2021 ، استمرار جهود الخفض التدريجي

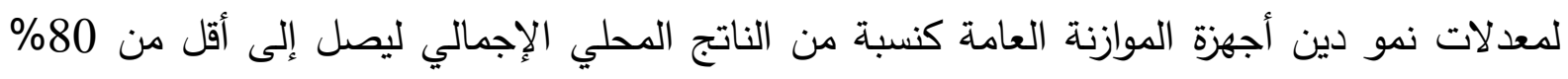
بحلول نهاية يونيو 2023، بما يسمح بتحقيق تحسن كبير وخفض في أعباء فاتورة خدمة الدين التى تزايدت

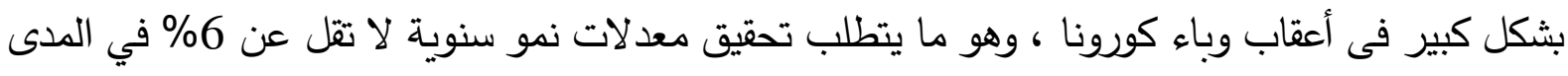

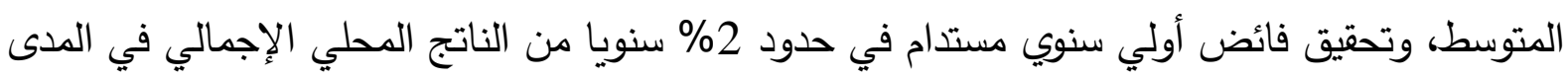
المتوسط.

وقد أعلنت وزارة المالية أن إجمالي المصروفات المستهدفة بموازنة 2020-2021 تبلغ نحو 1.7 تريليون جنيه مقابل 1.5 تريليون جنيه بموازنة 2019 / 2020. زيادة الدصروفات إلى الزيادات المرتبطة بحتميات الأجور، وكذلك التكاليف المرتبطة بالقرارات الرئاسية لتحسين أوضاع التئ العاملين بالجهاز الإداري

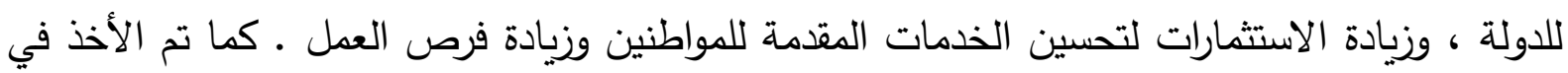
الاعتبار الأثر المالي المترتب على استكمال تطوير والتوسع في تطبيق منظومة التأمين الصحي الثامل ، وزيادة مخصصات الإنفاق على الصحة لتحسين جودة الخدمات المقدمة للمواطنين ولتغطية تكلفة التأمين الصحي والأدوية ، وحوافز أعضاء القطاع الصحي وعلاج غير القادرين على نفقة الدولة ، حيث تبلغ مخصصات الصحة 258.5 مليار جنيه بزيادة 83.2 مليار جنيه بنسبة زيادة \% 47 عن عن العاء العام المالي

أما الايرادات العامة ، فسوف تثهد زيادة فى عام 2020-2021 مقارنى بالعام المالى السابق لتصل الى1288.8 مليار جنيه ؛ ويرجع سبب ارتفاعها الى زيادة حصيلة الدولة من الايرادات الضريبية لأن

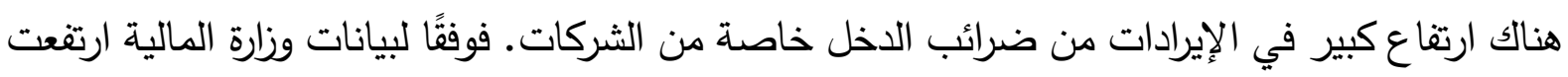

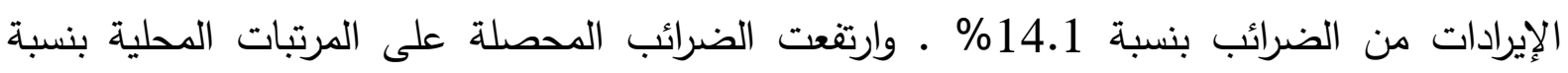

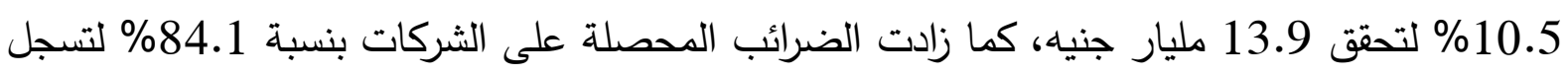
24.1 مليار جنيه ، والنتيجة النهائية انخفاض العجز الكلى للموازنة العامة من 8 8. 975 مليار جنيه

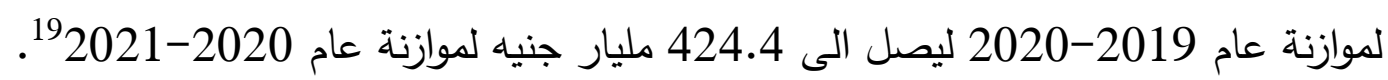

19 ) وزارة المالية ، دليل مبسط عن انفاق الموازنة العامة لعام $10-4120$ ، ( القاهرة : وزارة المالية ، 2020) ، ص ص . 10-4 
شكل رقم (11) ايرادات ومصروفات الموزانة العامة للدولة وتطورها خلال الفترة ( 2018-2021)

\section{مليار جنيه}

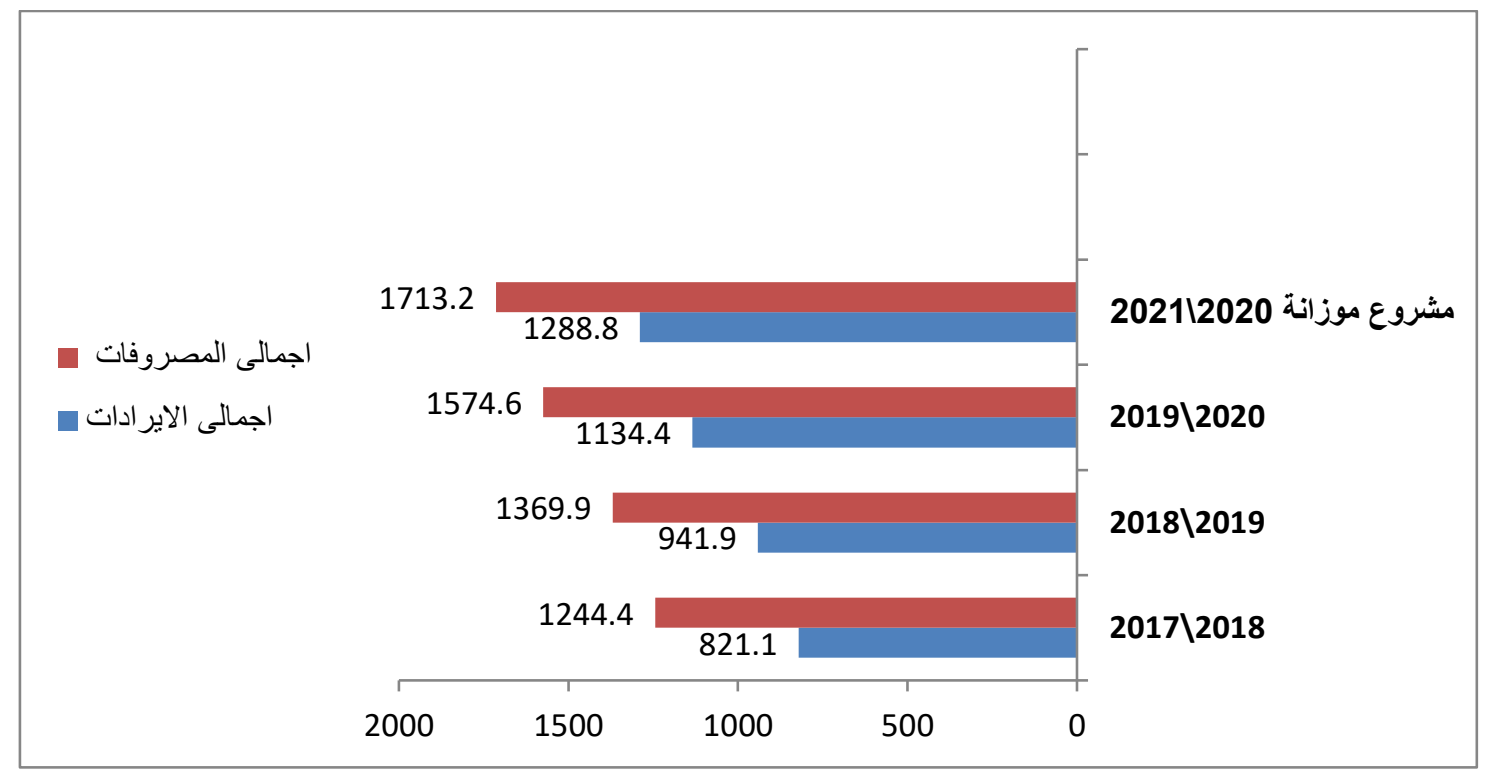

المصدر : من اعداد الباحثة استتادا الى:

- وزارة المالية : دليل مبسط عن انفاق الموازنة العامة لعام 21 م ، ( القاهرة : وزارة المالية ، 2020) ، ص .5. 6) الدين العام الاخلى والخارجى : بلغ رصيد الدين الخارجي لمصر نحو 123.5 مليار دولار أمريكي في نهاية يونيو 2020 بزيادة

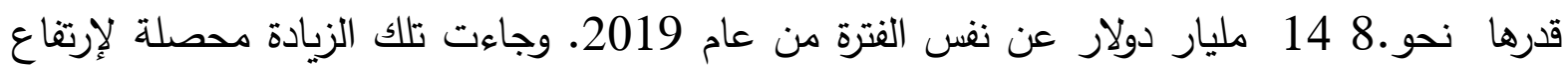
صافى المستخدم من القروض والتسهيلات بنحو.4 .15 مليار دولار، وانخفاض أسعار صرف معظم العملات المقترض بها أمام الدولار الأمريكي بنحو 0.6 مليار دولار ـ وبالنسبة لأعباء خدمة الدين

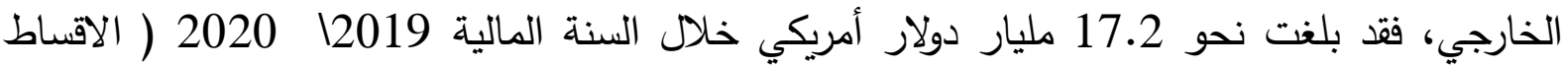

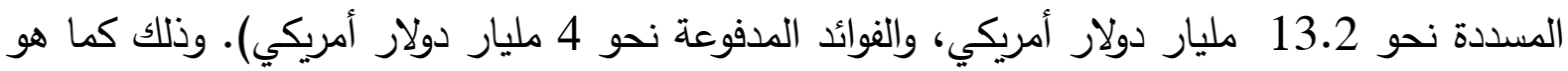
موضح بالثكل رقم (10) ، حيث جاء حجم الديون الخارجية فى تزايد ومعظمها فى شكل قروض ثنائية من المؤسسات الدولية ، يليها سندات وأذون الخزانة الحكومية . وتظهر المؤشرات تراجع نسبة رصيد الدين الخارجي إلى الناتج المحلى الإجمالي لتبلغ.1 .34 ٪؛

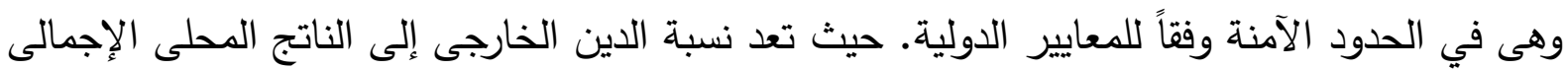

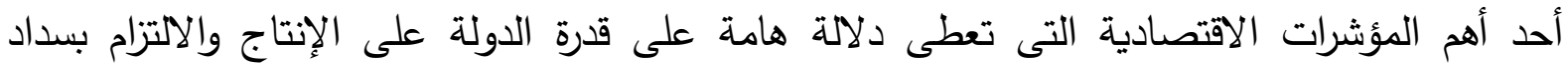

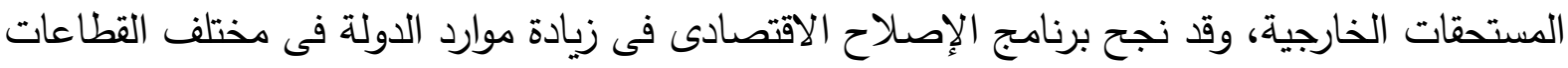
الاقتصادية والحفاظ على توازن السياستين المالية والنقدية وتحديدًا فى هذه الفترة العصيبة على اقتصادات 
العالم على وقع جائحة كورونا. وعندما وافق صندوق النقد الدولى على طلب مصر الحصول على مساعدة مالية طارئة قدرها 2,772 مليار دولار لتلبية احتياجات التمويل العاجلة لميزان الددفوعات التى نتجت عن التهات تقشى جائحة كوفيد-19، والحفاظ على مكتسبات نجاح برنامج الإصلاح الاقتصادى الذى رفع معدلات

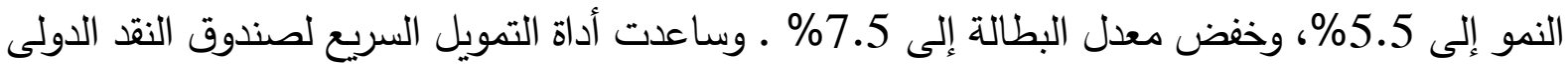
على تخفيف احتياجات التمويل العاجلة، بما فى ذلك الإنفاق على الصحة وتوفير الحماية الاجتماعية ودعم القطاعات الأشد تأثرا وشرائح المجتمع الهشئ. شكل رقم (12) هيكل الدين الخارجى لمصر خلال الفترة (2018-2020)

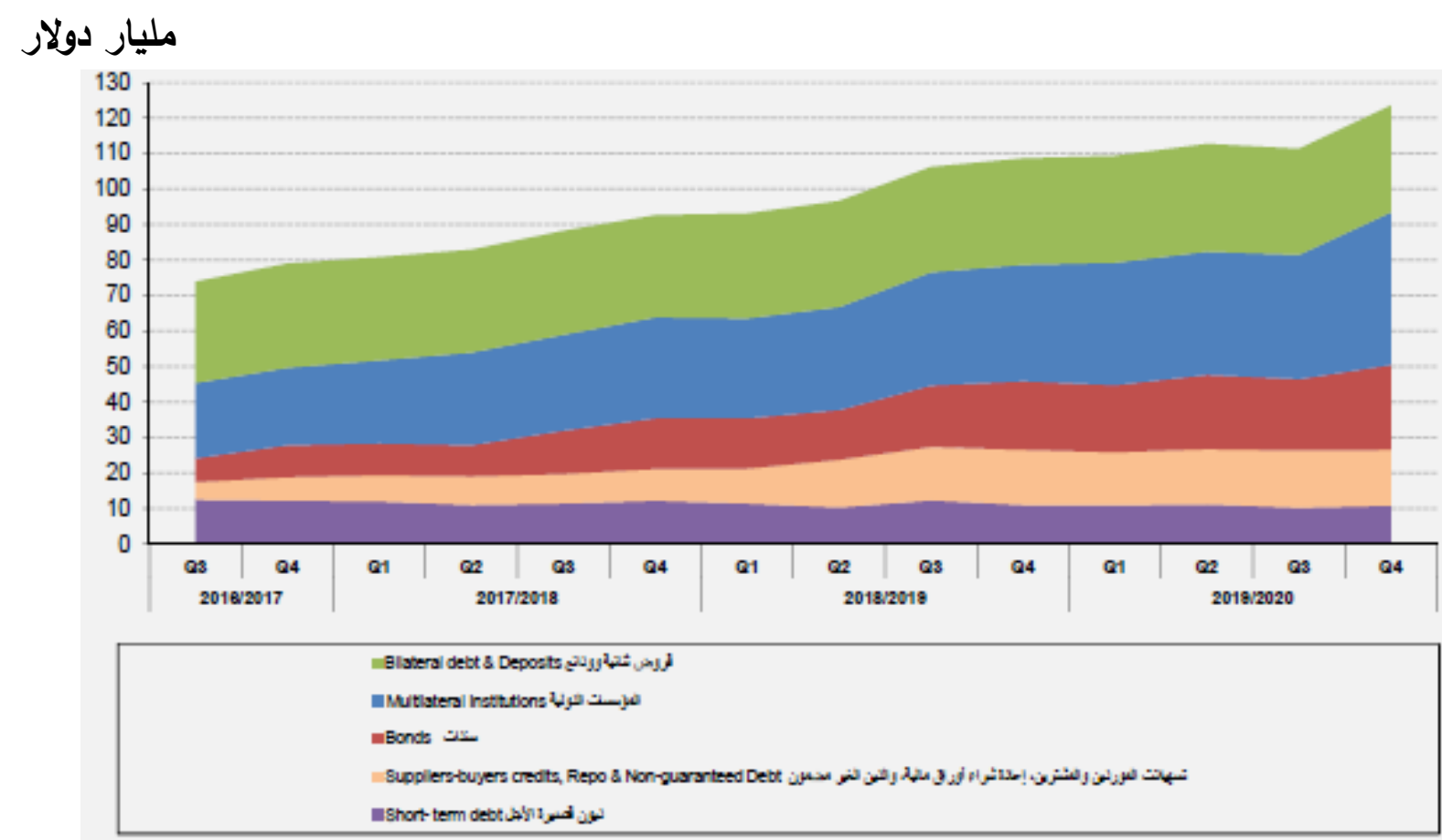

- - المصدر : البنك المركزى المصرى ، النشرة الاحصائية الثهرية ، العدد 283، ( القاهرة : البنك المركزى المصرى ، اكتوبر 2020 )، ص : 101.

وفيما يتعلق بالدين العام المحلى ، فقد بلغ إجماليه نحو 4354.5 مليار جنيه أو ما يمثل8 . 74 \% من الناتج المحلي الإجمالي (في نهاية ديسمبر 2019 منه 8. 87 \% مستحق علي الحكومة، و5.9\% على الهيئات العامة الاقتصادية، و 6.3\% على بنك الاستثمار القومي • وبلغ صافي رصيد الدين المحلي المستحق على الحكومة نحو 3824.3 مليار جنيه في نهاية ديسمبر 2019 ، بزيادة قدرها نحو 5. 93 مليار جنيه خلال الفترة يوليو / ديسمبر من السنة المالية 2019 202020.

20 ) البنك المركزى المصرى ، النشرة الاحصائية الثهرية ، مرجع سبق ذكره ، ص • 4 . 


\section{شكل رقم (13) اجمالى الدين المحلى لمصر خلال الفترة (2014-2020)}

\section{مليار جنيه}

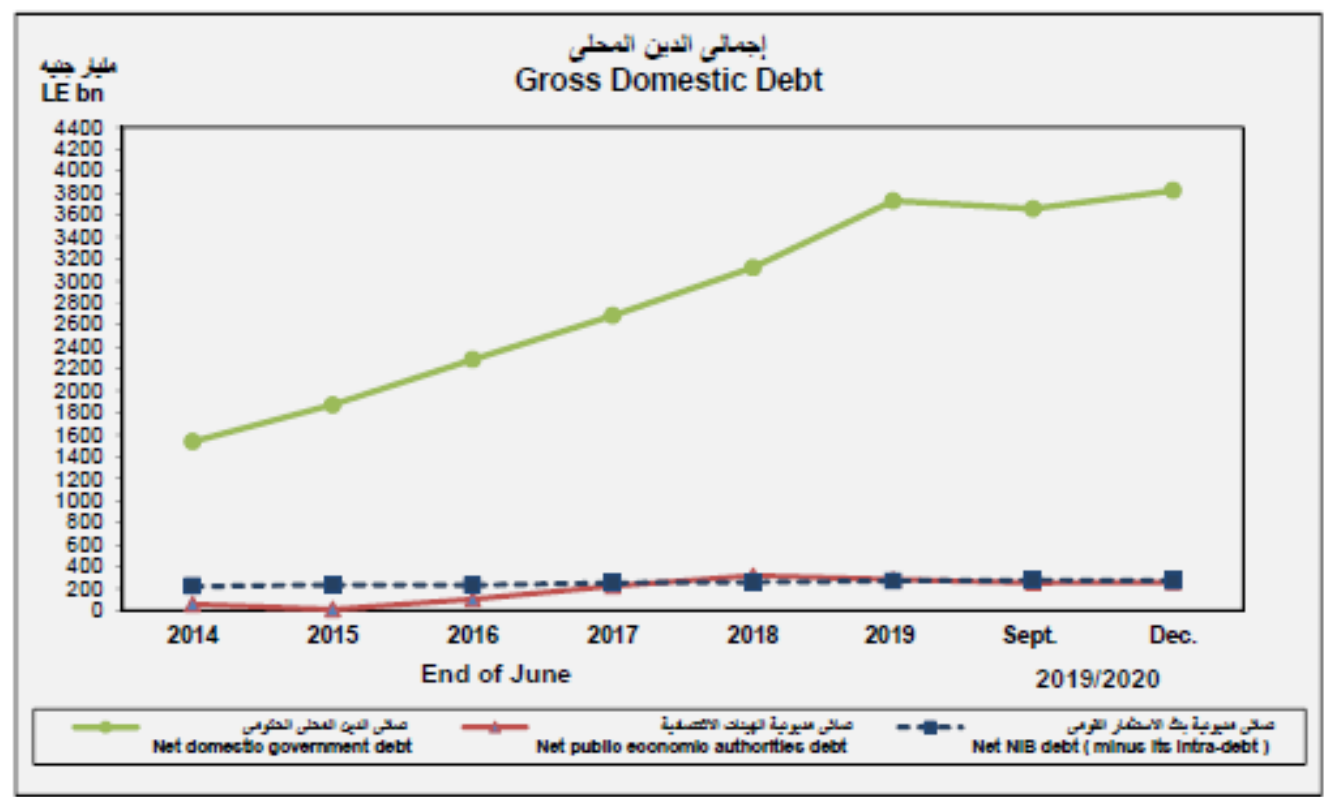

- المصدر : البنك المركزى المصرى ، النشرة الاحصائية الثهرية ، العدد 283، ( القاهرة : البنك المركزى المصرى ، اكتوبر 2020 )، ص:15 (115.

\section{ثالثاً - السياسات الاقتصادية المصرية لمواجهة وباء كورونا : لمورية}

نجحت مصر بمجموعة من الإجراءات التى اتخذتها الحكومة في التخفيف من وطأة الموجة الأولى من فيروس كورونا المستجد، في الوقت الذى سيطرت الجائحة على دول كبرى حول العالم. ولعل الإجراءات الاقتصادية التي اتخذتها الحكومة في سبيل دعم الاقتصاد كانت الأبرز من حيث اشادات المؤسسات الدولية المعنية بالإصلاح الاقتصادى. حيث تم تخصيص 100 مليار جنيه لتمويل خطة الدولة لمواجهة تداعيات الفيروس • ومن أهم تلك الاجراءات ما يلى 21 :--

21 ) البنك المركزى المصرى ، تعليمات واجراءات البنك المركزى للحد من تداعيات فيروس كورونا المستجد ، 2020 ،

$$
\text { متاح على الرابط التالى :- }
$$

https://www.cbe.org.eg/ar/Pages/HighlightsPages/\%D8\%A5\%D8\%AC\%D8\%B1\%D8\%A7\% D8\%A1\%D8\%A7\%D8\%AA-\%D8\%A7\%D9\%84\%D8\%A8\%D9\%86\%D9\%83-

\%D8\%A7\%D9\%84\%D9\%85\%D8\%B1\%D9\%83\%D8\%B2\%D9\%8A-

\%D8\%A7\%D9\%84\%D9\%85\%D8\%B5\%D8\%B1\%D9\%8A-

\%D9\%84\%D9\%84\%D8\%AD\%D8\%AF-\%D9\%85\%D9\%86-

\%D8\%AA\%D8\%AF\%D8\%A7\%D8\%B9\%D9\%8A\%D8\%A7\%D8\%AA-

\%D9\%81\%D9\%8A\%D8\%B1\%D9\%88\%D8\%B3-

\%D9\%83\%D9\%88\%D8\%B1\%D9\%88\%D9\%86\%D8\%A7-

\%D8\%A7\%D9\%84\%D9\%85\%D8\%B3\%D8\%AA\%D8\%AC\%D8\%AF.aspx 


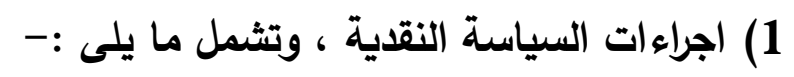

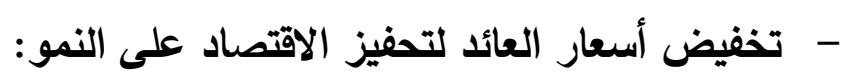

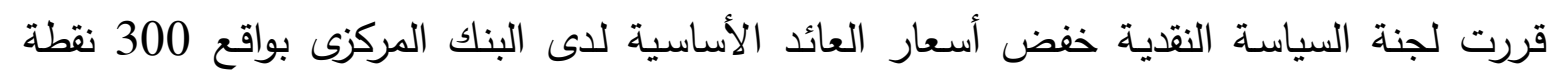

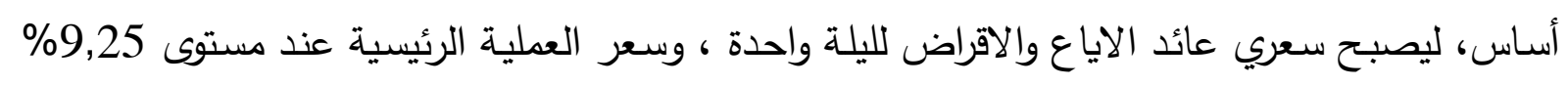

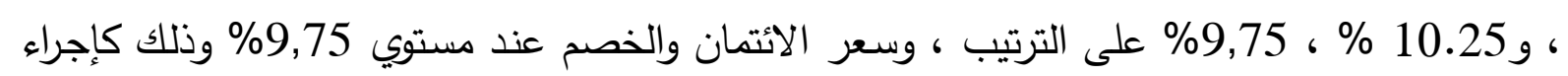
استثائى لدعم النشاط الاقتصادي بكافة قطاعاته. وفى سبتمبر 2020 تمت خفض ولت أسعار العائد الأساسية مرة أخرى بواقع 50 نقطة أساس ليصل سعري عائد الايداع والاقراض لليلة واحدة ، وسعر العملية

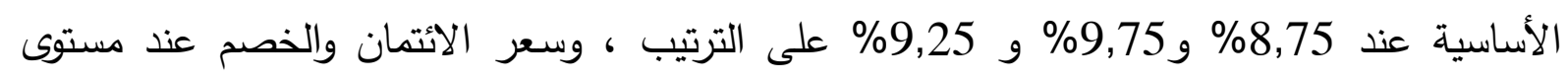

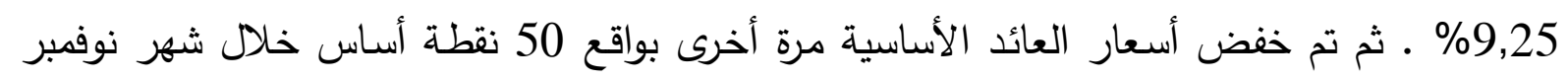

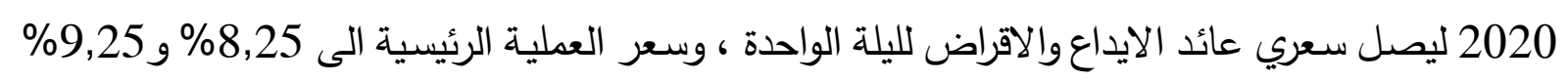

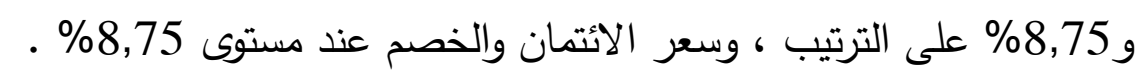
- تأجيل كافة الاستحقاقات الائتمانية للعملاء من المؤسسات والأفراد :

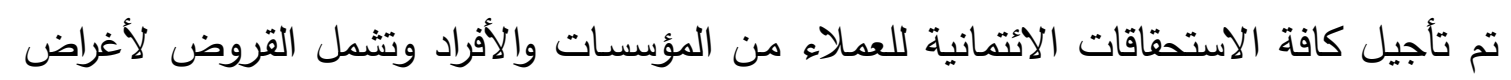

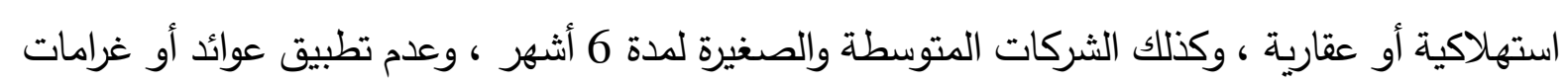

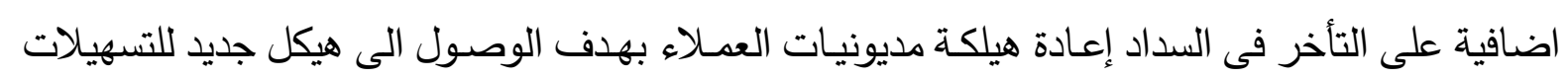

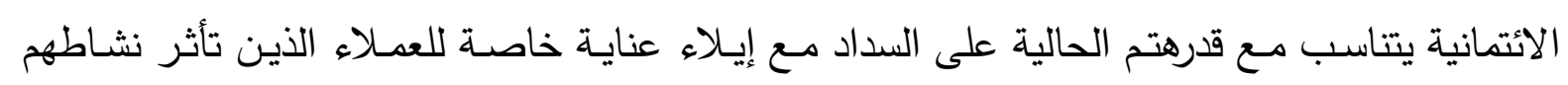

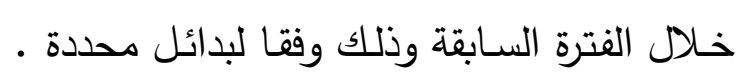

- - اجراءات للحد من التعاملات النقدية وتيسير استخدام الوسائل الاليكترونية فى الدفع :

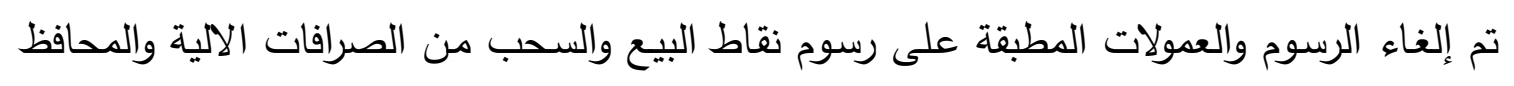

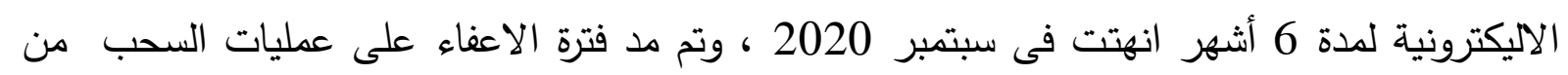

$$
\text { الصرافات الالية حتى نهاية غام } 2020 \text {. } 2020
$$

كما تم إصدار بعض الاستثناءات لاستخدام وسائل وأدوات الدفع الاليكترونية ؛ وذلك تيسريًا ععلى المواطنين

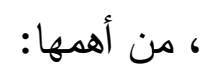

- تعديل الحدود القصوى لحسابات الهاتف المحمول والبطاقات الددفوعة مقدما - - تسجيل اشتراك الانترنت البنكى لعملاء البنك الحاليين باستخدام البيانات المسجلة مسبقًا لدى البنك.

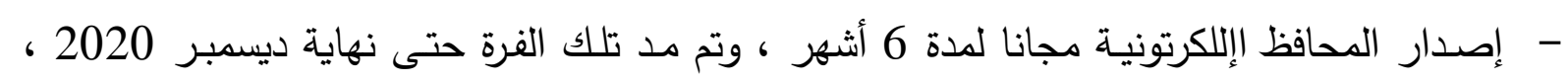

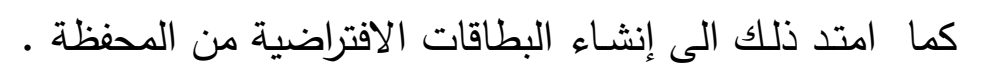
- - إلغاء كافة العمولات والرسوم الخاصة بعمليات التحويل بني حسابات الهاتف المحمول حتى نهاية ديسمبر 2020 . 
وضع حد أقصى يوميا لعمليات الحسب والايداع بفروع البنوك بمبلغ 50 ألف جنيه للأفراد ، ومبلغ 20 ألف جنيه لعمليات السحب والايداع من ماكينات الصرف الالى وذلك لفترة مؤقتتة. - اتاحة التمويل اللازم لاستيراد السلع الاستراتيجية ودعم القطاعات والثركات الأكثر تأثرا :-

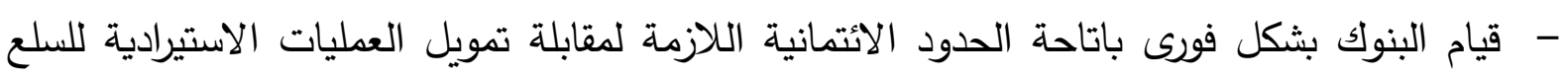
الأساسية والاستراتيجية خاصة السلع الغذائية .

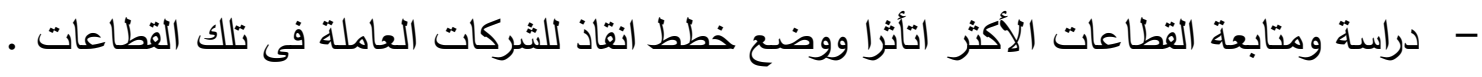

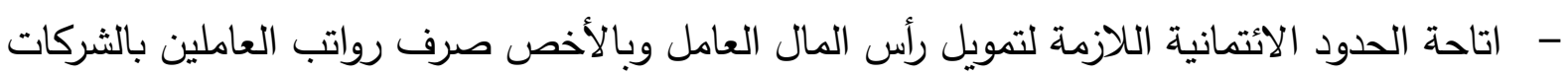

- اجراءات دعم القطاعات الاقتصادية المتضررة ، وتثمل :- اجراءات الاعم الاقتصادى للقطاع السياحى 22 : - - قيام البنك المركزى بدراسة لتقديم تمويل للمنشات السياحية والفندقية من أجل الحفاط عل العمالة بفائدة

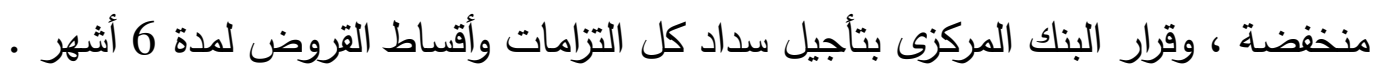

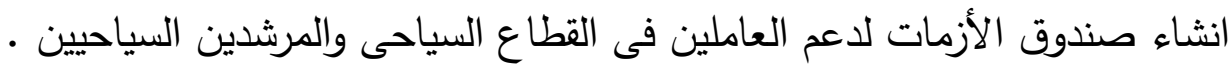

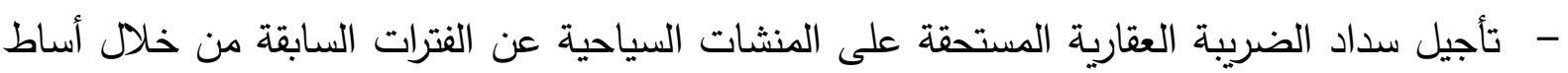

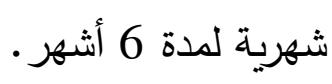
- - مبادرة العملاء غير المنتظمين من الأشخاص الاعتبارية العاملة بقطاع السياحة وتسرى على الثركات

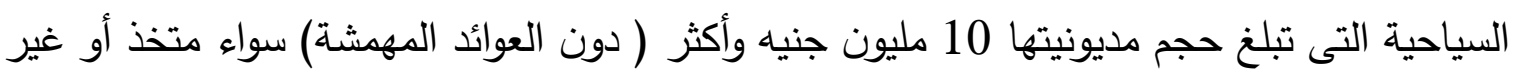
متخذ بشأنهم اجراءات قضائية ، حيث يتم الحذف من قوائم الحظر ، والتتازل عن جميع القضايا

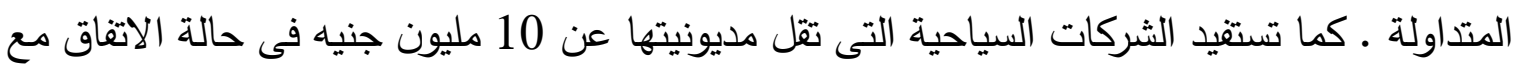

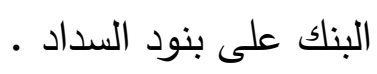
- مبادرة القطاع الخاص الصناعى والزراعى وقطاع المقاولات :- -

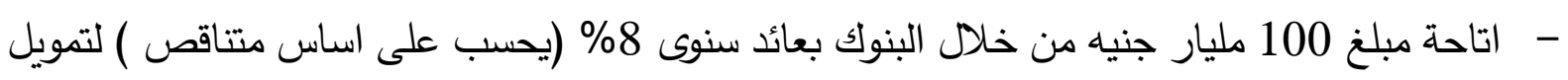

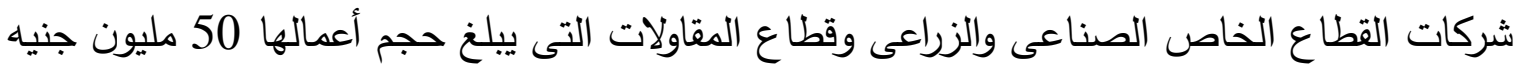

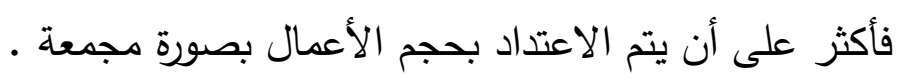

22 أ .د سلوى محمد مرسى ، ود. زينب محمد الصاوى ، مرجع سبق ذكره ، ص .12 .

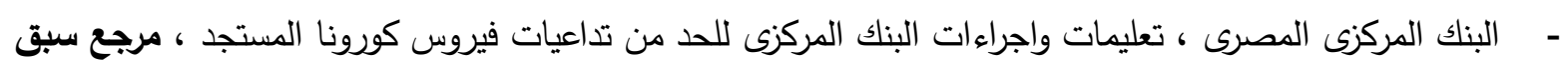
ذكره ، ص .4. 
- - اصدار تعهد بقيمة 7 مليار جنيه لصالح شركة ضمان مخاطر الائمان لتغطية نسبة من المخاطر

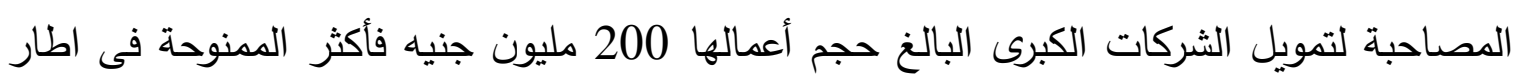

$$
\text { 2) المبادرة · اجراءات اجتماعية ، وتثمل ما يلى 23. }
$$

- للتخفيف من تداعيات الأزمة على المواطن المصرى، تمت زئمل هادة أجور العاملين والموظفين بالدولة

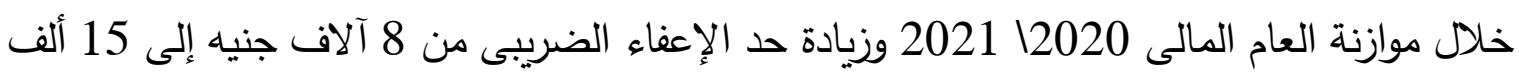

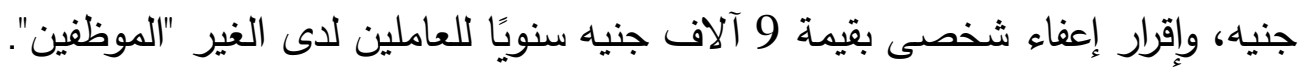

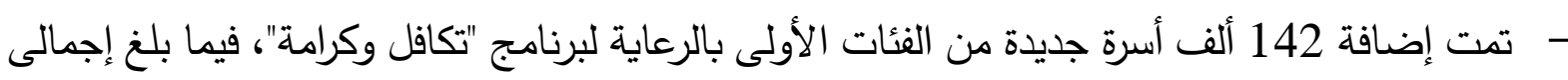
الخدمات والإعانات المقدمة من وزارة التضامن الاجتماعي والجمعيات والمؤسسات الأهلية نحو 20 مليون خدمة بتكلفة إجمالية بلغت 1.7 مليار جنيه، وقد استفاد منها نحو 64 مليون فرد.

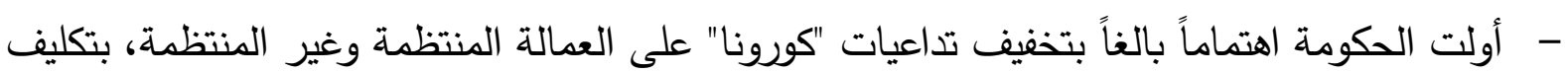

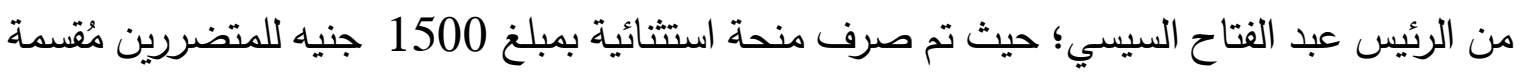
على ثلاث دفعات، من خلال 4000 مكتب بريد على مستوى الجمهورية، وقيام صندوق إعانات الطوارئ للعمال بوزارة القوى العاملة بصرف مرتبات العمالة المنتظمة للعاملين في القطاعات المتضررة.

رابعاً - اشادات دولية بصمود الاقتصاد المصرى أمام جائحة كورونا :

لاقت الإجراءات التى اتخذتها مصر استحسانًا من المؤسسات الدولية التى أشادت بصمود الاقتصاد

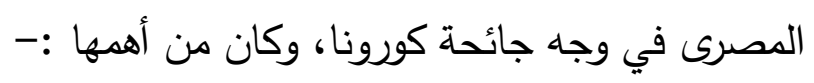

- تقرير المرصد المصرى الذى أصدره البنك الدولى في نوفمبر 2020، والذى أكد خلاله أنه برنامج

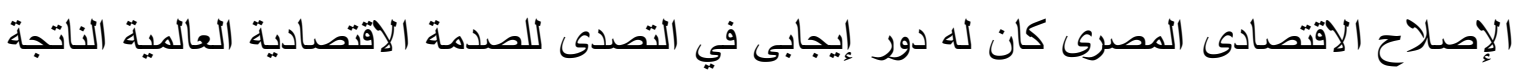

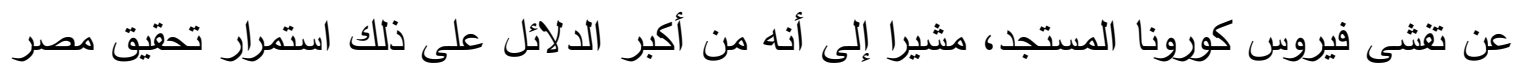
لمعدلات نمو إيجابية وصلت لـ3.6 ٪ في العام المالى (2019 2020 ) واستمرار الفائض الأوليى للموازنة.

23 الهيئة العامة للاستعلامات ، أهم الاجراءات الحكومية لمواجهة فيروس كورونا خلال 100 يوم ، 6 يونيو 2020 ، https://www.sis.gov.eg/Story/204421/\%D8\%A3\%D9\%87\%D9\%85-

$$
\text { متاح على الرابط التالى :- }
$$

\%D8\%A7\%D9\%84\%D8\%A5\%D8\%AC\%D8\%B1\%D8\%A7\%D8\%A1\%D8\%A7\%D8\%AA\%D8\%A7\%D9\%84\%D8\%AD\%D9\%83\%D9\%88\%D9\%85\%D9\%8A\%D8\%A9\%D9\%84\%D9\%85\%D9\%88\%D8\%A7\%D8\%AC\%D9\%87\%D8\%A9\%D9\%81\%D9\%8A\%D8\%B1\%D9\%88\%D8\%B3\%D9\%83\%D9\%88\%D8\%B1\%D9\%88\%D9\%86\%D8\%A7\%D8\%AE\%D9\%84\%D8\%A7\%D9\%84-100-\%D9\%8A\%D9\%88\%D9\%85?lang=ar 
وأكد التقرير على أن جائحة كورونا خلقت أخطر أزمة صحية واقتصادية يشهدها العالم منذ سبعة عقود، على الأقل، إلا أن مصر شهدت جهود قوية لضبط أوضاع المرائ المالية العامة وأرصدة المعاملات

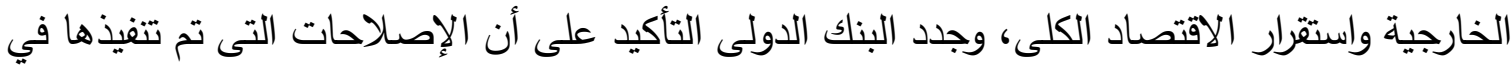

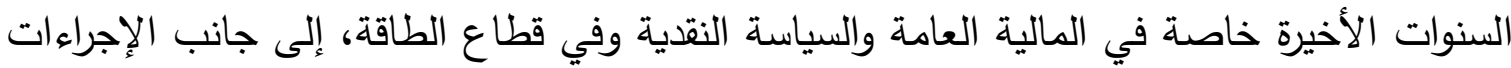

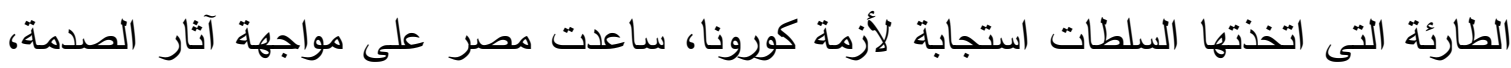

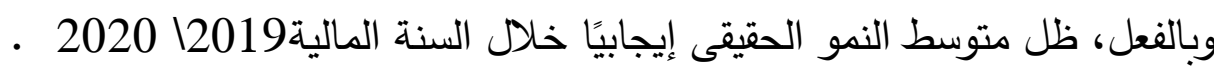
بالنسبة لمنظمة الأمم المتحدة التى أكدت أنه رغم ما شهده العالم جراء التداعيات السلبية لجائحة

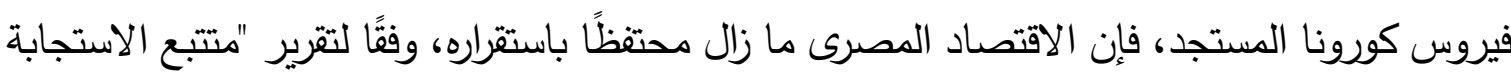

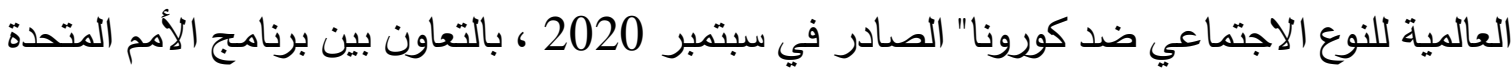

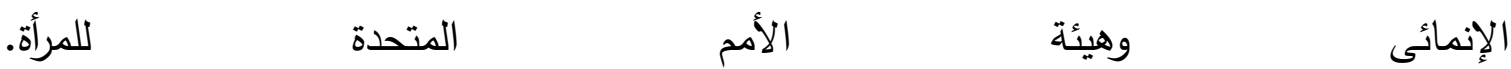

- - أما مجموعة "هوريزون" الأمريكية، فقالت إن مصر تعد من الدول الأفضل تجهيزًا لمواجهة "كورونا والتعافى بشكل أسرع من تبعات الجائحة، حيث أصدرت المؤسسة مؤشر التعافى الاقتصادى من جائحة

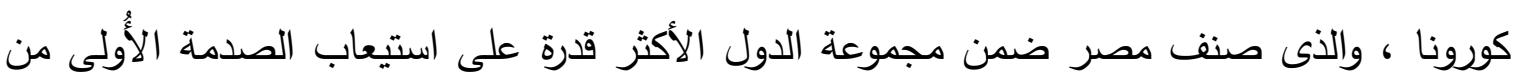
الجائحة، وذلك بتحقيقها 51.2 نقطة من 100 نقطة؛ لتأتى في المركز الـ 70من بين 122 دولة،

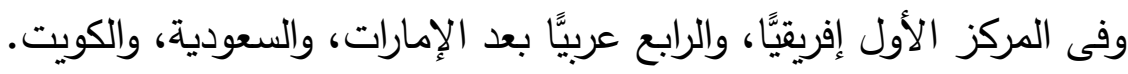

- - أعلن صندوق النقد الدولى قرب صرف الثريحة الثانية من قرض الصندوق البالغة قيمته 5.2 مليار

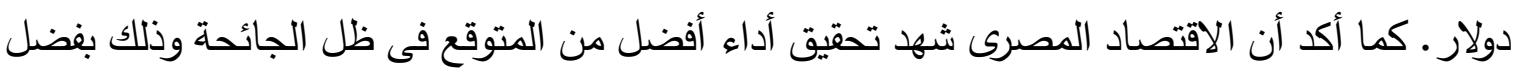
حزمة الإجراءات التنشيطية السريعة والثاملة والمتوازنة التي اتخذتها الحكومة، واستجابة السياسة النقدية، ومبادرات القطاع المالي الموجهة للقطاعات والفئات المتضررة 24. - - أشارت توقعات فيتش بشأن نجاح مصر في زيادة احتياطيات النقد الأجنبي في السنوات المقبلة ، وهو

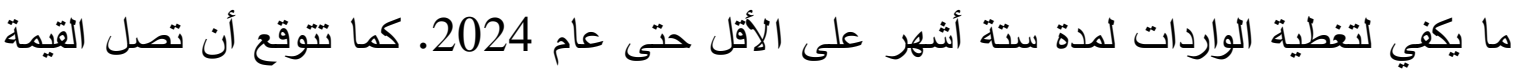
الإجمالية للصادرات من السلع والخدمات إلى 47.7 مليار دولار في عام 2020 وأن تستمر في أنى تصلئ

${ }^{24}$ ) State Information Service, Sisi satisfied with IMF's praise to performance of Egyptian economy, 21 November 2020, Available at :

https://www.sis.gov.eg/Story/153099/Sisi-satisfied-with-IMF\%E2\%80\%99s-praise-toperformance-of-Egyptian-economy?lang=en-us 
الارتفاع إلى 55.3 مليار دولار في عام 2024. 25 في يوليو 2020، أكدت وكالة فيتش للتصنيف

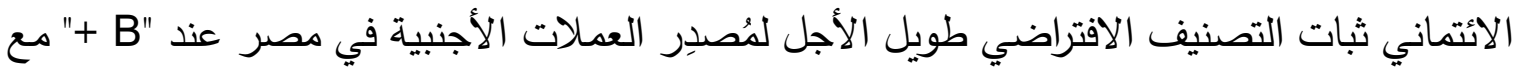

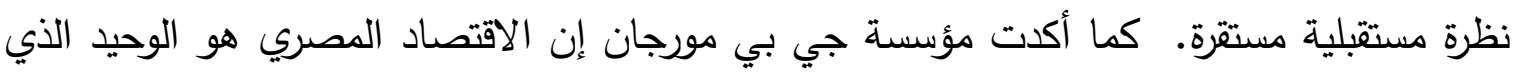

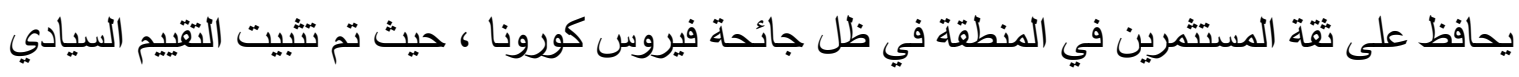

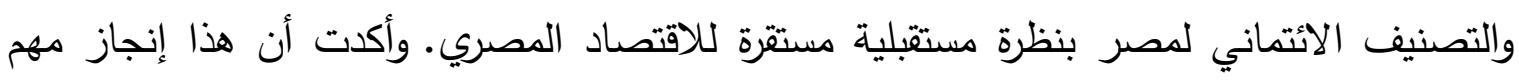

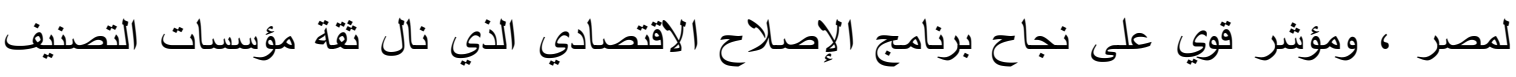

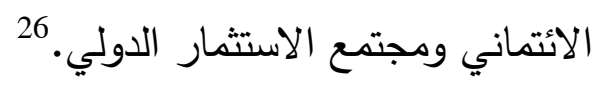
خامساً - نتائج الاراسة:

تأثر الاقتصاد المصرى بتداعيات وباء كورونا مثله مثل معظم اقتصادات العالم ، ومن خلال ما تم

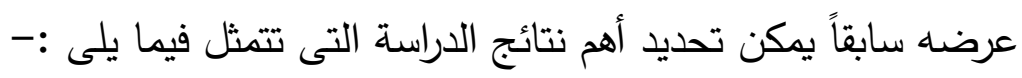

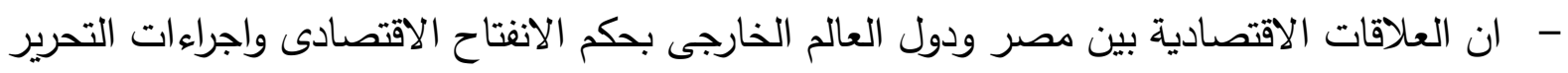

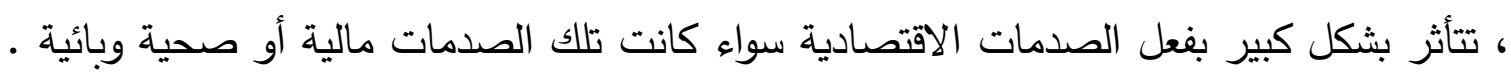

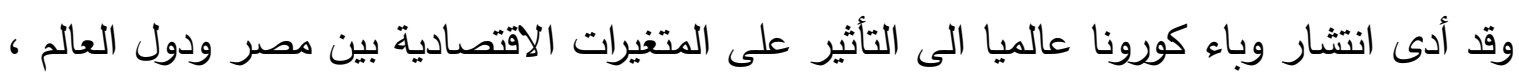

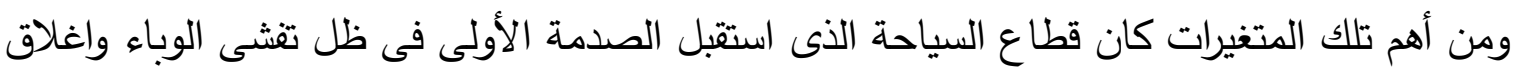

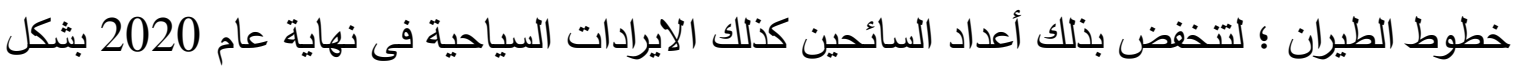

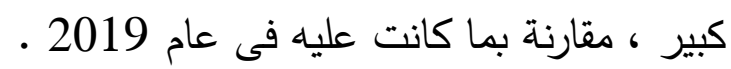

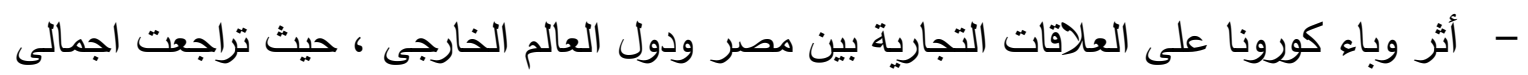
الصادرات المصرية للخارج بشكل طفيف لا يتجاوز نسبته 9.7\% حتى نهاية عام 2020 ، كذلك

25 ) Egypt Independent, Egypt's economic situation receives international praise: Report August 30, 2020, Available at :

https://egyptindependent.com/egypts-economic-situation-receives-international-praise-report/

${ }^{26}$ ) Egypt Today , " JP Morgan praises Egyptian economy performance amid pandemic: Finance Ministry", 6 August. 2020, Available at :

https://www.egypttoday.com/Article/3/90465/JP-Morgan-praises-Egyptian-economyperformance-amid-pandemic-Finance-Ministry 
الواردات انخفضت بنسة 7.8\% ما بين عامى 2019 و2020 ، فى الوقت الذى ظهر فيه مؤشرا جيدا وهو انحفاض عجز الميزان التجارى بنسبة كبيرة تصل الى 67\%. - انخفضت تدفقات الاستثمار الأجنبي المباشر بنسبة 57\% إلى ما يقدر بنحو 1.9 مليار دولار أمريكي في النصف الأول من عام 2020 ، ثم تحسنت نسبياً لتصل إلى 3.09 مليار دولار أمريكي في الربع الرابع من العام المالى 2020/2019 متأثرة بذلك بالانكماش العميق الذى قاد الشركات العالمية مما

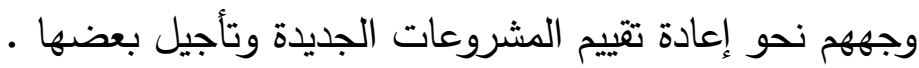
- ارتقعت تحويلات العاملين بالخارج فى الربع الأول من عام 2020 نتيجة حالة الذعر والخوف التى سيطرت عليهم خوفا من انتشار الوباء وتقلب الظروف الاقتصادية ، ولكن سرعان ما تراجعت بشكل ملحوظ فى الربع الأخير من عام 2020 ـ كذلك الحال بالنسبة الى ايرادات قناة السويس التى شهدت تقلبا ملحوظا خلال عام 2020 لتنهى الربع الأخير منه بانخفاض فى عدد السفن العابرة بالقناة وتراجع ايرادات قناة السويس بفعل ضعف حركة التجارة الدولية بعد تفشى انتشار وباء كورونا.

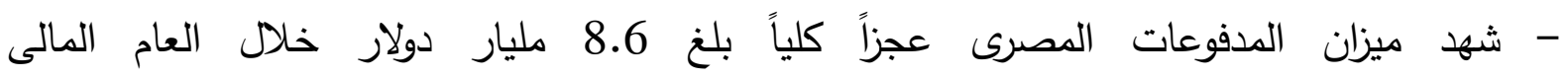

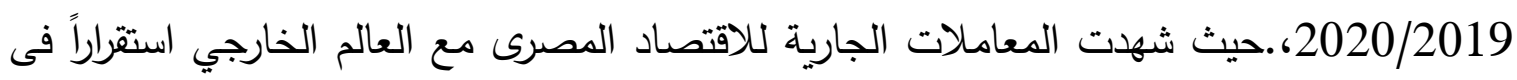

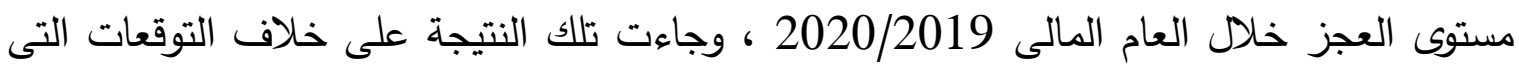

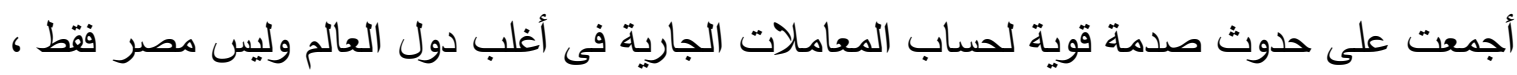

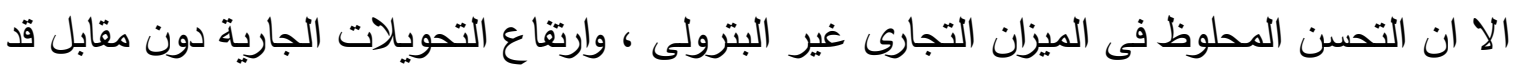
ساهم فى تخفيف هذه الصدمة على الاقتصاد المصرى.

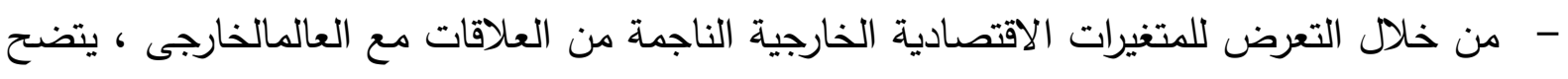

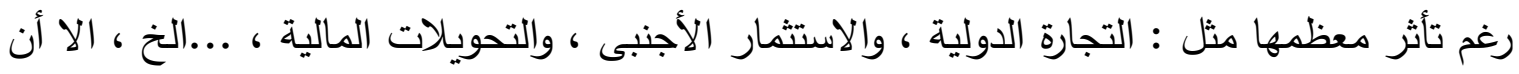

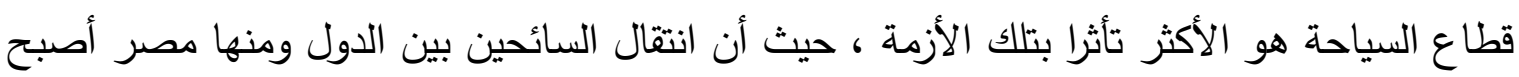

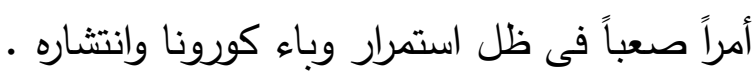

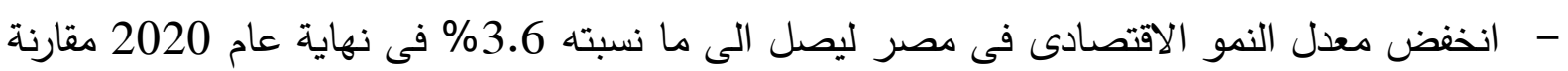

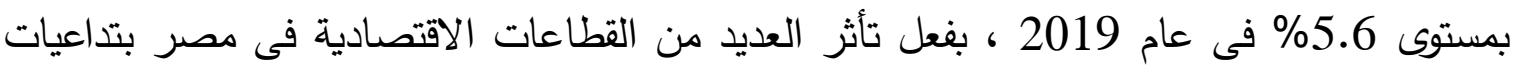
وباء كورونا ، الا أن الاقتصاد المصرى ظل الوحيد الذى حقق معدل نمو موجب فى الاقتصادات الناشئة . - ارتفع معدل البطالة الى 9.6\% من إجمالى قوة العمل فى الربع الأول من عام 2020 ، مقابل 8.1\% فى الربع الأول من العام السابق 2019 ـ. أما فيما يتعلق بالقطاع غير الرسمى ، فقد نحو 1.6 مليون فرد لوظائفهم فى هذا القطاع ، حيث يثكل العاملين فى القطاع غير الرسمى نحو 63\% من اجمالى 
العاملين فى مصر ، مما أثر سلباً على مستوى معيشة العديد من أفراد المجتمع المصرى ، ودفع الكثيرين نحو فجوة الفقر . - - على الرغم من تأثير وباء كورونا على الأداء الداخلى للاقتصاد المصرى ، الا أن التأثير ضغط بشكل

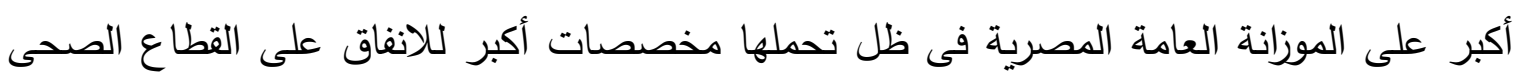
والتعليم ، واجراءات الحماية الاجتماعية ـ فقد تحملت الموزانة المالية لعام 2019-2020 تخصيص 100 مليار جنيه لمواجهة انعكاسات وباء كورونا على الاقتصاد المصرى ، حيث بلغت إجمالي المصروفات المستهدفة بموازنة 2020-2021 تبلغ نحو 1.7 تريليون جنيه مقابل 1.5 تريليون جنيه بموازنة 2019 / 2020أما الايرادات العامة ، فسوف تشهد زيادة فى عام 2020-2021 مقارنى بالعام المالى السابق لتصل الى 1288.8 مليار جنيه ؛ ويرجع سبب ارتفاعها الى زيادة حصيلة الدولة من الايرادات الضريبية لأن هناك ارتقاع كبير في الإيرادات من ضرائب الدخل خاصة من الشركات. - - بلغ رصيد الدين الخارجي لمصر نحو 123.5 مليار دولار أمريكي في نهاية يونيو 2020 بزيادة

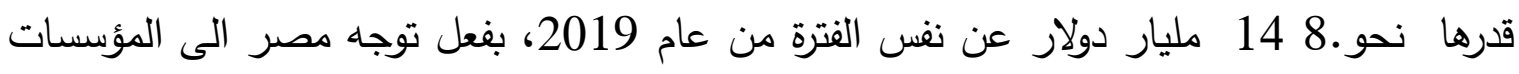

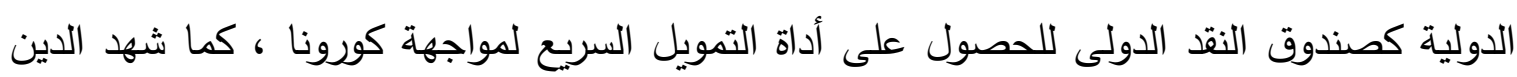
المحلى ارتفاعا طفيفا أيضا صدارات الدولة من أدوات الدين الحكومية (أذون- سندات خزانة) في أول التولئ

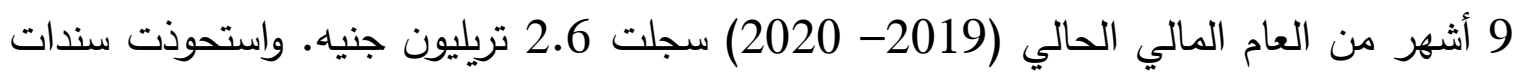
الخزانة على نصيب الأسد من أدوات الدين بواقع 1.84 تريليون جنيه، فيما كان نصيب السندات 82020 مليار جنيه، خلال الفترة من يوليو 2019 حتى مارس 2020، طبقًا للتقرير المالي الصادر عن الونيان الوزارة عن هذه الفترة.

- أطلقت مصر خطة تحفيز اقتصادية لمواجهة تداعيات وباء كورونا على الاقتصاد المصرى ، وكانت

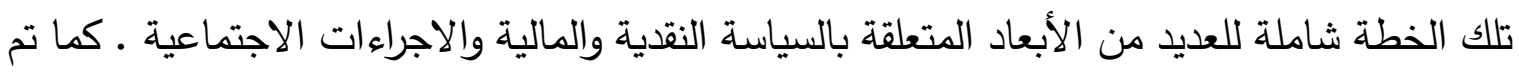
اطلاقها فى وقت مبكر من الأزمة مما ساهم بثكل كبير فى استيعاب جزء من اثارها السلبية على الإنى

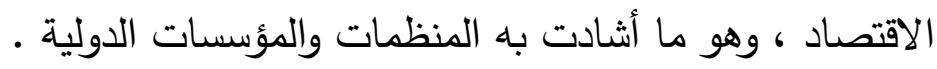

- تنوع هيكل الاقتصاد المصري ساهم بشكل كبير فى مواجهة الأزمة، كذلك نتائج برنامج الإصلاح

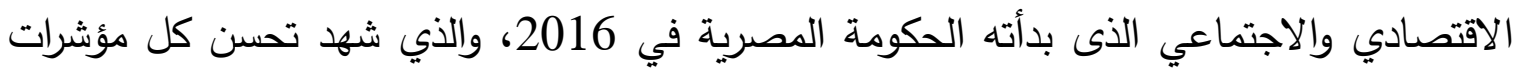

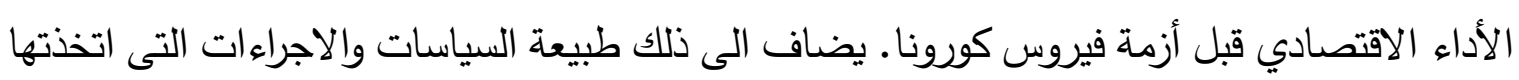


مصر لمواجهة انعكاسات الوباء على الاقتصاد ، كل ذلك قد ساهم فى تخفيف اثار أزمة وباء كورونا

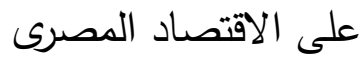

وفى النهاية يمكن اثبات صحة فرضية الدراسة ، حيث كان لأزمة وباء كورونا تأثير سلبى على

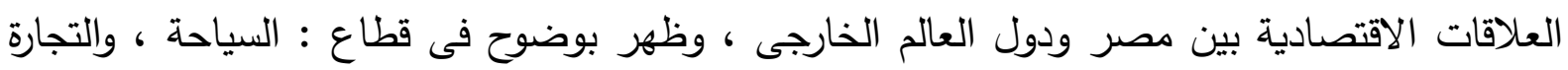

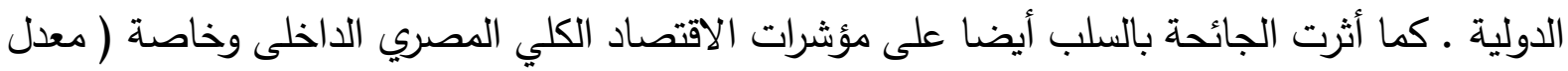

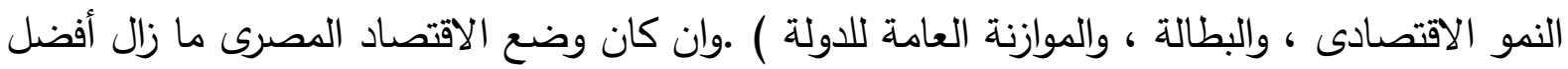
من غيره فى العديد من الاقتصادات الناشئة والنامية ، ومن عوامل صمود الاقتصاد المصري في مواجهة الأها أزمة كوفيد-19، هو تتوع هيكل الاقتصاد المصري الذي ساهم فى مواجهة الأزمة، كذلك نتائج برنامج الأنج

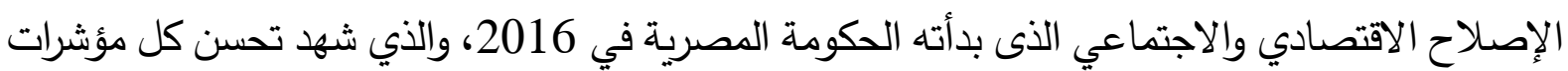
الأداء الاقتصادي قبل أزمة فيروس كورونا.

\section{سادساً - توصيات الدراسة :}

من خلال العرض السابق لانعكاسات وباء كورونا على الاقتصاد المصرى ، يمكن اقتراح عدة توصيات

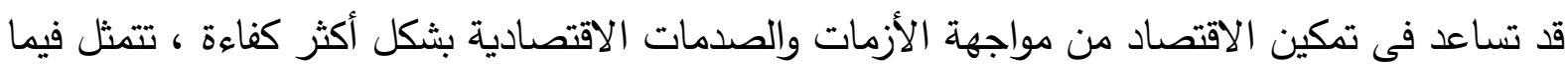
يلى :-

- - على الحكومة أن تواصل مشروعاتها الضخمة اللازمة في إطار البرنامج الاصلاحى الاقتصادى ـ كما تحتاج إلى التعجيل بإعادة هيكلة وتطوير مؤسساتها وتكييف الإطار التنظيمي المناسب لها. لها.

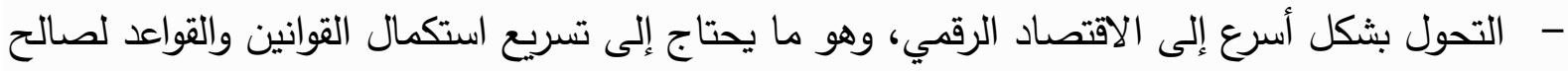

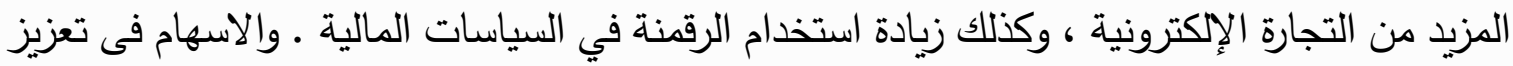
الثمول المالى بما فى ذلك تبنى الاليات الخاصة بالتمويل عبر الانترنت وتعزيز منصات التكنولوجيا

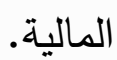

- تعزيز الصادرات غير النفطية والاعتماد على تطوير سلاسل الإنتاج المحلية وصناعات التغذية بدلاً

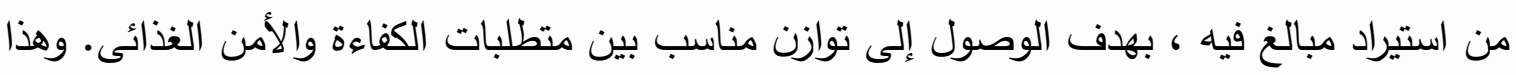

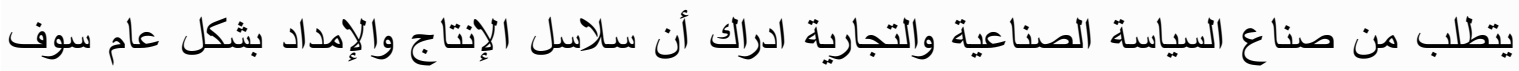

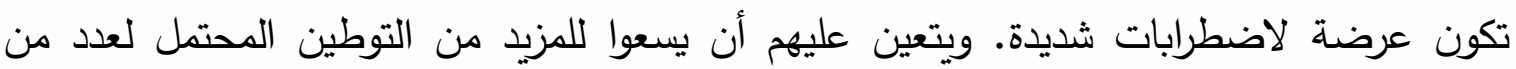
الصناعات ، مثل صناعة النسيج والملابس بدلاً من الاعتماد المفرط على الصين ونين وغيرها في في استيراد المنسوجات والأقشة.

- - مراجعة لنفقات الميزانية العامة لمصر في ضوه تأثير الفيروس التاجي على الايرادات المالية . حيث

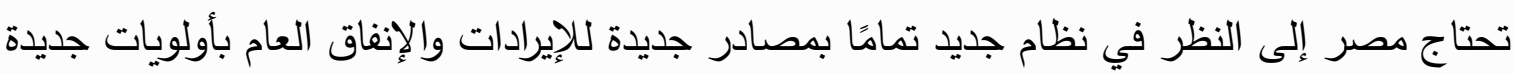


تؤدي فيها الدولة دورًا أكبر في مجالات الرعاية الصحية والتعليم وتوطين الاستثمار في التكنولوجيا والبنية التحتية.

- الاعتماد على الصناعات المحلية وتعزيز الانتاجية المحلية ، والاهتمام بالمشروعات الصغيرة والمتوسطة .

- ادراج قطاع السياحة ضمن القطاعات التى تحتاج الى حزم الطوارىء الاقتصادية الوطنية والاقليمية

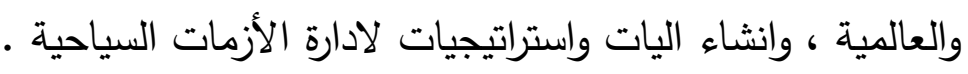




\section{: أولاًَ- مراجع باللغة العربية

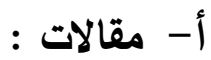

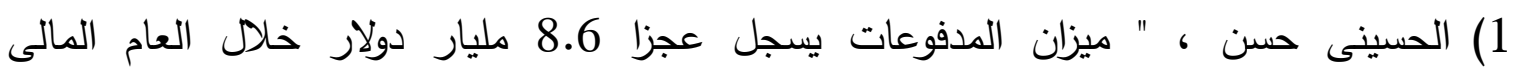

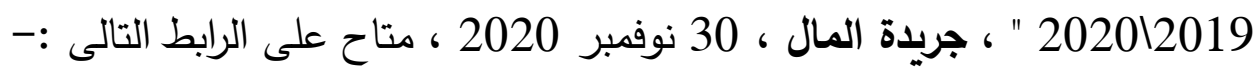
https://almalnews.com/\%D9\%85\%D9\%8A\%D8\%B2\%D8\%A7\%D9\%86\%D8\%A7\%D9\%84\%D9\%85\%D8\%AF\%D9\%81\%D9\%88\%D8\%B9\%D8\% A7\%D8\%AA-\%D9\%8A\%D8\%B3\%D8\%AC\%D9\%84\%D8\%B9\%D8\%AC\%D8\%B2\%D8\%A7\%D9\%8B-8-6\%D9\%85\%D9\%84\%D9\%8A\%D8\%A7\%D8\%B1\%D8\%AF\%D9\%88\%D9\%84

2) جريدة الثرق الأوسط ، " ارتفاع معدل البطالة بصر الى 9,6\% فى الربع الثانى من 2020 "، 17 أغسطس 2020 ، متاح على الرابط التالى :-

https://aawsat.com/home/article/2453066/\%D8\%A7\%D8\%B1\%D8\%AA\%D9\% 81\%D8\%A7\%D8\%B9-\%D9\%85\%D8\%B9\%D8\%AF\%D9\%84\%D8\%A7\%D9\%84\%D8\%A8\%D8\%B7\%D8\%A7\%D9\%84\%D8\%A9\%D8\%A8\%D9\%85\%D8\%B5\%D8\%B1-\%D8\%A5\%D9\%84\%D9\%89-96\%D9\%81\%D9\%8A-\%D8\%A7\%D9\%84\%D8\%B1\%D8\%A8\%D8\%B9\%D8\%A7\%D9\%84\%D8\%AB\%D8\%A7\%D9\%86\%D9\%8A\%D9\%85\%D9\%86-2020

1) اسماء رفعت ، البطالة وتحسين اوضاع سوق العمل فى مصر ، المركز المصرى للفكر وللدراسات

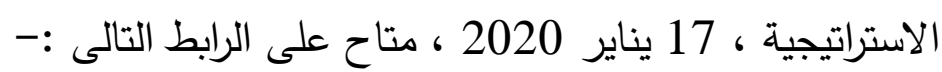

/https://www.ecsstudies.com/13168

2) المركز المصرى للدراسات الاقتصادية ، متابعة اثار كوفيد على الاقتصاد المصرى قطاع السياحة/ ، نوفمبر 2020 ، العدد 25 ، متاح على الرابط التالى :http://www.eces.org.eg/PublicationsDetails

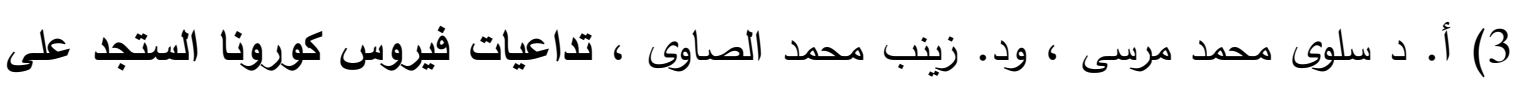

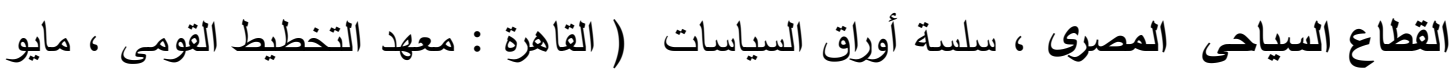
. ( 2020 
4) سارة ناصح ، مؤشرات مختلطة : كيف اثر وباء كورونا على التجارة الخارجية المصرية ، المركز

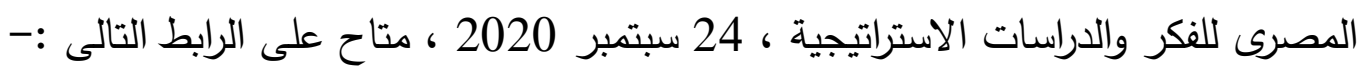
https://www.ecsstudies.com/11060

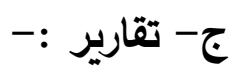

1) البنك المركزى المصرى ، تقرير السياسة النقدية 2020 ، ( القاهرة : البنك المركزى

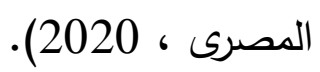

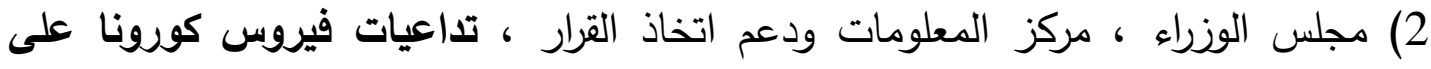
الاقتصاد العالمى وإنعكاساتها على الاقتصاد المصرى ، ( القاهرة : مركز المعلومات ودعم

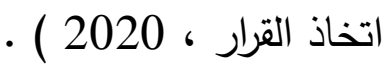

3) وزارة المالية ، التقرير المالى الثهرى ، ( القاهرة : وزارة المالية ، نوفمبر 13 ، 2020 )، المجلد 15 ، العدد 13.

، دليل مبسط عن انفاق الموازنة العامة لعام 21120 ، ( القاهرة : وزارة المالية $(4$

(2020 ،

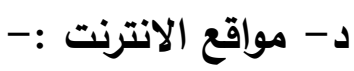

1) الجهاز المركزى للتعبئة العامة والاحصاء ، نثرة التجارة الخارجية ، أكتوبر 2020 ، متاح على التى الرابط التالى :-

https://www.capmas.gov.eg/Pages/Publications.aspx?page_id=5107\&Yera= $\underline{23320}$

، معدل البطالة السنوى ، 2020 ، متاح على الرابط التالى :$(2$

https://www.capmas.gov.eg/Pages/IndicatorsPage.aspx?Ind_id=1117

3) الجهاز المركزى للتعبئة العامة والاحصاء ، معدل التضخم ، 2020 ، متاح على الرابط التالى

https://www.capmas.gov.eg/Pages/IndicatorsPage.aspx?page id=6130\&ind $\underline{\mathrm{id}=2542}$ 
4) البنك المركزى المصرى ، تعليمات واجراءات البنك المركزى للحد من تداعيات فيروس كورونا

$$
\text { المستجد ، } 2020 \text { ، متاح على الرابط التالى :- }
$$

https://www.cbe.org.eg/ar/Pages/HighlightsPages/\%D8\%A5\%D8\%AC\%D8\%B 1\%D8\%A7\%D8\%A1\%D8\%A7\%D8\%AA\%D8\%A7\%D9\%84\%D8\%A8\%D9\%86\%D9\%83\%D8\%A7\%D9\%84\%D9\%85\%D8\%B1\%D9\%83\%D8\%B2\%D9\%8A\%D8\%A7\%D9\%84\%D9\%85\%D8\%B5\%D8\%B1\%D9\%8A\%D9\%84\%D9\%84\%D8\%AD\%D8\%AF-\%D9\%85\%D9\%86\%D8\%AA\%D8\%AF\%D8\%A7\%D8\%B9\%D9\%8A\%D8\%A7\%D8\%AA\%D9\%81\%D9\%8A\%D8\%B1\%D9\%88\%D8\%B3\%D9\%83\%D9\%88\%D8\%B1\%D9\%88\%D9\%86\%D8\%A7\%D8\%A7\%D9\%84\%D9\%85\%D8\%B3\%D8\%AA\%D8\%AC\%D8\%AF.aspx

$$
\text { 5) الكيئة العامة للاستعلامات ، أهم الاجراءات الحكومية لمواجهة فيروس كورونا خلال } 62020 \text { ، متاح على الرابط التالى :- } 100 \text { يوم }
$$

https://www.sis.gov.eg/Story/204421/\%D8\%A3\%D9\%87\%D9\%85\%D8\%A7\%D9\%84\%D8\%A5\%D8\%AC\%D8\%B1\%D8\%A7\%D8\%A1\%D8 $\% \mathrm{~A} 7 \% \mathrm{D} 8 \% \mathrm{AA}-$ \%D8\%A7\%D9\%84\%D8\%AD\%D9\%83\%D9\%88\%D9\%85\%D9\%8A\%D8 \%A9-\%D9\%84\%D9\%85\%D9\%88\%D8\%A7\%D8\%AC\%D9\%87\%D8\%A9\%D9\%81\%D9\%8A\%D8\%B1\%D9\%88\%D8\%B3\%D9\%83\%D9\%88\%D8\%B1\%D9\%88\%D9\%86\%D8\%A7\%D8\%AE\%D9\%84\%D8\%A7\%D9\%84-100\%D9\%8A\%D9\%88\%D9\%85?lang=ar

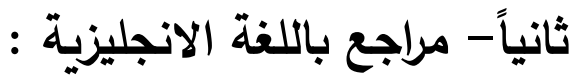

\section{A-Articles:}

1) Egypt Independent, Egypt's economic situation receives international praise: Report August 30, 2020 , Available at :

https://egyptindependent.com/egypts-economic-situation-receivesinternational-praise-report/

2) Egypt Today, " JP Morgan praises Egyptian economy performance amid pandemic: Finance Ministry", 6 August. 2020 , Available at :

https://www.egypttoday.com/Article/3/90465/JP-Morgan-praises-Egyptianeconomy-performance-amid-pandemic-Finance-Ministry 
3) Daily News , " Egyptian pound appreciates 30 piasters against US dollar in 2020 despite COVID-19 ", January 2.2020, Available at :https://dailynewsegypt.com/2021/01/02/egyptian-pound-appreciates-30piasters-against-us-dollar-in-2020-despite-covid-19/

4)Lara Williams , " The state of play: FDI in Egypt ", Invesment Monitor , 28 Aug 2020 Available at :

https://investmentmonitor.ai/middle-east-north-africa/the-state-of-play-fdi-inegypt

\section{B- Research Papers :}

1) Ministry of Planning and Economic Development, Impact of COVID19 on the Egyptian economy: Economic sectors, jobs, and households , REGIONAL PROGRAM POLICY NOTE 06 , ( Cairo : Ministry of Planning and Economic Development, June 2020).

\section{D- Internet Sites:}

1) Nordea, Country profile Egypt, Foreign direct investment (FDI) in Egypt, Available at :

https://www.nordeatrade.com/en/explore-new-market/egypt/investment

2) Reuters , Egypt workers' remittances rose to $\$ 8$ billion in the JulySeptember quarter, DECEMBER 7, 2020 , Available at :-

https://www.reuters.com/article/egypt-cenbank-int-idUSKBN28H1PF

3) State Information Service , " EGP among best world currencies against dollars in 4 years" , 15 February 2021, Available at :https://www.sis.gov.eg/Story/154246?lang=en-GB 4) , Sisi satisfied with IMF's praise to performance of Egyptian economy, 21 November 2020, Available at : https://www.sis.gov.eg/Story/153099/Sisi-satisfied-with-IMF\%E2\%80\%99spraise-to-performance-of-Egyptian-economy?lang=en-us 
